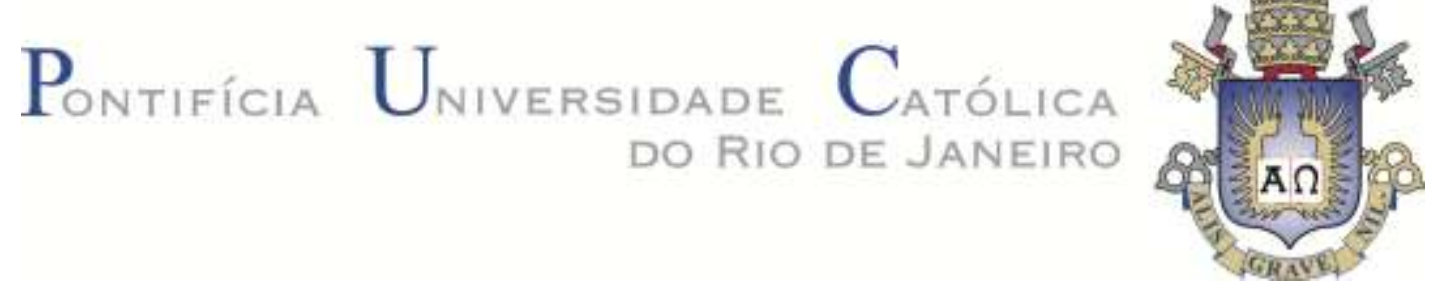

Andrea Nascimento Vecci

\title{
Análise Probabilística da Estabilidade de um Talude de Mineração
}

\section{Dissertação de Mestrado}

Dissertação apresentada ao Programa de Pósgraduação em Engenharia Civil da PUC-Rio como requisito parcial para obtenção do grau de Mestre em Engenharia Civil.

Orientador: Prof. Alberto Sampaio Ferraz Jardim Sayão 
Andrea Nascimento Vecci

\title{
Análise Probabilística da Estabilidade de um \\ Talude de Mineração
}

Dissertação apresentada como requisito parcial para obtenção do grau de Mestre pelo Programa de Pósgraduação em Engenharia Civil da PUC-Rio. Aprovada pela Comissão Examinadora abaixo assinada.

\author{
Prof. Alberto Sampaio Ferraz Jardim Sayão \\ Orientador \\ Departamento de Engenharia Civil e Ambiental - PUC-Rio
}

Prof. Marcelo Motta de Freitas

Departamento de Geografia e Meio Ambiente - PUC-Rio

Prof. Sandro Salvador Sandroni SEA - Sandro Sandroni Engenheiros Associados Ltda

Prof $^{\text {a }}$. Anna Laura Lopes da Silva Nunes Universidade Federal do Rio de Janeiro - COPPE/UFRJ

Prof ${ }^{\mathrm{a}}$. Márcio da Silveira Carvalho

Coordenador Setorial do Centro

Técnico Científico - PUC-Rio

Rio de Janeiro, 24 de abril de 2018. 
Todos os direitos reservados. É proibida a reprodução total ou parcial do trabalho sem autorização do autor, do orientador e da universidade.

\section{Andrea Nascimento Vecci}

Graduou-se em Engenharia Geológica pela Escola de Minas da Universidade Federal de Ouro Preto (UFOP) em Ouro Preto, Minas Gerais em agosto de 2015. Ingressou no mestrado na Pontifícia Universidade Católica do Rio de Janeiro em março de 2016, desenvolvendo dissertação na linha de pesquisa de Geotecnia Experimental.

Ficha Catalográfica

Vecci, Andrea Nascimento

Análise Probabilística da Estabilidade de um Talude de Mineração / Andrea Nascimento Vecci; orientador: Alberto Sampaio Ferraz Jardim Sayão. 2018.

v., 82 f.: il. color. ; $29,7 \mathrm{~cm}$

Dissertação (mestrado) - Pontifícia Universidade Católica do Rio de Janeiro, Departamento de Engenharia Civil, 2018.

Inclui referências bibliográficas.

1. Engenharia civil - Teses. 2. Análise Probabilística; 3 FOSM; 4 Estimativas Pontuais; 5 Monte Carlo; 6 Mina do Cauê; 7 Probabilidade de Ruptura; 8 Índice de Confiabilidade I. Sayão, Alberto S. F. J. II. Pontifícia Universidade Católica do Rio de Janeiro. Departamento de Engenharia Civil. III. Título. 
Ao meu pai Marco, minha mãe Anésia, meus irmãos Amanda e Gustavo, e às minhas avós Aurora e Percília (in memorian). 


\section{Agradecimentos}

Ao meu pai, que com poucas palavras e muito exemplo me ensinou que com ética e força de vontade é possível conquistar o que quisermos. Seu abraço firme, acompanhado de um sorriso profundo, não me deixou dúvidas de que peguei o caminho certo quando ingressei no mestrado. E foram dois anos de desafios, sucesso e realizações: muito obrigada.

À minha mãe que não permitiu que 4 engenheiros ofuscassem os lados criativos e sensíveis da família. Com eles o caminho foi mais leve e bem vivido.

Aos meus irmãos, Amanda e Gustavo, que deixei bem jovens em casa, quando fui em busca de um futuro melhor. Sinto falta de ter tido mais dias ao lado de vocês, mas, também muito jovem, tive oportunidades de crescimento que não pude recusar.

À minha avó Percília França (in memorian) pelas orações e pela torcida à espera feliz de um telefonema a cada conquista. Com você aprendi o verdadeiro sentido de querer bem, e diariamente faço o melhor que posso para semear seus exemplos.

Ao meu orientador, Alberto Sayão por estar sempre disposto a dividir comigo seu vasto conhecimento e incentivar minha evolução pessoal e profissional, com conselhos técnicos ou paternais. Com certeza, é um grande exemplo a ser seguido e suas lições serão utilizadas sempre.

À incomparável equipe de colegas geotécnicos que levo para a vida, que me acompanharam em todos os momentos de conquistas ou dificuldades ao longo destes intensos anos de mestrado: Alan, Ana Luiza, Arthur, Bruno, Carol, Jainor, Larissa, Luana, Mari, Raquel, Raul, Rodrigo, Thaís. Juntos formamos uma equipe exemplar, cujo cooperativismo deve ser exemplo para as futuras gerações.

Especialmente às amigas Ana Luiza Rossini e Mariana Bernardo, pela parceria na pesquisa e pelo papel de porto seguro sem restrições de horário ou assunto.

Ao professor Sandro Sandroni, pela generosidade ao doar conhecimentos e material de pesquisa, sempre empenhado em ajudar.

Ao amigo Jainor Huamam, que, com sua generosidade em repassar seus conhecimentos, me impulsionou e me fez perceber que, com dedicação, podemos alcançar mais do que imaginamos, sem perder a delicadeza.

Ao professor Eduardo Marques, que foi minha motivação inicial para ingresso no universo da geologia, e que até hoje incentiva minha evolução profissional com a mais pura e boa vontade, sendo exemplo a ser seguido pelos que buscam transformar o país. 
Ao amigo Cahio que à distância foi motivador e sempre torceu pelo meu sucesso.

Se ainda há tempo de agradecer... Ao Alex Mendes, quem amenizou meus medos e inseguranças sendo apoio e motivação para eu me tornar uma Engenheira Geóloga.

Ao mesmo Alex, graças à força mágica que em mim despertou, meu primeiro período foi sucesso decisivo diante de um dos maiores desafios da minha vida.

Ao amigo Fernando Azevedo, quem me abriu as portas para este caminho e esteve sempre de braços abertos quando precisei de um abraço.

À família UFV, que me apoia e me acompanha há mais de uma década, me fazendo confiante e segura de que com amor e dedicação somos capazes de conquistar o melhor que o mundo oferece.

Ao T.T. Burger e sua equipe pelo contágio de seus sorrisos virais e os sacodes semanais me alegrando durante 2 anos.

Aos amigos de vida, que nunca me perderam de vista nem quando oceanos ou montanhas nos separavam: Arthur, Diza, Clarissa, Fátima, Maria Fernanda Jessica, Daniara, PH, Cibele, Tchó Tchó, Letícia, Bah, Luiza, Julia Hot, Antonino, Josi, Kirla, Lirha, Maria Antônia, Divina, Millena, Higor, Gisele, Bilman, Tiaguinho, Bruna, Renata e Índio, Sarah, Raissa, Luiza, Annelise, Luisa, Karla, Julia Vidal, Dani, Marianita, Andre, Carioca, Natalia, Luiz Gustavo, Juh, João, Ítalo, Marília, Thales, Riger e Murilo.

À família mais espetacular que uma pessoa poderia ter, França e Nascimento, que quando completa enche um estádio de futebol de muita bondade e alegria, vocês são indescritíveis.

À minha bruxinha particular, Raissa Nascimento, que teve as fórmulas secretas de para me motivar durante esse processo.

Ao Departamento de Engenharia Civil e Ambiental da PUC-Rio (Pontifícia Universidade Católica do Rio de Janeiro), pela oportunidade de obter uma formação de mestre enriquecedora.

À CAPES e FAPERJ, pelo apoio financeiro, fundamental para o desenvolvimento do trabalho. 


\section{Resumo}

Vecci, Andrea Nascimento; Sayão, Alberto de Sampaio Ferraz Jardim (Orientador). Análise Probabilística da Estabilidade de um Talude de Mineração. Rio de Janeiro, 2018. 82p. Dissertação de Mestrado. Departamento de Engenharia Civil e Ambiental, Pontifícia Universidade Católica do Rio de Janeiro.

$\mathrm{Na}$ prática geotécnica, a estabilidade de taludes é atualmente estudada apenas com análises determinísticas, obtendo-se o valor do Fator de Segurança (FS) da estrutura geotécnica. Estas análises são simplificadas, pois fornecem valores de FS sem considerar a variabilidade intrínseca dos solos e rochas. Desprezar as incertezas dos parâmetros geotécnicos pode levar a resultados pouco confiáveis sobre a segurança de taludes. Análises fundamentadas em conceitos estatísticos, chamadas probabilísticas, passam ser mais frequentes na geotecnia por permitirem considerar efeitos da variabilidade inerente aos materiais. Estas análises incorporam elementos estatísticos que possibilitam tratar FS como uma função e estudar suas propriedades. Como resultados finais, os métodos probabilísticos fornecem o índice de confiabilidade $(\beta)$ e a probabilidade de ruptura $(\operatorname{Pr})$ da estrutura averiguada. Este trabalho aplica análises determinísticas e probabilísticas de um talude de 200m de altura da Mina do Cauê, Itabira, MG. A estabilidade do talude foi analisada por cinco métodos determinísticos usuais e três probabilísticos (FOSM, EP e MC). Os resultados indicam que a fixação da superfície crítica de ruptura fornece, em geral, valores de $\beta$ e Pr semelhantes aos obtidos quando a superfície pode variar livremente. Com a superfície crítica fixa observou-se, também, que os resultados de $\beta$ e $\operatorname{Pr}$ do talude variam significativamente com o método de equilíbrio limite adotado. Após comparação dos resultados, pode-se recomendar o uso de análises probabilísticas FOSM com base no método de Morgenstern-Price em análises semelhantes ao caso estudado.

\section{Palavras-chave}

Análise Probabilística; FOSM; Estimativas Pontuais; Monte Carlo; Mina do Cauê; Probabilidade de Ruptura; Índice de Confiabilidade. 


\section{Abstract}

Vecci, Andrea Nascimento; Sayão, Alberto de Sampaio Ferraz Jardim (Advisor). Probabilistic Analysis of a Mine Slope Stability. Rio de Janeiro, 2018. 82p. Dissertação de Mestrado. Departamento de Engenharia Civil e Ambiental, Pontifícia Universidade Católica do Rio de Janeiro.

In current geotechnical practice, slope stability assessments are usually carried out only based on deterministic methods, obtaining a value of Safety Factor (FS). These analyses are simplified because the FS values do not consider the natural variability of soils and rocks. Disregarding the uncertainties inherent to geotechnical parameters may lead to unreliable results of slope safety. Probabilistic analyses, based on statistical concepts, have become more frequent in geotechnical practice, as they allow incorporating the materials intrinsic variability. These analyses are based on statistical elements that allow treating the FS as a function and studying its properties. The probabilistic methods indicate the reliability index $(\beta)$ and the probability of failure $(\operatorname{Pr})$ of the verified geotechnical structure. This work presents deterministic and probabilistic analyses of a 200m high slope at the Cauê Mine, located in Itabira, Minas Gerais, Brazil, with basis on five usual deterministic methods and three probabilistic techniques (FOSM, Point Estimates and Monte Carlo). The results indicate that fixing the critical deterministic surface generally gives values of $\beta$ and $\operatorname{Pr}$ similar to those achieved when the surface is free to vary. It was also concluded that, with a fixed critical surface, $\beta$ and $\operatorname{Pr}$ results change significantly, when different Limit Equilibrium methods are adopted. It is recommended to use probabilistic FOSM analysis with Morgenstern and Price stability method in analyses similar to the one presented herein.

\section{Keywords}

Probabilistic Analysis; FOSM; Point Estimates; Monte Carlo; Cauê Mine; Failure Probability; Reliability Index. 


\section{Sumário}

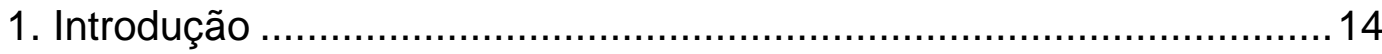

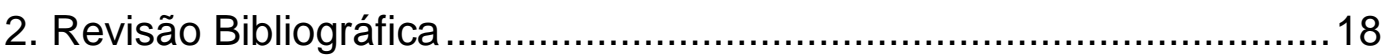

2.1. Análises Determinísticas - Métodos de Equilíbrio Limite 18

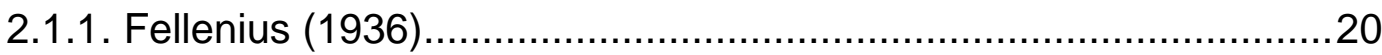

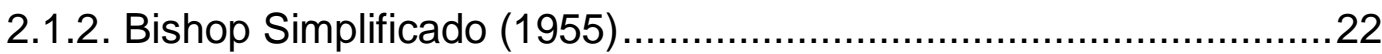

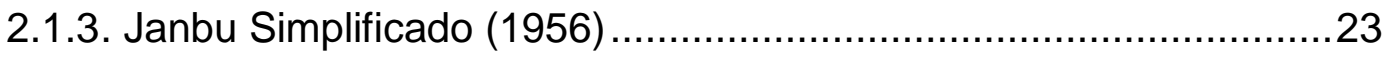

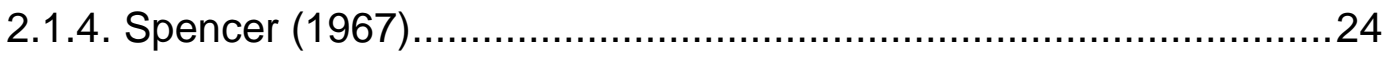

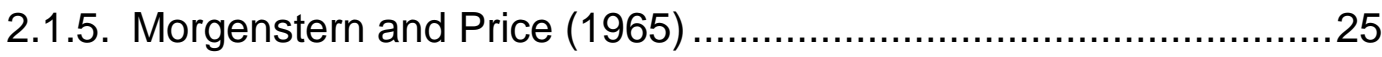

2.2. Conceitos Básicos de Probabilidade e Estatística 25

2.3. Métodos Probabilísticos 31

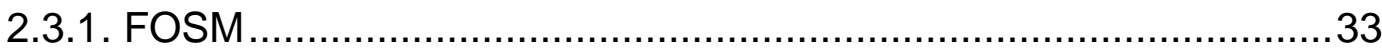

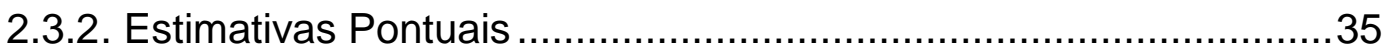

2.3.3. Método da Simulação de Monte Carlo...........................................38

2.3.4. Índice de Confiabilidade e Probabilidade de Ruptura......................39

2.3.5. Análises Probabilísticas em Estabilidade de Taludes.....................44

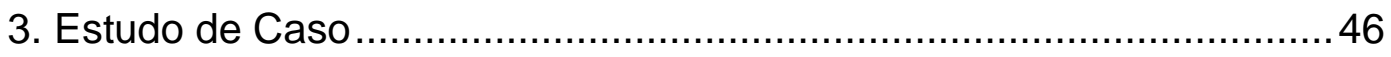

3.1. Localização 46

3.2. História da Mina 47

3.3. Características Geológico-Geotécnicas 50

4. Reavaliação do Caso e Análises Complementares...............................53

4.1. Análises Determinísticas de Estabilidade 54

4.2. Análises Probabilísticas de Estabilidade 55

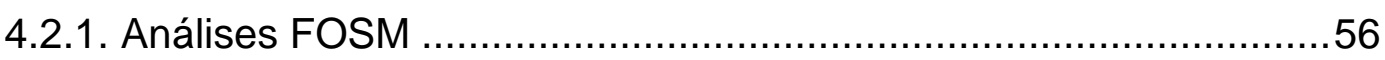

4.2.2. Análises por Estimativas Pontuais ............................................58

4.2.3. Análises por Simulação de Monte Carlo........................................60

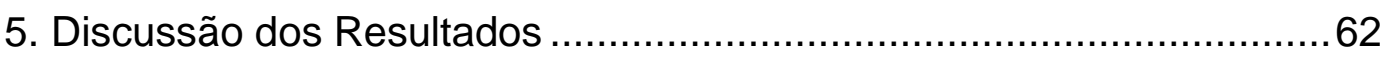

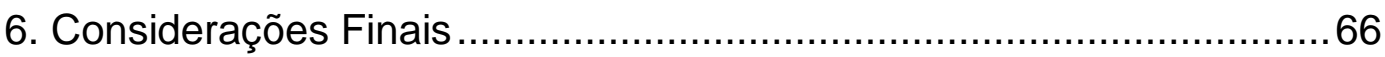

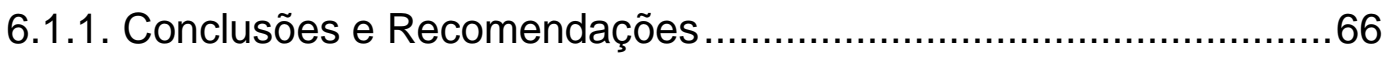


6.1.2. Sugestões Para Estudos Futuros ...............................................67

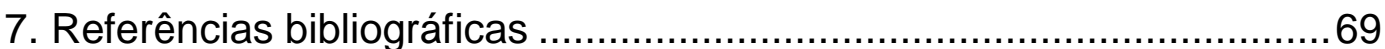




\section{Lista de Figuras}

Figura 2.1 - Forças atuantes em uma fatia da massa de solo no Métodos das Fatias.

Figura 2.2 - Forças consideradas no método de Fellenius. 21

Figura 2.3 - Forças atuantes em uma fatia.

Figura 2.4 - Fatia com forças consideradas no Método de Bishop Simplificado.

Figura 2.5 - Forças atuantes na base da fatia no Método de Spencer. 24

Figura 2.6- Forças atuantes em uma fatia infinitesimal pelo método de Morgenstern and Price (1965).

Figura 2.7 - Função densidade de probabilidade de FS para casos A e B (adaptado de Sandroni e Sayão, 1992).

Figura 2.8 - Curva típica de Distribuição de Probabilidade.

Figura 2.9 - Ciclo de tomada de decisão em análises probabilísticas (adaptado de Einsten e Baecher, 1983).

Figura 2.10- Índice de confiabilidade x probabilidade de ruptura (Flores, 2008).

Figura 2.11 - Valores usuais de probabilidade e consequências de rupturas em projetos de engenharia. Adaptação de Baecher (1982b) por Flores (2008).

Figura 2.12 - Níveis de aceitação de probabilidades de ruptura pelo US Army Corps of Engineers

Figura 3.1 - Mapa de localização de Itabira e do complexo minerário de Itabira.

Figura 3.2 - Vista geral da cidade de Itabira a partir de um acampamento na Mina do Cauê (fonte: Vale S.A., 2016).

Figura 3.3 - Vista geral da cidade de Itabira no século XXI (fonte: Google, 2018).

Figura 3.4 - Vista da cava de mineração da Mina do Cauê em 1992 (foto cedida por Sandro Sandroni).

Figura 3.5 - Vista da cava de mineração da Mina do Cauê em 2017 (fonte: Google Earth Pro, 2017). 
Figura 3.6 - Seção típica do talude da Mina do Cauê simplificada.

Figura 5.1- Gráfico de influência dos parâmetros variáveis na Pr para superfície crítica fixa ou livre por Bishop.

Figura 5.2- Influência dos parâmetros variáveis na Pr para métodos distintos de Equilíbrio Limite para superfície de ruptura fixa. 


\section{Lista de Tabelas}

Tabela 2.1 - Valores típicos de coeficiente de variação sugeridos por Sandroni e Sayão (1992).

Tabela 2.2- Índices de confiança para distribuição normal (Harr, 1987).

Tabela 2.3 - Valores típicos de $\beta$ e $\operatorname{Pr}$ (Avanzi e Sayao, 1998).

Tabela 2.4 - Resumo das principais conclusões sobre análises probabilísticas.

Tabela 3.1 - Parâmetros geotécnicos e estatísticos de talude da Mina do Cauê.

Tabela 4.1 - Fatores de segurança determinísticos

Tabela 4.2 - Exemplificação de $n+1$ análises no método FOSM por Bishop Simplificado e superfície crítica determinística fixa para a Mina do Cauê.

Tabela 4.3 - Resumo de resultados das análises FOSM.

Tabela 4.4 - Influência das variáveis aleatórias pelo método FOSM na $\operatorname{Pr}(\%)$

Tabela 4.5 - Exemplificação de $2 n$ análises no método EP por Bishop Simplificado e superfície crítica determinística fixa para a Mina do Cauê.

Tabela 4.6 - Resumo de resultados das análises por Estimativas Pontuais.

Tabela 4.7 - Resumo de resultados das análises por Simulação de Monte Carlo.

Tabela 5.1 - Resumo de resultados das análises probabilísticas e determinísticas. 


\section{1}

\section{Introdução}

Em projetos geotécnicos, as análises da segurança de taludes objetivam reduzir o índice de acidentes e suas consequentes perdas. Portanto, a necessidade de estudos de estabilidade de taludes em projetos desta natureza é indiscutível.

Devido à heterogeneidade natural dos materiais geotécnicos, ainda não existem análises que reproduzam seu comportamento real em campo. Para isto ser possível, o número de amostras de material deveria ser extremamente grande, o que é inviável. Esta realidade leva os engenheiros geotécnicos a tomarem decisões com base em quantidades limitadas de dados, cujas análises levam a resultados imprecisos, que podem levar a erros de projeto e consequentes acidentes. Análises de estabilidade de um talude são usualmente realizadas aplicando-se métodos determinísticos.

O Fator de Segurança (FS) é o resultado típico obtido em análises determinísticas. O procedimento considera apenas os valores médios dos parâmetros do solo, desconsiderando, portanto, a variabilidade natural dos mesmos. Há algumas décadas, a abordagem probabilística passou a ser utilizada para suprir esta deficiência. As análises probabilísticas permitem estimar a probabilidade de ruptura de um determinado talude e a participação percentual de cada variável na estabilidade do mesmo. Nestas análises, a natureza variável dos parâmetros do solo e suas incertezas é considerada por meio da introdução de conceitos probabilísticos básicos, como desvio padrão, função densidade de probabilidade e forma de distribuição de probabilidade, dentre outros, resumidos no Capítulo 3.

$\mathrm{Na}$ prática geotécnica são atualmente realizadas apenas análises determinísticas, as quais possuem papel simplificador diante do fator complexo que é a heterogeneidade do solo. Esta simplificação limita a atuação do engenheiro geotécnico, aumentando assim a chance de acidentes. As análises probabilísticas aplicadas à geotecnia fornecem resultados mais confiáveis, porém 
ainda não são usuais em projetos de engenharia, pela falta de costume dos projetistas, apesar da simplicidade, rapidez e baixo custo de suas aplicações.

A inserção de estudos e parâmetros estatísticos nas análises permite que o engenheiro tome decisões mais conscientes e seguras, preveja eventuais alterações de projeto, reduza custos e garanta a segurança da obra. A associação de análises probabilísticas às determinísticas amplia a compreensão do engenheiro geotécnico diante da obra estudada, aumentando seu poder de decisão.

É importante observar que não existe correlação entre os valores de FS e Pr. Existem casos onde o valor de FS é alto e o de Pr é baixo, e outros casos em que os valores de FS e Pr são ambos altos.

Este trabalho vem, por meio de estudo de caso, ressaltar a relevância da aplicação prática de análises probabilísticas complementares às determinísticas, em análises de estabilidade. Neste contexto, será realizado o estudo um talude de mineração localizado na Mina do Cauê, situada em Itabira, MG, e pertencente à empresa Vale S.A. Análises de estabilidade do mesmo talude são encontradas na literatura. O presente trabalho, além de reanalisar o caso, traz abordagens determinísticas e probabilísticas que vão além das já existentes.

\section{OBJETIVOS:}

Este trabalho baseia-se nas interpretações de análises aplicadas a um talude de mineração feito por cinco métodos determinísticos e três probabilísticos. A partir das análises e dados obtidos, objetivou-se:

- Apresentar formas usuais de abordagem probabilística aplicadas em análises de estabilidade de taludes;

- Estudar o efeito da fixação da superfície crítica de ruptura nos valores de $\beta$ e Pr semelhantes aos obtidos quando a superfície pode variar livremente;

- Estudar a influência do método de equilíbrio limite influencia na contribuição relativa dos parâmetros do solo na estabilidade do talude utilizando-se o método FOSM; 
- Avaliar a influência do método determinístico nos resultados das análises probabilísticas;

- Comparar resultados de análises probabilísticas realizadas por métodos distintos, indicados na literatura.

Para execução das análises, foram utilizados o programa Slide, versão 5.014, do pacote Rocscience, e planilhas Excel para processamento de dados.

\section{ESTRUTURA DO DOCUMENTO:}

Para facilidade de manuseio do leitor, este trabalho foi divido em seis capítulos, sendo este primeiro um capítulo de introdução ao tema da pesquisa, sua importância, e objetivos do estudo.

O Capítulo 2, de Revisão Bibliográfica, visa apresentar conclusões e considerações de estudos anteriores que serão fundamentos básicos para o desenvolvimento do presente estudo. Neste mesmo capítulo são reforçados conceitos básicos de estatística e apresentados Métodos Determinísticos e Probabilísticos utilizados nas análises de estabilidade de taludes.

O Capítulo 3 apresenta o objeto de estudo, a Mina do Cauê, que é contextualizada por meio de sua caracterização: localização, contextos histórico e geológico-geotécnico. Nele também serão apresentados estudos prévios utilizados como referências para descrição de sua geometria e obtenção de parâmetros necessários nas presentes análises de estabilidade.

O Capítulo 4 trata do estudo de caso propriamente dito. Nele são feitas as análises de estabilidade do talude de mineração em questão, e são apresentados os resultados das análises determinísticas e probabilísticas.

O Capítulo 5 apresenta as interpretações e discussões dos resultados visando chegar a conclusões de utilidade prática em projetos de obras geotécnicas. 
O Capítulo 6 resume as principais conclusões provenientes das análises e de suas interpretações, além de sugestões para estudos futuros. Nele também são apresentadas recomendações práticas que possam auxiliar engenheiros geotécnicos a criarem metodologias de análises de estabilidade, e tomarem decisões mais seguras embasadas nos estudos aqui realizados. 


\section{2 Revisão bibliográfica}

Neste capítulo serão apresentados conceitos, teorias, e considerações préexistentes necessárias para compreensão do estudo realizado neste trabalho.

\section{1 \\ Análises Determinísticas - Métodos de Equilíbrio Limite}

Análises determinísticas são as análises de estabilidade de materiais geotécnicos que fornecem Fatores de Segurança obtidos por meio de cálculos que utilizam os valores médios dos parâmetros. Foram desenvolvidos métodos para realização destes cálculos, dos quais se destacam os métodos de equilíbrio limite. Fatores de Segurança estão diretamente relacionados à resistência de rochas e/ou solos envolvidos em um projeto geotécnico, inclusive na estabilidade de taludes.

Um conceito básico para o estudo desta resistência é o princípio das tensões efetivas de Terzaghi. Este princípio determina que, perpendicularmente a qualquer plano de um elemento de solo, atuam uma tensão total $\sigma$ e uma poropressão $\mathrm{u}, \mathrm{e}$ que a tensão denominada efetiva ( $\left.\sigma^{\prime}\right)$, é igual à tensão total menos a poropressão, como expressa a Equação 2.1 (Terzaghi, 1936):

$$
\sigma^{\prime}=\sigma-\mathrm{u}
$$

A definição de tensão efetiva é fundamental nos estudos de resistência do solo, pois é ela quem controla sua resistência e deformações quando solicitado. Alterações nestas solicitações podem gerar elevação ou redução de poropressão levando o solo à ruptura ou ao ganho de resistência, respectivamente (Pinto, 2006).

Uma vez obtidos a coesão (c'), o ângulo de atrito (Ф'), e a poropressão (u) relativos a uma tensão de ruptura de uma amostra por meio de ensaios de laboratório ou campo, é possível determinar a resistência ao cisalhamento (S) do 
mesmo pela Equação 2.2, conforme o critério de Mohr-Coulomb (Lambe \& Whitman, 1969):

$$
S=c^{\prime}+(\sigma-u) \tan \phi^{\prime}
$$

O fator de segurança (FS) é definido pela razão entre a tensão cisalhante máxima suportada pelo solo e a tensão cisalhante atuante no solo, Equação 2.3 (Bishop, 1955). Quando FS é igual a 1, o solo não resiste aos esforços solicitados e se rompe.

$$
\mathrm{FS}=\mathrm{S} / \mathrm{T}
$$

Existem diferentes métodos de equilíbrio limite registrados na literatura para obtenção de FS. Estes métodos são também conhecidos como Métodos das Fatias, pois, como inicialmente proposto por Fellenius $(1927,1936)$, são baseados no equilíbrio estático de cada fatia que compõe a massa total de solo acima da superfície definida como superfície de ruptura potencial (Figura 2.1). As condições de equilíbrio a serem atendidas são de forças horizontais, verticais ou momentos, como representadas nas equações a seguir:

$$
\begin{aligned}
& \sum \text { Forças Horizontais }=0 \\
& \sum \text { Forças Verticais }=0 \\
& \sum \text { Momentos }=0
\end{aligned}
$$

O sistema encontrado ao se satisfazer as equações $2.4,2.5$ e 2.6 possui mais incógnitas do que equações. Neste contexto, cada método é único ao levantar suas próprias hipóteses simplificadoras, de forma a permitir que o sistema de equações de equilíbrio tenha solução. As hipóteses são principalmente sobre a consideração de forças entre fatias (Duncan, et al., 2014). 


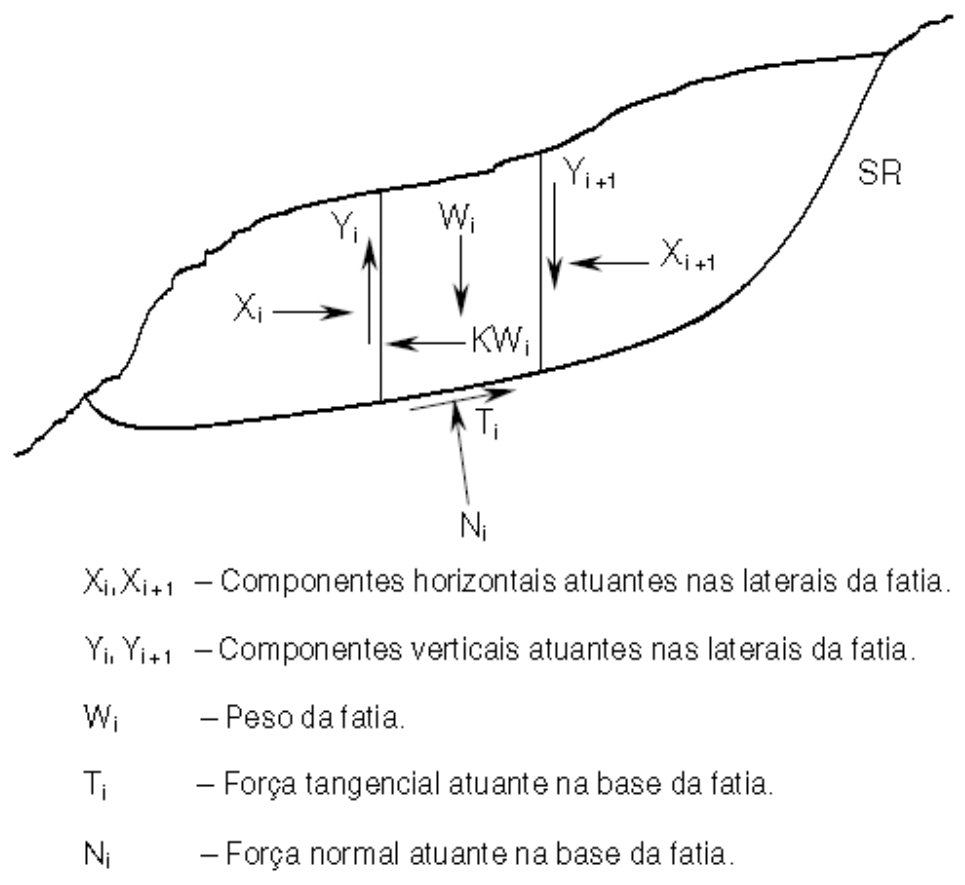

Figura 2.1 - Forças atuantes em uma fatia da massa de solo no Métodos das Fatias.

Todos estes métodos se baseiam nas seguintes hipóteses:

- A superfície de ruptura é bem definida;

- O critério de ruptura de Mohr-Coulomb é atendido ao longo da superfície de ruptura;

- A condição de ruptura da massa é generalizada e incipiente;

- O fator de segurança é único ao longo da superfície de ruptura.

Neste trabalho são utilizados 5 destes métodos (Fellenius, Bishop Simplificado, Janbu Simplificado, Spencer e Morgenstern-Price), os quais são brevemente apresentados a seguir:

\subsection{1}

\section{Fellenius (1936)}

Foi o primeiro método das fatias registrado na literatura. Sua simplicidade permite o cálculo manual de FS. Como hipótese simplificadora, neste método, a as forças entre fatias são consideradas paralelas à base da fatia, anulando uma a outra (Figura 2.2). 


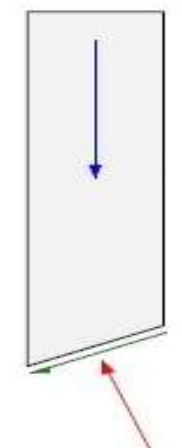

Figura 2.2 - Forças consideradas no método de Fellenius.

Como esquematizado na Figura 2.3, o peso da fatia pode ser decomposto em uma parcela equivalente à força normal atuante na fatia, aumentando a resistência do solo; e uma paralela à sua base, atuando contra a segurança do talude. O método de Fellenius (1936) admite superfície de ruptura circular e trabalha com somatório de momentos, desconsiderando o equilíbrio de forças verticais e horizontais. Devido à simplificação adotada, os valores de FS encontrados neste método são menores que os valores reais de FS, tornando-o conservador.

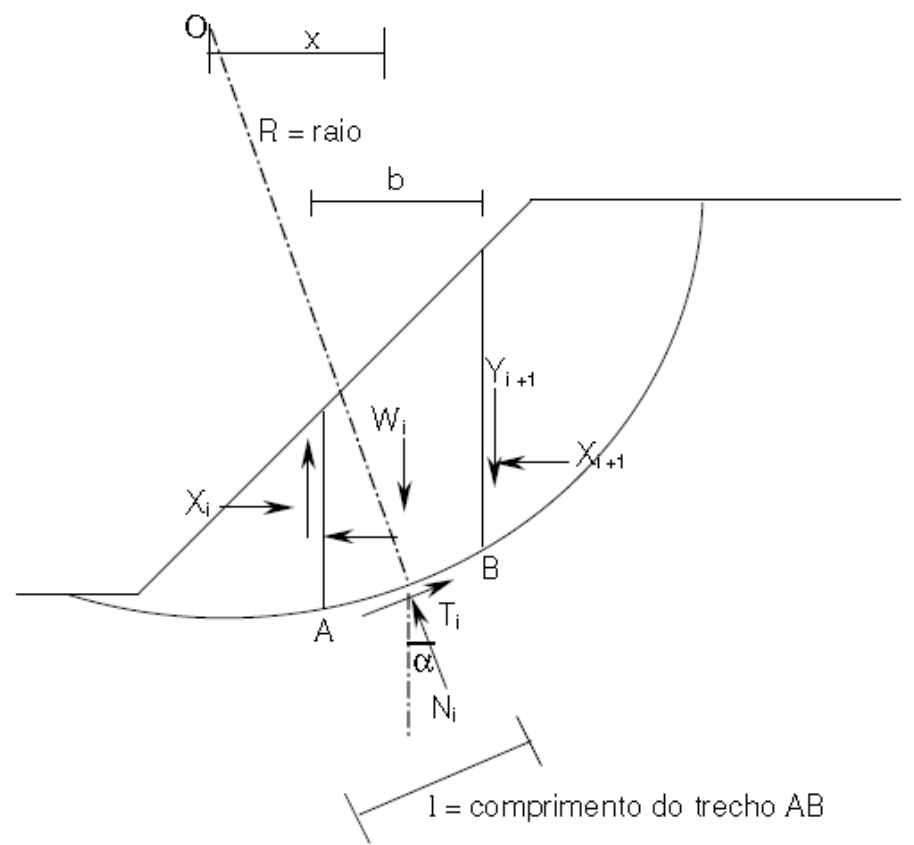

Figura 2.3 - Forças atuantes em uma fatia.

Aplicando-se, então o equilíbrio de momentos na fatia, tem-se o FS pelo método de Fellenius dado por:

$$
\mathrm{FS}=\frac{\Sigma\left[\mathrm{c}^{\prime}\left(\frac{\mathrm{b}}{\cos \alpha}\right)+\left(\mathrm{W} \cos \alpha-\mathrm{u}\left(\frac{\mathrm{b}}{\cos \alpha}\right)\right) \operatorname{tg} \Phi^{\prime}\right]}{\Sigma \mathrm{W} \operatorname{sen} \alpha}
$$


onde $\mathrm{u}=$ poropressão, $\mathrm{c}^{\prime}=$ coesão efetiva do solo, $\phi^{\prime}=$ ângulo de atrito efetivo do solo.

Este procedimento é repetido para todas as fatias consideradas, e o FS crítico é o menor valor de FS encontrado.

\subsection{2}

\section{Bishop Simplificado (1955)}

Assim como o método de Fellenius, este método também supõe superfície de ruptura circular. Método descrito por Bishop (1995), em que a hipótese simplificadora considera apenas as componentes horizontais das forças entre fatias, desconsiderando as cisalhantes. São satisfeitas somente as equações de equilíbrio de forças verticais e de momentos. Uma fatia com a representação das forças consideradas no equilíbrio é mostrada na Figura 2.4.

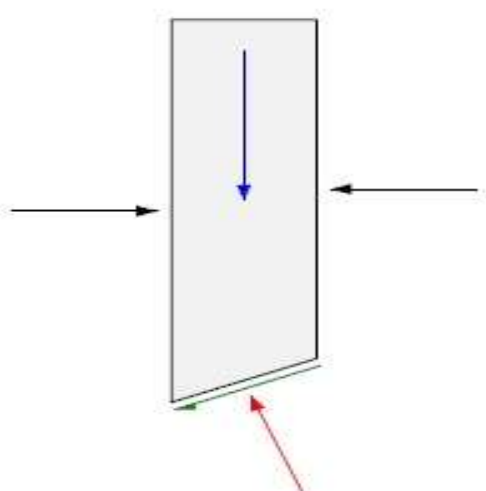

Figura 2.4 - Fatia com forças consideradas no Método de Bishop Simplificado.

Ao acrescentar-se o equilíbrio de forças verticais à Equação 2.7, o fator de segurança é obtido pela Equação 2.8:

$$
\mathrm{FS}=\frac{1}{\Sigma \mathrm{Wsen} \alpha} \Sigma\left[\mathrm{c}^{\prime} \cdot \mathrm{b}+(\mathrm{W}-\mathrm{ub}) \operatorname{tg} \Phi^{\prime}\right] / m_{\alpha}
$$

onde

$$
\mathrm{m}_{\alpha}=\cos \alpha\left[1+\frac{\operatorname{tg} \alpha \cdot \operatorname{tg} \Phi^{\prime}}{\mathrm{FS}_{\mathrm{i}}}\right]
$$


A solução é encontrada aplicando-se um processo iterativo no qual são arbitrados valores de $\mathrm{FS}_{\mathrm{i}}$ na Equação 2.9 e, a partir disto, calculados os valores de FS a eles correspondentes na Equação 2.8. A solução se revela quando o valor de FS é igual ao valor de $\mathrm{FS}_{\mathrm{i}}$.

O método de Bishop fornece resultados mais próximos dos métodos rigorosos do que o método de Fellenius.

\subsection{3}

\section{Janbu Simplificado (1956)}

Assim como o método de Bishop Simplificado, o método de Janbu Simplificado considera apenas forças horizontais entre fatias, e ignora as forças cisalhantes entre elas. Ele se difere do método de Bishop Simplificado por satisfazer equações de equilíbrio de forças horizontais e verticais, e não considerar o equilíbrio de momentos. Janbu et al. (1956) propuseram um fator de correção $f_{0}$ empírico, dependente do tipo de solo e da forma da superfície de ruptura, para satisfazer parcialmente o equilíbrio de momentos.

Neste método o fator de segurança é expresso por:

$$
\mathrm{FS}=\frac{\mathrm{f}_{0}}{\sum \mathrm{Wtg} \alpha} \sum\left[c^{\prime} \cdot b+(W-u b) \operatorname{tg} \Phi^{\prime}\right] / \cos \alpha \cdot m_{\alpha}
$$

onde

$$
\mathrm{m}_{\alpha}=\cos \alpha\left[1+\frac{\operatorname{tg} \alpha \cdot \operatorname{tg} \Phi^{\prime}}{\mathrm{FS}_{\mathrm{i}}}\right]
$$

O mesmo processo iterativo usado no método de Bishop é aqui utilizado para se encontrar FS que se iguale a $\mathrm{FS}_{\mathrm{i}}$.

Pela sua natureza simplificadora, o método de Janbu Simplificado fornece fatores de segurança conservadores. 


\subsection{4} Spencer (1967)

Método rigoroso que faz análises de estabilidade satisfazendo as condições de equilíbrio de forças horizontais e verticais, e de momentos. Aceita tanto superfícies circulares quanto não circulares.

Spencer substituiu as forças $X_{i}, Y_{i}, X_{i+1}$, e $Y_{i+1}$ (Figura 2.3) por uma resultante $Q_{i}$ inclinada de $\delta_{i}$ em relação à horizontal. Ao satisfazer o equilíbrio de momentos, a força $Q_{i}$ passa pelo ponto médio da base da fatia, interseção das forças $T_{i}, W_{i}$, e $N_{i}$ conforme ilustrado na Figura 2.5.

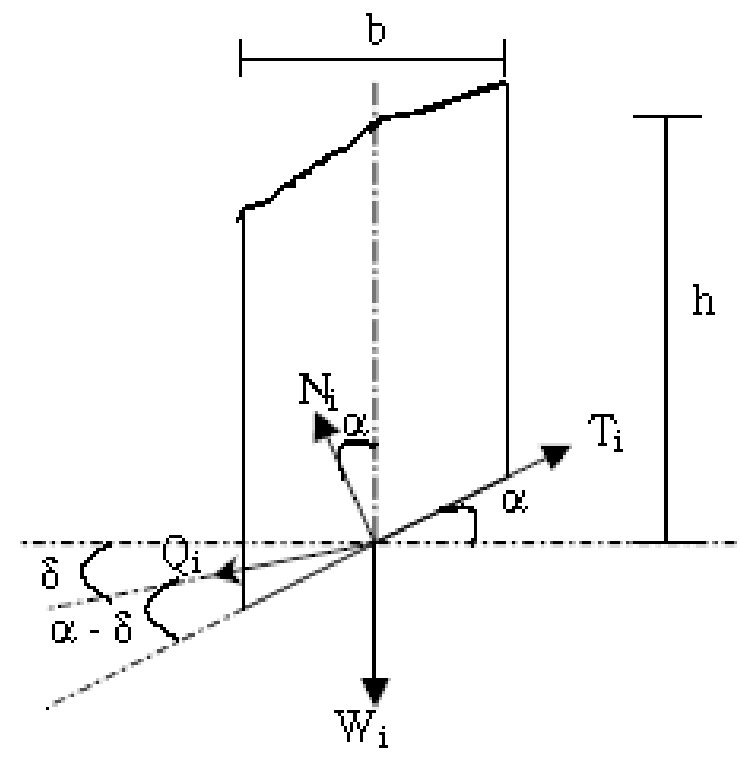

Figura 2.5 - Forças atuantes nas fatias no Método de Spencer.

Considerando o critério de ruptura de Mohr-Coulomb e aplicando o equilíbrio nas direções normal e paralela à base da fatia chega-se à Equação 2.12:

$$
Q=\frac{\frac{c^{\prime} b \cdot \sec \alpha}{F}+\frac{\operatorname{tg} \Phi^{\prime} \cdot(h \cos \alpha-u b \sec \alpha)}{F}-W \operatorname{sen} \alpha}{\cos (\alpha-\delta) \cdot\left[1+\frac{\operatorname{tg} \Phi^{\prime} \operatorname{tg}(\alpha-\delta)}{F}\right]}
$$




\subsection{5}

Morgenstern and Price (1965)

Método rigoroso aplicado a superfícies de ruptura quaisquer. As condições de estabilidade satisfazem, simultaneamente, todas as condições de equilíbrio de momentos e forças. A massa de potencial deslizamento é dividida em fatias infinitesimais, necessitando-se do auxílio de um computador para realização dos cálculos. Nele são consideradas as forças normais e cisalhantes entre fatias, ilustradas na Figura 2.6.

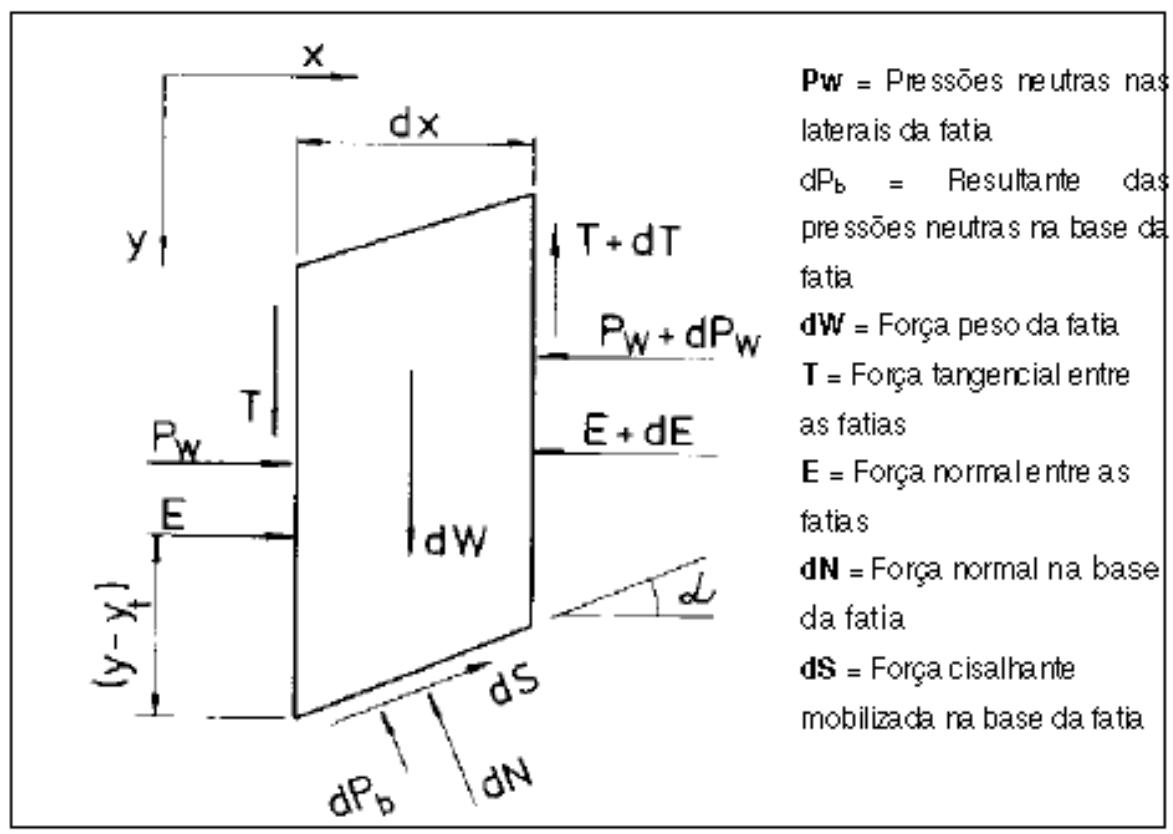

Figura 2.6- Forças atuantes em uma fatia infinitesimal pelo método de Morgenstern and Price (1965)

\section{2}

\section{Conceitos Básicos de Probabilidade e Estatística}

Solos são produtos do intemperismo de maciços rochosos que, por sua vez, são heterogêneos e apresentam características espacialmente variáveis devido aos processos ocorridos ao longo de sua história geológica (ex: dobramentos, falhas, exumação, erosão, diferenciação, soerguimento, metamorfismo, estratificação, sedimentação,...). Logo, pode-se concluir que solos são materiais cujo comportamento é de difícil previsão, pois suas características podem variar de ponto a ponto. $\mathrm{Na}$ abordagem determinística, obtem-se um valor de FS que é função dos parâmetros médios do solo, e desconsidera sua variabilidade espacial. 
A abordagem probabilística é uma técnica capaz de minimizar as incertezas das análises geotécnicas de estabilidade, e de complementar as análises determinísticas.

Quando análises probabilísticas são aplicadas a estudos de estabilidade de taludes, o FS deixa de ser um valor médio e passa a ser entendido como uma função. Assim, passa-se a ter FS como uma variável aleatória dependente de outras variáveis chamadas independentes, as quais normalmente são os parâmetros variáveis ao longo do solo como: coesão efetiva (c'), ângulo de atrito efetivo (Ф'), poropressão (u), peso específico seco ( $\left.\searrow_{n a t}\right)$, peso específico saturado $\left(\mathrm{\gamma}_{\text {sat }}\right)$, e resistência não drenada $(\mathrm{Su})$.

Na Figura 2.7, são apresentadas duas curvas de distribuição de FS (A e B), nas quais é possível perceber a importância do conhecimento da função densidade de probabilidade do FS no cálculo da probabilidade de ruptura de um talude.

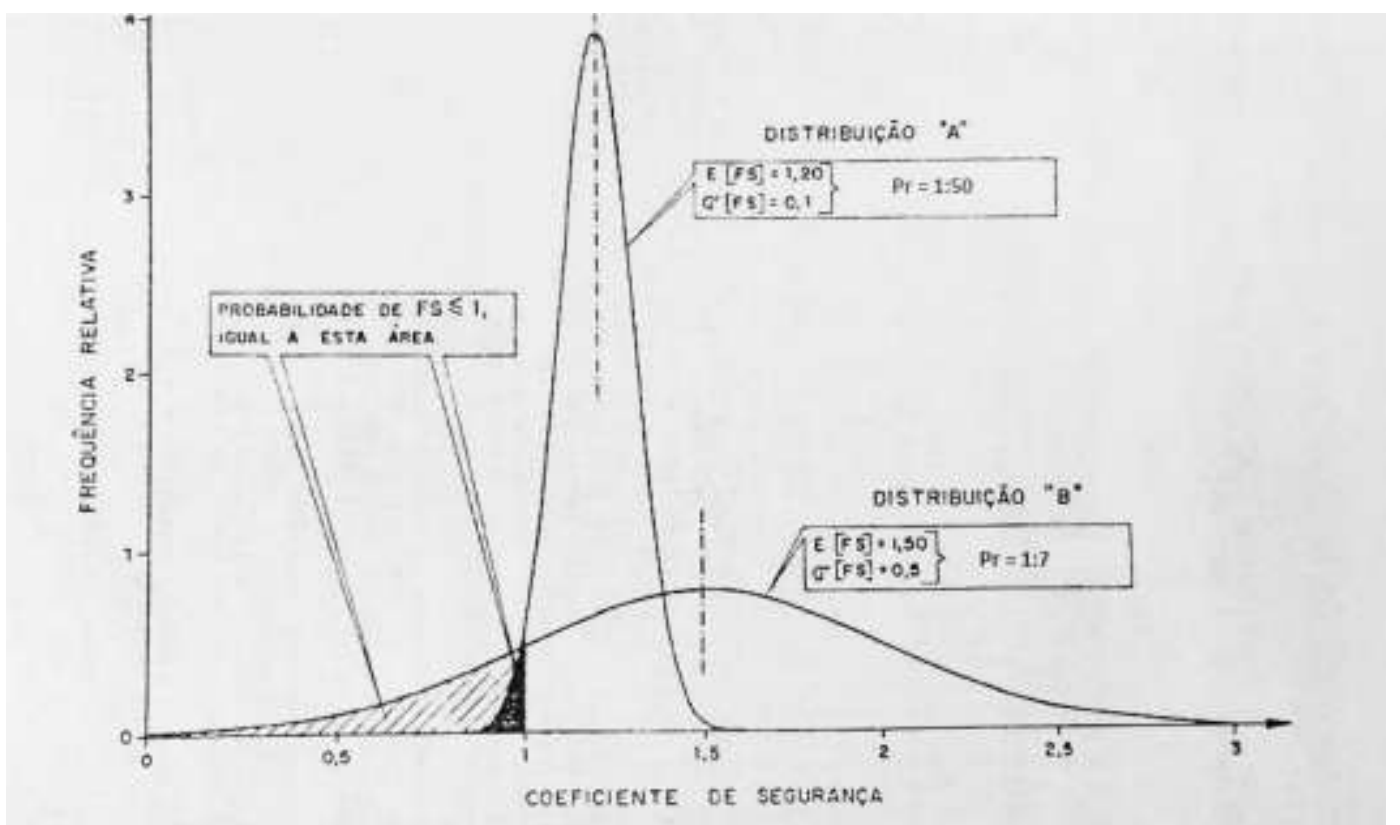

Figura 2.7 - Função densidade de probabilidade de FS para casos A e B (adaptado de Sandroni e Sayão, 1992).

A área abaixo de uma curva de distribuição de probabilidade correspondente a valores de abcissa $(\mathrm{FS}) \leq 1,0$ indica a probabilidade de ruptura de um talude cuja distribuição de FS é representada por tal curva. Nem sempre um menor valor de FS representa menor segurança, ou maior Pr, como ilustrado na Figura 2.7. Na mesma figura, é possível observar que um FS médio (E[FS]) de 1,20 corresponde a uma $\operatorname{Pr}$ de 1:50, enquanto o valor $\mathrm{E}[\mathrm{FS}]=1,50$ tem $\operatorname{Pr}=1: 7$. Este exemplo 
justifica a utilização de análises probabilísticas e a necessidade de conhecimento da dispersão da curva de FS para se entender a representatividade de seu valor médio em uma obra geotécnica.

Neste contexto, para obtenção das funções de distribuição de probabilidade, e aplicação de suas vantagens no estudo da estabilidade de um talude, é importante apresentar uma revisão de conceitos estatísticos básicos:

- Espaço Amostral (S)

É o conjunto que contém todos os resultados possíveis de um experimento.

- Variável Aleatória (X)

É uma variável quantitativa cujo valor depende de fatores aleatórios. Quando um espaço amostral apresenta continuidade formando um conjunto infinito de possíveis pontos amostrais, a variável envolvida é chamada variável aleatória contínua. As variáveis do universo geotécnico são consideradas contínuas. Existem também as variáveis discretas, as quais não serão abordadas neste estudo.

- Média ou Valor Esperado

Medidas estatísticas necessárias para se determinar a distribuição de probabilidade de uma função são os chamados momentos. O primeiro momento de uma variável aleatória é a média $(\mu)$ ou valor esperado $E[X]$. Ela é uma medida da tendência central da distribuição da variável, e é expressa pela Equação 2.13:

$$
\mu=\int_{-\infty}^{\infty} x . f(x) d x
$$


- Variância

A variância $(\mathrm{V}[\mathrm{X}])$, ou segundo momento, é calculada em função da média da amostra e mede a dispersão da distribuição de probabilidade. Ela é definida por:

$$
V[X]=\sigma^{2}=\int_{-\infty}^{\infty}(x-\mu)^{2} \cdot f(x) d x
$$

À raíz quadrada da variância se dá o nome de desvio padrão $(\sigma)$. Altos valores de $\sigma$ indicam alta dispersão em torno da média, enquanto baixos valores indicam pouca dispersão. Este padrão pode ser respectivamente observado pelas curvas de distribuição A e B da Figura 2.7.

Além do primeiro e segundo momentos mencionados, média e variância respectivamente, existem outros momentos necessários ao conhecimento do comportamento da função densidade de probabilidade de uma variável aleatória. Estes momentos fornecem o comportamento da curva em relação à sua simetria $\mathrm{e}$ curtose. Os métodos probabilísticos utilizados nas análises aqui presentes utilizarão apenas o primeiro e segundo momentos da função, portanto os demais não serão discutidos no texto. Para conhecimento do comportamento da função densidade de probabilidade do "Fator de Segurança", é possível aplicar-se técnica de geração aleatória de números utilizados como valores da variável conhecida como Simulação de Monte Carlo apresentada mais adiante (Dell'Avanzi, 1995).

- Função Densidade de Probabilidade

É a função que descreve a curva de distribuição da probabilidade de ocorrência dos valores de uma variável aleatória. Para uma variável contínua (X), só terão interesse as probabilidades onde $\mathrm{X}$ assuma um intervalo. Neste caso, esta função deve atender às seguintes condições:

i) $f(x) \geq 0$

ii) $\int_{a}^{b} f(\mathrm{x}) \mathrm{dx} \geq 0$ 
A Figura 2.8 ilustra uma curva de distribuição de probabilidade onde a probabilidade de $\mathrm{X}$ estar entre os valores a e b é representada pela área sombreada. A notação formal que representa esta probabilidade é $\mathrm{P}(\mathrm{a} \leq \mathrm{X} \leq \mathrm{b})=$ $\int_{a}^{b} f(\mathrm{x}) \mathrm{dx} \geq 0$.

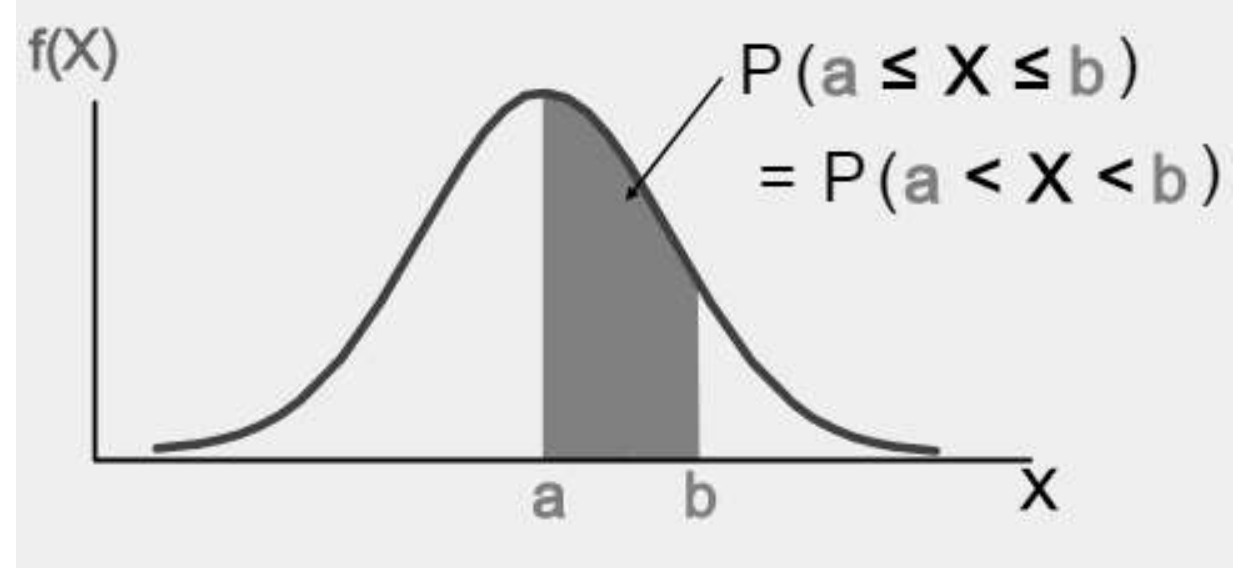

Figura 2.8 - Curva típica de Distribuição de Probabilidade.

De acordo com a geometria da curva, são caracterizados tipos distintos de distribuição: normal (ou gaussiana), lognormal, gama e qui-quadrado, dentre outras. A distribuição normal, também conhecida como gaussiana, caracteriza-se por sua simetria em torno da média, apresentando o formato da seção em corte de um sino, e é representada pela Equação 2.17:

$$
f(x)=\frac{1}{\sqrt{2 \pi \sigma^{2}}} \cdot e^{\frac{1}{2}\left(\frac{x-\mu}{\sigma}\right)^{2}}
$$

A distribuição normal é geralmente considerada adequada ao comportamento de materiais geotécnicos (Lee et al., 1983). Portanto, no estudo de caso deste trabalho são consideradas distribuições normais para apresentação do comportamento do solo. 
- Coeficiente de Variação

Medida de dispersão dos dados em relação à sua própia média aritmética. Este coeficiente é função da média e do desvio padrão, e é expresso em porcentagem:

$$
C v(x)=\frac{\sigma}{E[X]} * 100
$$

Quando não há ensaios suficientes para o cálculo da variância dos parâmetros considerados variáveis, é possível recorrer à literatura e utilizar coeficientes de variação típicos para um estudo preliminar da estabilidade de segurança dos taludes. A Tabela 2.1 apresenta valores típicos de coeficiente de variação para certos parâmetros, apresentados por Sandroni e Sayão (1992).

Tabela 2.1 - Valores típicos de coeficiente de variação sugeridos por Sandroni e Sayão (1992).

\begin{tabular}{|l|c|}
\hline \multicolumn{2}{|c|}{ Valores típicos do coeficiente de variação. } \\
\hline \multicolumn{1}{|c|}{ Parâmetro } & Coeficiente ale Variação \\
\hline Peso específico & $03(02$ a 08) \\
Coesão & $40(20$ a 80) \\
Ângulo efetivo de resistência & $10(04$ a 20) \\
Coesão não-drenada & $30(20$ a 50) \\
\hline
\end{tabular}

- Covariância

Em casos de existência de dependência entre duas variáveis $x$ e $y$, a covariância, expressa pela Equação 2.19, é capaz de introduzir esta dependência nos cálculos:

$$
\operatorname{Cov}(x, y)=\frac{\sum_{i=1}^{n}(x-\bar{x})(y-\bar{y})}{n-1}
$$

Quando as variáveis são independentes, a covariância é nula. Uma maneira prática de se expressar esta dependência entre parâmetros é utilizando-se o conceito de coeficiente de correlação, $\rho$ (x,y), definido na Eq 2.20: 


$$
\rho(\mathrm{x}, \mathrm{y})=\frac{\operatorname{Cov}(x, y)}{\sigma(x) \cdot \sigma(y)}
$$

Se uma mesma variável apresenta correlação entre seus próprios valores amostrados em pontos distintos separados por uma distância $r$, esta dependência pode ser expressa pela chamada autocorrelação, definida por:

$$
\operatorname{Cov}_{r}(x)=\frac{\sum_{i=1}^{n}\left(x_{i}-\bar{x}\right)\left(x_{i+r}-\bar{x}\right)}{n-1}
$$

sendo $x_{i+r}$ o valor da variável aleatória em um ponto que dista de $\mathrm{r}$ em relação à medida $x_{i}$.

\section{3}

\section{Métodos probabilísticos}

O termo probabilidade possui vasto significado e distintas aplicações. Trabalhos que envolvem análises probabilísticas podem abranger desde teorias matemáticas básicas até as mais sofisticadas. A inserção de conceitos estatísticos e métodos de cálculos probabilísticos na geotecnia parece afastar os geotécnicos de tal prática. Entretanto, conceitos básicos e métodos relativamente simples são de relevante aplicabilidade em análises de estabilidade de obras geotécnicas. Esta importância se justifica pelo fato de análises probabilísticas permitirem a quantificação, até certo ponto, de incertezas inerentes ao estudo de solos. Estas incertezas foram descritas por Withman (1984) em quatro classes:

1. Erro estatístico devido à quantidade insuficiente de amostras para realização de ensaios para obtenção de parâmetros de resistência do solo, ensaios de caracterização, medições piezométricas e ou de qualquer outra propriedade do solo que venha a ser considerada variável;

2. Medidas tendenciosas como os valores de parâmetros não condizentes com a realidade de campo provenientes de manuseio, armazenagem, molde e transporte das amostras e/ou corpos de prova e erros de 
reprodução de condições de carregamento existentes no campo em laboratório;

3. Variabilidade espacial dos parâmetros de resistência do solo, resultante de seus próprios processos não uniformes de formação (rocha de origem, intemperismo, estado de tensões, etc);

4. Ruídos ou erros de medição, os quais são atribuídos a falhas no manuseio, leitura e/ou calibração de equipamentos. Segundo Sandroni e Sayão (1992), estas falhas podem ser minimizadas tomando-se os devidos cuidados que envolvem, por exemplo, a qualificação de equipes e equipamentos, corretas especificações e acompanhamento adequado de ensaios e medições.

Einsten e Baecher (1983) apresentam um ciclo representativo do processo de tomada de decisão de um engenheiro geotécnico diante de resultados de análises probabilísticas que são precedidas de coleta de dados e análises determinísticas. A Figura 2.9 representa as fases envolvidas no ciclo, são elas: determinística, probabilística, informativa e de decisão. Seguindo-se o ciclo, é possível optar pela especificação e implantação de um projeto ao chegar-se na fase de decisão quando os dados e resultados obtidos são satisfatórios. Caso contrário, o recomendado é a coleta de novos dados, geração de novas informações, e repetição do processo reiniciando-se na fase determinística.

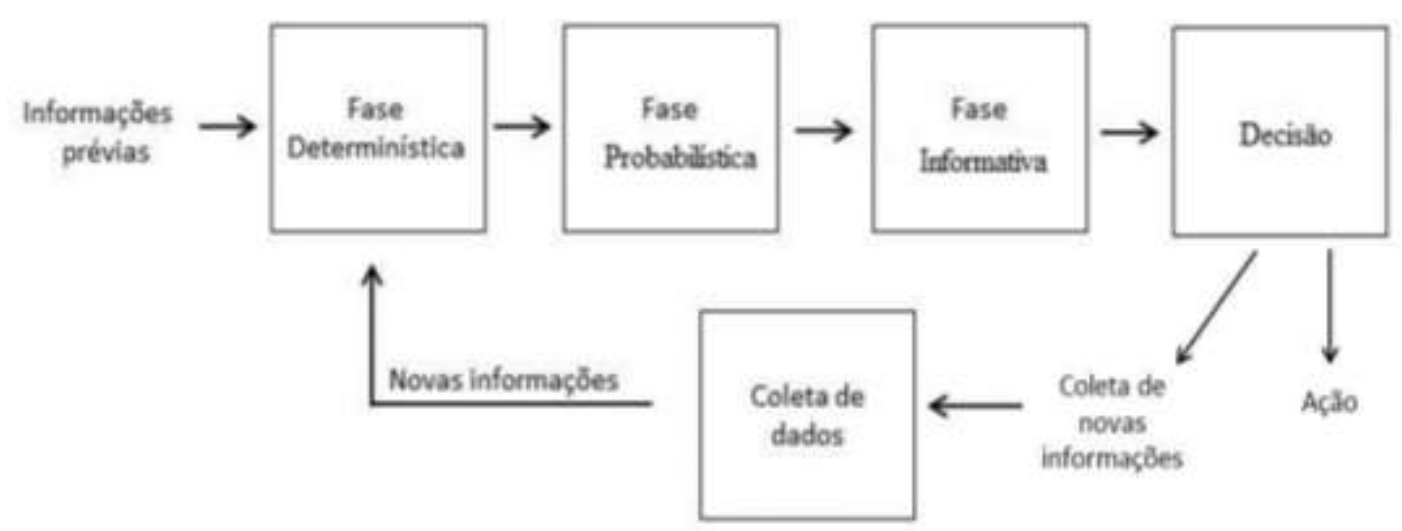

Figura 2.9 - Ciclo de tomada de decisão em análises probabilísticas (adaptado de Einsten e Baecher, 1983).

A seguir são apresentados três métodos probabilísticos frequentemente utilizados em práticas geotécnicas. Os dois primeiros, FOSM e Estimativas 
Pontuais, são métodos indiretos de cálculo de probabilidade de ruptura, pois fornecem média e desvio padrão de FS em função da média e desvio padrão dos parâmetros envolvidos no cálculo (Griffiths, 2004). Portanto, estes métodos permitem o cálculo de $\beta$ e Pr sem que seja necessário o conhecimento explícito da função densidade de probabilidade do FS. A simulação de Monte Carlo é um método direto que envolve mais cálculos. Permite que a função densidade de probabilidade seja explicitada, mas depende de programação computacional para ser aplicado.

\subsection{1} FOSM

O FOSM (First-Order, Second Moment) é o método de análise probabilística de aplicação mais simples dentre os estudos apresentados. Nele, não é obrigatório o conhecimento das funções de distribuição de probabilidade dos parâmetros considerados variáveis. Aproximações da média e variância de uma variável aleatória dependente são feitas por aplicação de série de Taylor em torno dos valores médios das variáveis independentes envolvidas (Christian et al., 1992).

Sendo $x_{1}, x_{2}, x_{3}, \ldots, x_{n}$ os parâmetros definidos como variáveis no cálculo de FS, pode-se representar o valor médio de $X$ e de sua função de desempenho por $\bar{X}$ e $F(\bar{X})$, respectivamente. Ambos são funções das médias das variáveis independentes (parâmetros $x_{i}$ ):

$$
\begin{aligned}
& \bar{X}=\left[\bar{x}_{1}, \bar{x}_{2}, \ldots, \bar{x}_{n}\right] \\
& F(\bar{X})=G\left(\bar{x}_{1}, \bar{x}_{2}, \ldots, \bar{x}_{n}\right)
\end{aligned}
$$

Representando-se a expansão da função $f(X)$ por meio de uma série de Taylor em torno de $\bar{X}$, tem-se:

$$
F(X)=f(\bar{X})+\frac{f^{\prime}(\bar{X})}{1 !}(X-\bar{X})^{1}+\frac{f^{\prime \prime}(\bar{X})}{2 !}(X-\bar{X})^{2}+\ldots
$$

onde $f^{n}(\bar{X})$ é a enésima derivada da função $f(X)$ em torno de $\bar{X}$. 
Ao truncar-se a Série 2.24 na primeira derivada e manipular-se a equação, chega-se a:

$$
f(X)-f(\bar{X})=f(\bar{X})(X-\bar{X})
$$

Quando a Equação 2.25 é elevada ao quadrado e manipulada algebricamente, uma aproximação de sua variância é obtida por:

$$
V[f(X)]=\left(f^{\prime}(\bar{X})\right)^{2} \cdot V(X)
$$

Como neste caso a variável de interesse é o FS, que é função de parâmetros classificados como independentes entre si, tem-se que sua variância é proporcional ao somatório do produto entre as derivadas parciais da função FS[X] em relação a cada parâmetro considerado variável e sua respectiva variância (Harr, 1987):

$$
V[F S]=\sum_{i=1}^{n}\left(\frac{\delta F S}{\delta x_{i}}\right)^{2} \cdot V\left[x_{i}\right]
$$

Em casos de existência de dependência entre dois parâmetros $x_{i}$ e $x_{j}$, a variância de FS é aproximada por:

$$
V[F S]=\sum_{i=1}^{n} \sum_{j=1}^{n}\left(\frac{\delta F S}{\delta x_{i}}\right) \cdot\left(\frac{\delta F S}{\delta x_{j}}\right) \cdot \operatorname{Cov}\left[x_{i}, x_{j}\right]
$$

Li e Lumb (1983) ressaltam que, para se obter as derivadas parciais de FS, é necessário expressar sua função explicitamente. Como isto nem sempre é um procedimento simples, em vários casos práticos a diferenciação formal para realização de cálculos estatísticos se torna bastante complexa. Nestes casos, uma alternativa é fazer a aproximação das derivadas parciais por meio da metodologia das diferenças divididas (Christian et al., 1992).

Esta metodologia consiste na variação (incrementação ou diminuição) individual de cada parâmetro definido como variável aleatória, e registro do efeito 
desta variação no valor de FS. A razão entre a variação do valor de FS e a variação de parâmetro $\left(\delta x_{i}\right)$ que provocou esta mudança no FS fornecem a aproximação de sua derivada parcial em relação a cada parâmetro:

$$
\frac{\delta F S}{\delta x_{i}}=\frac{F S\left(x_{i}+\delta x_{i}\right)-F S\left(\overline{x_{l}}\right)}{\delta x_{i}}
$$

Segundo El-Ramly, Morgenstern e Cruden (2003b), o método FOSM é preferencialmente indicado para problemas onde não existam correlações entre as variáveis. O que não impede investimento de esforço extra para aplicação em situações em que existam correlações entre parâmetros. Quanto mais parâmetros correlacionados, maior a dificuldade de aplicação do método.

Dell'Avanzi (1995) ressalta a importância de fazer-se $\delta x_{i}$ pequena o suficiente para que $\delta \mathrm{FS} / \delta x_{i}$ seja constante e independa de valor de $\delta x_{i}$. Ele sugere variação máxima de $10 \%$ para cada parâmetro, independentemente de serem incrementais ou decrementais.

Além da simplicidade dos cálculos e da aplicação do método FOSM, a possibilidade de calcular-se uma probabilidade de ruptura sem que se conheça sua função densidade de probabilidade é uma de suas vantagens. A determinação da participação percentual de cada parâmetro considerado variável na estabilidade da obra geotécnica em questão, também é um ponto vantajoso deste sobre os demais métodos apresentados.

\subsection{2}

\section{Estimativas Pontuais}

O método descrito e denominado Método das Estimativas Pontuais (EP) por Rosenblueth (1975) é, assim como o FOSM, um método indireto de aproximação numérica da média e variância da variável aleatória de interesse. O método é de fácil aplicação, e requer pouco conhecimento teórico sobre probabilidade (Baecher e Christian, 2003).

Ele consiste em um simples procedimento que permite a estimativa dos dois primeiros momentos probabilísticos de uma função $F(X)$ sem que se conheça $\mathrm{F}(\mathrm{X})$ explicitamente, a partir do conhecimento dos dois primeiros momentos das variáveis aleatórias $X_{i}$. Isto é possível a partir de uma função geradora de 
momentos que é encontrada realizando-se um número de análises de estabilidade equivalente a $2^{n}$, em que $\mathrm{n}$ é o número de parâmetros tomados como variáveis. Para que se obtenha $2^{n}$ análises, o valor médio de cada parâmetro variável é acrescido ou reduzido de seu desvio padrão, e o resultado obtido é combinado de todas as formas possíveis de forma a gerar valores para a função de desempenho $\mathrm{F}(\mathrm{X})$.

Ao considerar um caso particular em que a função de desempenho é dependente de apenas duas variáveis ( $n=2)$, Rosenblueth (1975) demonstrou que a função geradora de momentos para cálculo do valor médio da função de desempenho é dada por:

$F(\bar{X})=P_{++}\left(F(X)_{++}\right)+P_{+-}\left(F(X)_{+-}\right)+P_{-+}\left(F(X)_{-+}\right)+P_{--}\left(F(X)_{--}\right)$

onde,

$P_{++}=$probabilidade de ocorrência simultânea dos valores das duas variáveis serem acrescidas de seus desvios padrão;

$P_{+-}$e $P_{-+}=$probabilidade de ocorrência simultânea de uma variável ser acrescida e a outra subtraída de seus respectivos desvios padrão, na ordem imposta pelos símbolos $-\mathrm{e}+$;

$P_{--}=$probabilidade de ocorrência simultânea dos valores das duas variáveis serem subtraídas de seus desvios padrão;

$F(X)_{++}=$valor da função $F(X)$ considerando os valores das duas variáveis acrescidas de seus desvios padrão;

$F(X)_{+-} e F(X)_{-+}=$valor da função $F(X)$ considerando a ocorrência simultânea de uma variável ser acrescida e a outra subtraída de seus respectivos desvios padrão, na ordem imposta pelos símbolos $-\mathrm{e}+$;

$F(X)_{--}=$valor da função $F(X)$ considerando os valores das duas variáveis subtraídos de seus desvios padrão.

Sendo $\bar{x}_{1}$ e $\bar{x}_{2}$ os valores médios das duas variáveis aleatórias que compõem a função geradora de momentos, as probabilidades de ocorrência de valores acrescidos e subtraídos são dadas por: 


$$
\begin{aligned}
& P_{++}=P\left[\bar{x}_{1}+\sigma_{x_{1}}\right] \cdot P\left[\bar{x}_{2}+\sigma_{x_{2}}\right] \\
& P_{+-}=P\left[\bar{x}_{1}+\sigma_{x_{1}}\right] \cdot P\left[\bar{x}_{2}-\sigma_{x_{2}}\right] \\
& P_{-+}=P\left[\bar{x}_{1}-\sigma_{x_{1}}\right] \cdot P\left[\bar{x}_{2}+\sigma_{x_{2}}\right] \\
& P_{--}=P\left[\bar{x}_{1}-\sigma_{x_{1}}\right] \cdot P\left[\bar{x}_{2}-\sigma_{x_{2}}\right]
\end{aligned}
$$

onde $\mathrm{P}[$ ] representa a probabilidade de ocorrência.

É importante ressaltar que, quando as variáveis $x_{1}$ e $x_{2}$ não são correlacionáveis, e as funções densidade de probabilidade são simétricas, as probabilidades são todas iguais a 1/4 (Rosenblueth, 1975), pois:

$$
\begin{gathered}
P_{++}=P_{+-}=P_{-+}=P_{--} \\
e \\
P_{++}+P_{+-}+P_{-+}+P_{--}=1
\end{gathered}
$$

A partir das informações consideradas nas relações 2.35 e 2.36, é possível reescrever a Equação 2.30 aplicada à função de FS, e encontrar sua média, por:

$$
E[F S]=\frac{F S_{++}+F S_{+-}+F S_{-+}+F S_{--}}{4}
$$

A função que fornece a variância neste método é explicitada pela Equação 2.38:

$V[F(X)]=P_{++} F(X)^{2}{ }_{++}+P_{+-} F(X)^{2}{ }_{+-}+P_{-+} F(X)^{2}{ }_{-+}+P_{--} F(X)^{2}{ }_{--}-[F(\bar{X})]^{2}$

A partir das informações resultantes das relações 2.35 e 2.36 , é possível encontrar a variância de FS por:

$$
V[F S]=E\left[F S^{2}\right]-(E[F S])^{2}
$$


Aqui, o método é apresentado de forma metonímica por meio do exemplo em que são consideradas apenas 2 variáveis, o que não impede que o mesmo procedimento seja empregado em casos de participação de $n$ variáveis, com $n \in\{N\}$. Entretanto, na existência de mais de duas variáveis aleatórias, o método das Estimativas Pontuais mostra-se menos vantajoso que o FOSM, pois o número de análises requeridas torna-se exponencialmente maior na medida que o número de variáveis consideradas aumenta. O método FOSM requer $n+1$ análises, ao passo que o método de análise EP demanda $2^{n}$ análises.

Segundo Pacheco (1990), o método EP é aplicável a qualquer problema que admita solução determinística, independente da forma como esta solução é obtida.

\subsection{3}

\section{Método da Simulação de Monte Carlo}

A Simulação de Monte Carlo é um método probabilístico aplicável em diferentes ciências e foi originalmente descrito em 1949 por John Von Neumann e Stanislav Ulam (Metropolis e Ulam, 1949). Trata-se de uma técnica de amostragem estatística em que são gerados quantos valores aleatórios forem necessários para se descrever $\mathrm{F}(\mathrm{X})$ de forma que esta seja representativa da realidade. $\mathrm{O}$ resultado se torna mais preciso à medida que os números de valores gerados e de análises realizadas tendem a infinito. Sendo impossível realizar infinitas simulações, um número mínimo $(\mathrm{N})$ de simulações a serem realizadas foi sugerido por Harr (1987). Ele é função da precisão $(\epsilon)$, do nível de confiança desejado (1- $\alpha$ ), e do número $n$ de parâmetros variáveis, como expresso na Equação 2.40:

$$
N=\left[\frac{\left(h_{\alpha / 2}\right)^{2}}{4 \epsilon^{2}}\right]^{n}
$$

onde, $h_{\alpha / 2}$ é um índice função do nível de confiança (1- $\alpha$ ), apresentado por Harr (1987) na Tabela 2.2.

O número $\mathrm{N}$ encontrado em 2.40 é, na maioria das vezes, muito grande e envolve inúmeras repetições de procedimento. Antes do desenvolvimento de softwares capazes de realizar milhares de simulações em poucos segundos, o 
número de análises envolvidas no Monte Carlo era um complicador na aplicação do método.

Tabela 2.2- Índices de confiança para distribuição normal (Harr, 1987).

\begin{tabular}{|c|c|}
\hline $\begin{array}{c}\text { Nível de Confiança }(\%) \\
(\mathbf{1}-\alpha)\end{array}$ & $\mathbf{h}_{\boldsymbol{\alpha} / \mathbf{z}}$ \\
\hline 85 & 1,44 \\
90 & 1,64 \\
95 & 1,96 \\
95,45 & 2,00 \\
98 & 2,33 \\
99 & 2,58 \\
99,5 & 2,81 \\
99,73 & 3,00 \\
99,9 & 3,29 \\
99,99 & 3,89 \\
99,994 & 4,00 \\
\hline
\end{tabular}

Aplicado à geotecnia, o método permite que se reproduza o comportamento de uma variável aleatória dependente (ex: FS) e se obtenha as probabilidades de ruptura, $\operatorname{Pr}=\mathrm{P}(\mathrm{FS}<1)$, de uma obra geotécnica desde que se conheça sua geometria, a média, desvio padrão e função característica de cada parâmetro variável (ex: $\Phi^{\prime}, \gamma$, c') que intervenha na função FS. A principal diferença entre esta simulação e os métodos FOSM e EP, é o número de análises envolvidas em cada um deles, e a necessidade de se conhecer a função densidade de probabilidade que descreve cada parâmetro no caso da Simulação de Monte Carlo.

Em aplicações da simulação em estudos geotécnicos, Silva (2015), Lima (1991), Dell'Avanzi (1995), Guedes (1997) e Rômulo (2008) se posicionaram a favor dos métodos FOSM e/ou EP em detrimento da exaustão causada pelo alto número de execuções de análises de estabilidade envolvidos na Simulação de Monte Carlo. Atualmente já existem softwares que permitem a aplicação do método quando os dados de entrada necessários são conhecidos: média, desvio padrão e função densidade de probabilidade dos parâmetros definidos como variáveis.

\subsection{4}

\section{Índice de confiabilidade e probabilidade de ruptura}

O resultado obtido em uma análise probabilística é uma grandeza chamada índice de confiabilidade $(\beta)$. Quando FS apresenta distribuição normal (ou 
gaussiana), ele é expresso pela Equação 2.41, indicando o número de desvios padrão que distanciam o E[FS] calculado das situações de ruptura, quando $F S=1$ :

$$
\beta=\frac{E[F S]-1}{\sigma[F S]}
$$

sendo $\mathrm{E}[\mathrm{FS}]=$ valor determinístico de FS, e $\sigma[\mathrm{FS}]=$ desvio padrão de FS.

Existem outras relações que expressam o valor de $\beta$ em casos de distribuições distintas da normal, como a lognormal, cuja expressão pode ser encontrada em Flores (2008).

$\beta$ pode ser relacionado a uma probabilidade de ruptura $(\operatorname{Pr})$ por meio do ábaco apresentado na Figura 2.10. Ele apresenta as correlações $\beta \times \operatorname{Pr}$ para distribuições normais e log-normais de FS com diferentes valores de covariantes. Em análise ao comportamento de $\beta$ x Pr, Flores (2008) conclui que, na insuficiência de dados, assumir distribuições normais é um procedimento a favor da segurança, já que a probabilidade de ruptura é ligeiramente maior quando se tem distribuição normal. A distribuição também pode ser considerada normal em casos que FS tenha outro tipo de distribuição, mas apresente $1,5<\beta<2,0$ (Christian et al., 1992).

As Pr encontradas pelos métodos probabilísticos descritos nos itens 2.3.1, 2.3.2 e 2.3.3 não revelam a probabilidade real de ruptura. Por mais que todos os parâmetros geotécnicos e geométricos variáveis sejam considerados, são muitos os fatores de risco influentes na probabilidade real de ruptura. Portanto, é necessário estipular-se valores aceitáveis de índices $\beta$ ou de probabilidades de ruptura a eles associadas. O tipo de obra em questão e as possíveis consequências de rupturas são fatores imperativos nesta decisão. Neste intuito, propõe-se aliar experiência com retroanálises de projetos já existentes para determinação de valores adequados de $\beta$ e, consequentemente, $\operatorname{Pr}$.

Os índices $\beta$ e Pr consideram apenas as incertezas possíveis de serem contabilizadas nas análises probabilísticas. Considerando-se que o universo de incertezas relativas à definição do comportamento do solo é infinito, os índices $\beta$ e Pr são relativos e sua qualidade se torna proporcional ao número de incertezas consideradas (Guedes, 1997). 
Ainda não existem valores de segurança normatizados para os índices probabilísticos. Portanto, os índices mínimos e máximos considerados são definidos considerando-se as possíveis perdas (de vidas e econômicas) em caso de ruptura, aliados ao custo da obra. Esta relatividade leva à necessidade de participação do engenheiro geotécnico com sua experiência e discernimento para definição de valores adequados a cada obra. Este tipo de estudo é denominado análise de risco.

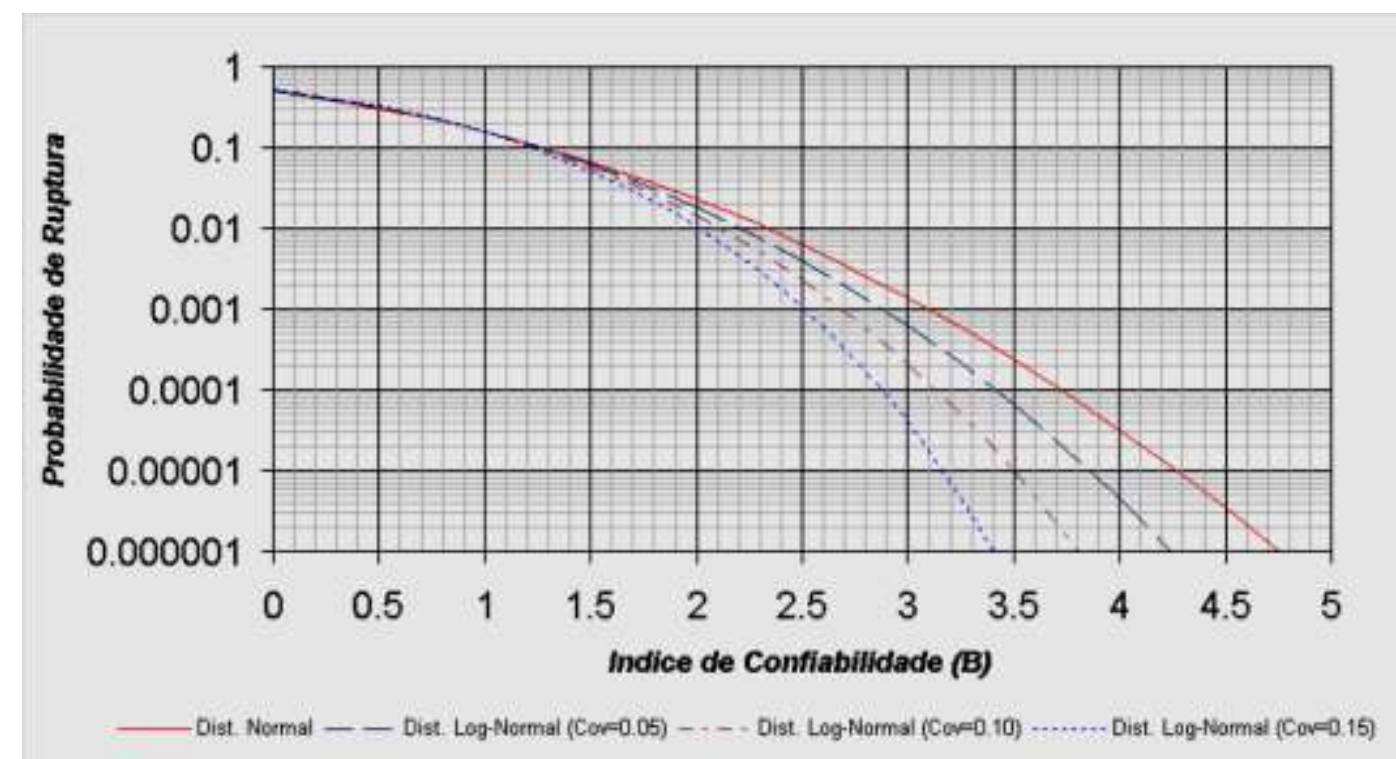

Figura 2.10- Índice de confiabilidade x probabilidade de ruptura (Flores, 2008).

O crescente aumento do emprego de análises probabilísticas em estudos geotécnicos pode proporcionar experiência suficiente para padronização de índices de confiabilidade e probabilidades de ruptura aceitáveis em cada tipo de obra. Guedes (1997) apresentou valores $\operatorname{Pr}$ e $\beta$ reportados na literatura que têm utilidade na padronização destes índices. Dell'Avanzi e Sayão (1998) apresentam, na Tabela 2.3, intervalos de valores de $\beta$ e Pr admissíveis em obras geotécnicas de natureza distintas, porém ainda não são valores normatizados e/ou absolutos para se tomar decisões em obras. 
Tabela 2.3 - Valores típicos de $\beta$ e $\operatorname{Pr}$ (Avanzi e Sayao, 1998).

\begin{tabular}{|c|c|c|c|}
\hline Caso & \multicolumn{2}{|c|}{$\beta$} & \multicolumn{2}{c|}{$\mathrm{Pr}$} \\
\hline Fundações & 2,3 a 3,0 & $10^{-2}$ a $10^{-3}$ \\
\hline $\begin{array}{c}\text { Taludes de } \\
\text { Mineração }\end{array}$ & 1,0 a 2,3 & $10^{-1}$ a $10^{-2}$ \\
\hline $\begin{array}{c}\text { Barragens } \\
\text { Estruturas } \\
\text { de } \\
\text { Contenção }\end{array}$ & 2,0 a 5,0 & $10^{-3}$ a $10^{-5}$ \\
\hline
\end{tabular}

Limites de risco admissíveis para cada tipo de obra geotécnica foram propostos por Baecher (1982) em forma de diagrama. A Figura 2.11 representa a adaptação deste diagrama por Flores (2008). Estes limites relacionam probabilidades de ruptura com as possíveis perdas de vida e econômicas em cada tipo de obra geotécnica, dados que auxiliam o engenheiro no processo de decisão de valores admissíveis de $\beta$ e Pr nos casos analisado. Baecher (1982b) apresentou diagrama que sugere regiões de risco ( $\operatorname{Pr} x$ perdas) para cada tipo de obra geotécnica (Figura 2.11). 


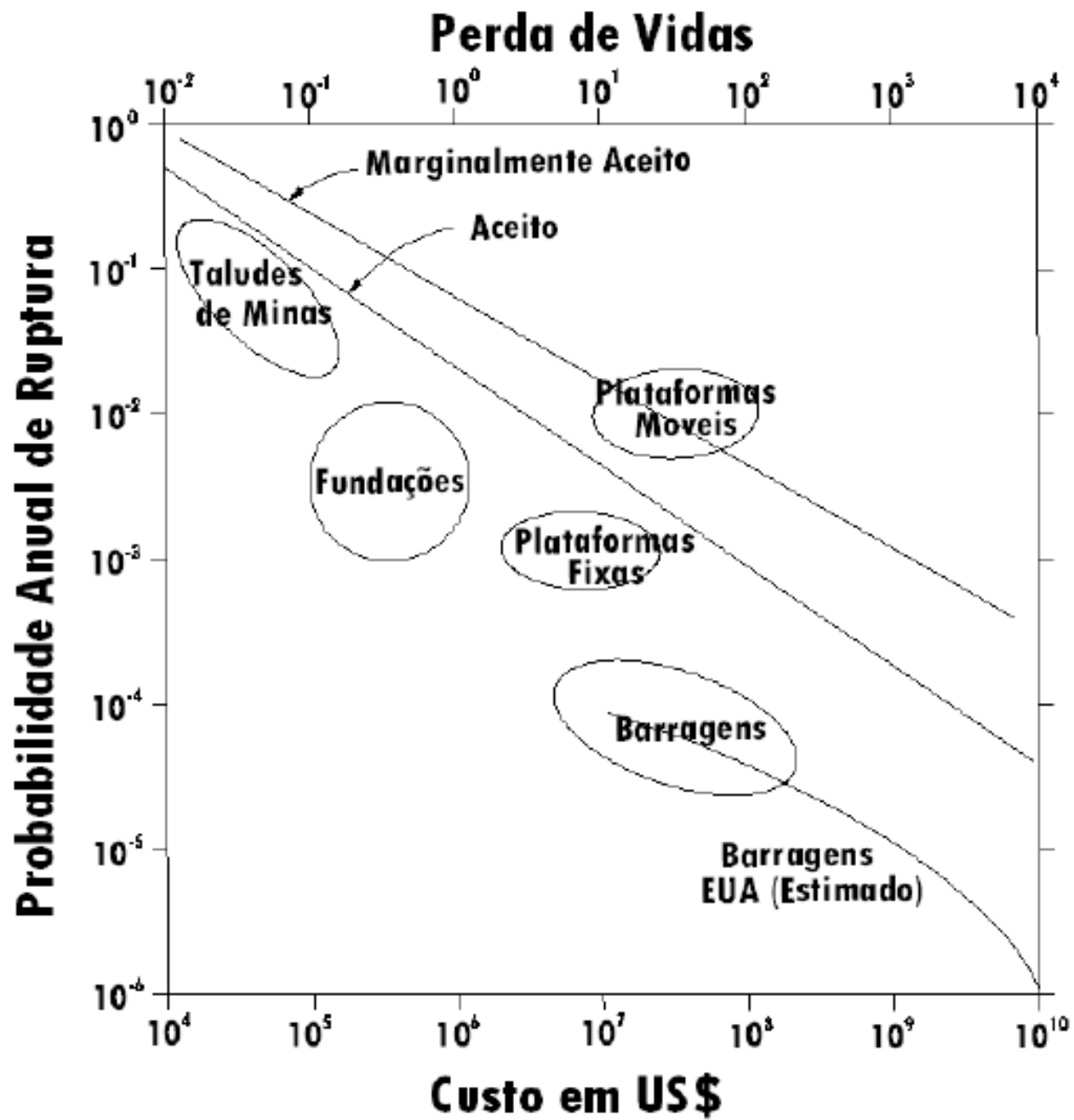

Figura 2.11 - Valores usuais de probabilidade e consequências de rupturas em projetos de engenharia. Adaptação de Baecher (1982) por Flores (2008).

A Figura 2.12 mostra diferentes níveis de aceitação de $\operatorname{Pr}$ e $\beta$ propostos pelo US Army Corps of Engineers (1995), sugerindo valores de Pr abaixo de $3 \times 10^{-5}$. 


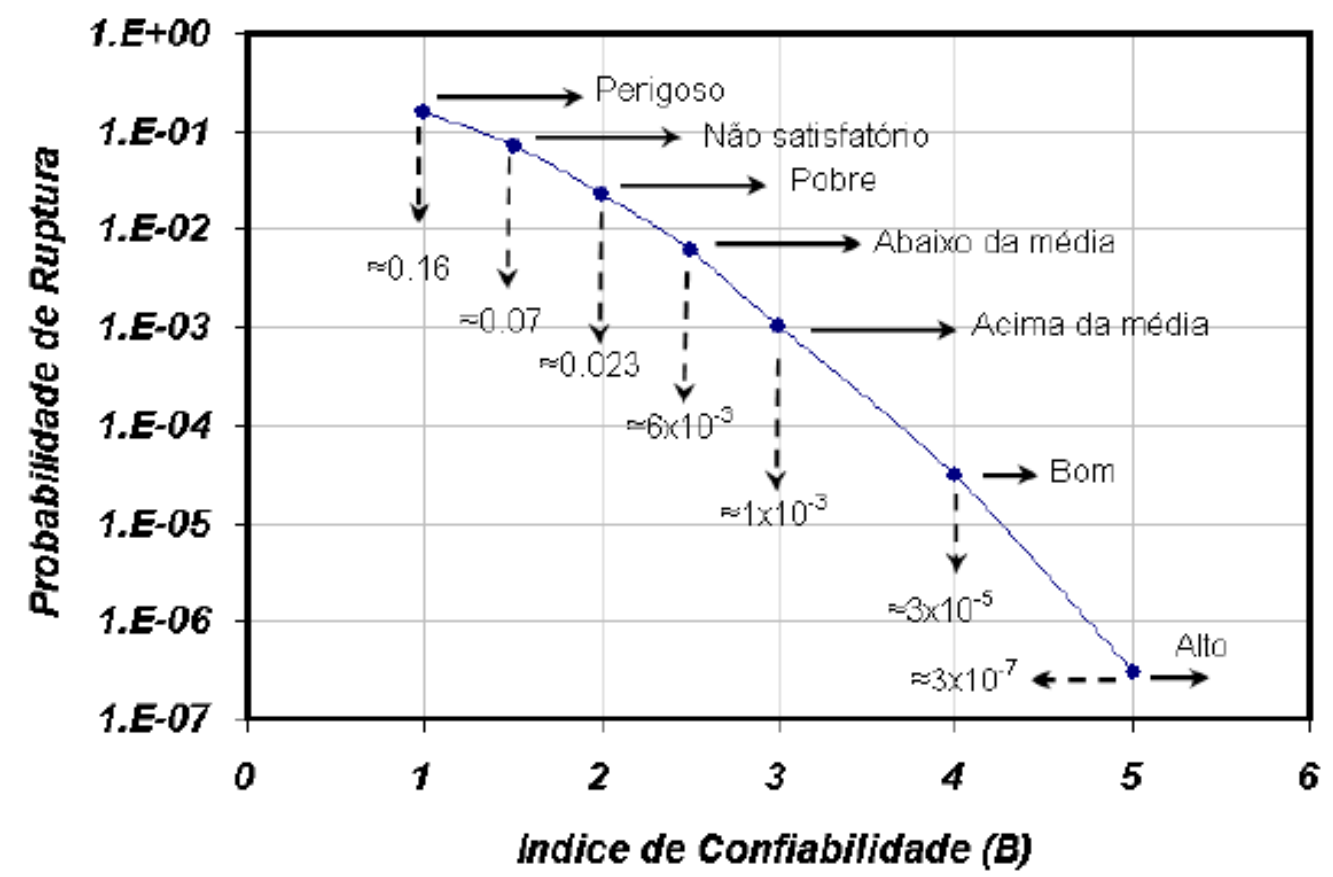

Figura 2.12 - Níveis de aceitação de probabilidades de ruptura pelo US Army Corps of Engineers.

Para El-Ramly (2001), o que impossibilita o emprego indiscriminado destes

gráficos e valores padrões de Pr sugeridos na literatura, é a generalização de condições particulares de cada obra geotécnica, como geometria, instrumentação, fonte de dados, variabilidade do solo, profundidade de investigação, procedimentos de execução de projeto, etc.

O mesmo autor pondera que os valores de Pr apresentados na literatura são conservadores. Portanto, uma $\operatorname{Pr}$ de $2 \times 10^{-2}$ equivalente a um $\beta$ igual a 2,0 pode ser entendida como um limite satisfatório para taludes, apesar de não ser uma referência definitiva.

\subsection{5}

\section{Análises Probabilísticas em Estabilidade de Taludes}

A Tabela 2.4 apresenta um resumo das principais conclusões relatadas em artigos e teses sobre análises probabilísticas ao longo das últimas décadas. A evolução das conclusões ao longo do tempo é de fundamental importância no presente e nos futuros estudos. 
Tabela 2.4 - Resumo das principais conclusões sobre análises probabilísticas.

\begin{tabular}{|c|c|}
\hline Autor & Conclusões \\
\hline $\begin{array}{l}\text { Withman (1984), Dell'Avanzi (1995), } \\
\text { Farias e Assis (1998), } \\
\text { Sandroni e Sayão (1992) }\end{array}$ & $\begin{array}{c}\text { Resultados de análises de confiabilidade dependem do } \\
\text { modelo determinístico utilizado e da qualidade dos } \\
\text { parâmetros estatísticos obtidos a partir dos dados } \\
\text { coletados. }\end{array}$ \\
\hline $\begin{array}{l}\text { Whitman (1984), Lima (1991), } \\
\text { Dell’Avanzi (1995), Duncan (2000), } \\
\text { Silva (2015) }\end{array}$ & $\begin{array}{l}\text { Análises probabilísticas devem ser sempre aliadas às } \\
\text { análises determinísticas e à experiência do } \\
\text { engenheiro. Não devem ser utilizadas isoladamente } \\
\text { em substituição às determinísticas. }\end{array}$ \\
\hline $\begin{array}{c}\text { Withman (1984), } \\
\text { Einsten and Baecher (1983), Lima (1991), } \\
\text { Dell'Avanzi (1995), Silva (2015) }\end{array}$ & $\begin{array}{l}\text { Análises probabilísticas são ferramentas que permitem } \\
\text { se conhecer a influência das incertezas envolvidas nos } \\
\text { cálculos de estabilidade e entender-se o custo de } \\
\text { reduzir-se tais incertezas. Possibilitando modificações } \\
\text { e otimizações de projetos. }\end{array}$ \\
\hline Lima (1991) & $\begin{array}{c}\text { Quando Pr é pequena, os métodos EP e MC fornecem } \\
\text { valores divergentes por estarem situados na faixa de } \\
\text { valores onde as probabilidades são sensíveis à } \\
\text { pequenas variações na curva. }\end{array}$ \\
\hline $\begin{array}{l}\text { Dell'Avanzi (1995), } \\
\text { Avanzi e Sayão (1998) }\end{array}$ & $\begin{array}{l}\text { Métodos de estabilidade mais rigorosos apresentam } \\
\text { maiores índices de confiabilidade }(\beta) \text { e menores Pr. }\end{array}$ \\
\hline Dell’Avanzi (1995) & FOSM é de utilização mais prática do que EP. \\
\hline Dell'Avanzi (1995) & $\begin{array}{l}\text { Pr mostra-se independente da distribuição de FS para } \\
\text { casos } \operatorname{com} \beta<1,5 \text {. }\end{array}$ \\
\hline Dell'Avanzi (1995) & $\begin{array}{l}\text { Recomenda-se taxas de variação não maiores do que } \\
10 \% \text { na prática FOSM. A variação pode ser } \\
\text { incremental ou decremental }\end{array}$ \\
\hline $\begin{array}{l}\text { Farias e Assis (1998), } \\
\quad \text { Maia (2003) }\end{array}$ & $\begin{array}{l}\text { FOSM e EP se complementam. FOSM fornece } \\
\text { participação de cada parâmetro, mas EP pode fornecer } \\
\text { Pr maiores. }\end{array}$ \\
\hline $\begin{array}{l}\text { Sandroni e Sayão (1992), } \\
\text { Farias e Assis (1998), Cruden et al. (2005) }\end{array}$ & $\begin{array}{l}\text { O empecilho para prática atual das análises } \\
\text { probabilísticas é a falta de valores de referência de Pr } \\
\text { para se fixar critérios de projeto. Essa tendência tende } \\
\text { a diminuir com a utilização e difusão do método. }\end{array}$ \\
\hline Duncan (2000) & $\begin{array}{c}\text { Sugere o termo "performance insatisfatória" como } \\
\text { substituto ao termo "probabilidade de ruptura" porque, } \\
\text { a depender de seu valor, ele pode não indicar rupturas } \\
\text { catastróficas. }\end{array}$ \\
\hline Maia (2003) & $\begin{array}{l}\text { Faixa aceita para taludes de mineração: } 1 \%<\operatorname{Pr}< \\
10 \%\end{array}$ \\
\hline Xu e Low (2006) & $\begin{array}{c}\text { Simplificações feitas nos métodos de equilíbrio limite } \\
\text { superestimam } \beta \text { se comparadas com métodos de } \\
\text { elementos finitos. }\end{array}$ \\
\hline Sayão et al. (2012) & $\begin{array}{l}\text { Simulação de Monte Carlo não permite a entrada da } \\
\text { piezometria como parâmetro variável. }\end{array}$ \\
\hline Silva $(2015)$ & $\begin{array}{l}\text { Análises EP e MC devem ser feitas posteriormente às } \\
\text { análises FOSM pois a última simplifica o processo } \\
\text { probabilístico ao permitir a desconsideração de } \\
\text { parâmetros pouco influentes na estabilidade da obra. }\end{array}$ \\
\hline
\end{tabular}




\section{3 Estudo de Caso}

Este trabalho tem como objetivo a aplicação dos conceitos previamente expostos em estudos de estabilidade de um talude de mineração. $\mathrm{O}$ objeto de estudo é um talude da cava de exploração da Mina do Cauê, Itabira, Minas Gerais. Nele serão feitas análises de estabilidade por distintos métodos de equilíbrio limite e probabilísticos.

A Mina do Cauê foi escolhida como estudo de caso devido à abundância de dados de ensaios já existentes em relatórios e estudos anteriores. Este capítulo destina-se à contextualização do talude da Mina do Cauê para subsequente exposição de análises e estudos de estabilidade realizados neste trabalho.

\section{1 \\ Localização}

O município de Itabira está localizado no interior do estado de Minas Gerais, Brasil, a aproximadamente $80 \mathrm{~km}$ (em linha reta) à nordeste de sua capital, Belo Horizonte (Figura 3.1). O Complexo Minerário de Itabira pertence à Vale S.A. e está inserido na região do Quadrilátero Ferrífero. Ele é composto por 7 minas de lavra a céu aberto, das quais as principais são: Mina do Cauê e Mina da Conceição. As outras 5 são minas menores cujo conjunto é conhecido por Minas do Meio.

A Mina do Cauê, objeto de estudo deste trabalho, localiza-se ao norte do centro de Itabira e no extremo norte do Complexo Itabira, cuja área total é de aproximadamente $150 \mathrm{~km}^{2}$. O centro de sua cava é marcado pelo ícone verde na Figura 3.1. 


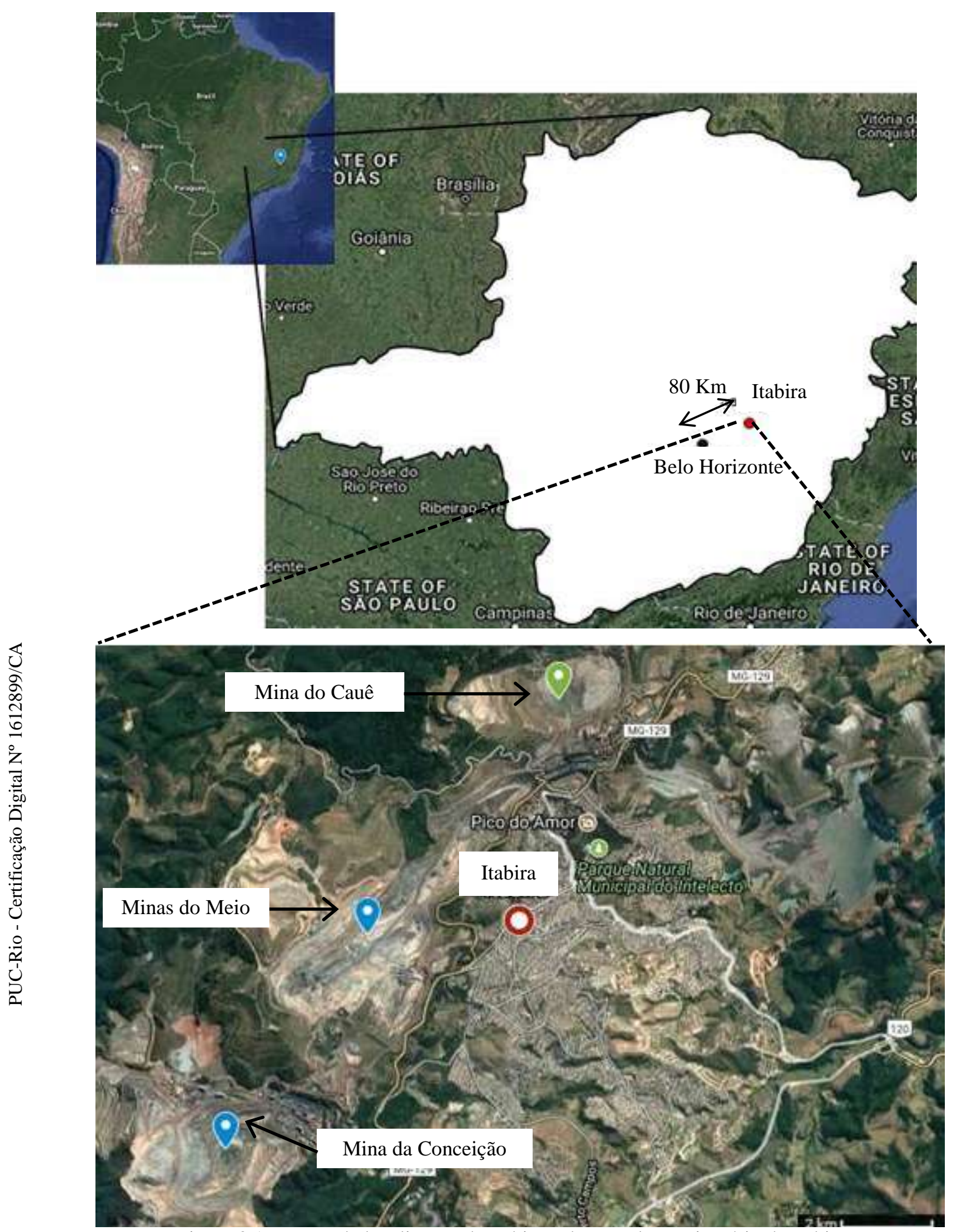

Figura 3.1 - Mapa de localização de Itabira e do complexo minerário de Itabira.

\section{2}

\section{História da Mina}

No século XVIII se estabeleceram os primeiros garimpeiros de ouro ao redor de uma única capela, dando origem ao povoado na região conhecida hoje 
como Itabira. A ocupação da área por famílias com seus escravos em busca de riquezas minerais ocasionou o início do desenvolvimento do povoado. Em 1848 Itabira teve sua emancipação político-administrativa, e hoje possui população de 119.285 habitantes (IBGE/2017) (Figura 3.2 e Figura 3.3).

No século XIX, o crescente povoamento e explotação de ouro ocasionou sua escassez, e levou a população à busca pelo ferro, que até hoje é explorado na região. A abundante ocorrência de minérios de ferro despertou a cobiça de empresários ingleses, que foram os primeiros a chegar em 1909 fundando a Itabira Iron Ore Company Limited. Em 1939, o Governo Federal comandado por Getúlio Vargas revogou o direito minerário dos ingleses, os quais se juntaram aos brasileiros formando a Companhia Brasileira de Mineração e Siderurgia e a Itabira Mineração S.A. Em 1942, Getúlio Vargas unifica as duas empresas inaugurando a estatal Companhia Vale do Rio Doce, que décadas depois se tornou Vale S.A. (Vale, 2016).

A exploração do minério de ferro pelo governo brasileiro em Itabira se deu em decorrência da Segunda Guerra Mundial. Época tal, em que o governo havia assumido compromissos políticos de exportar material para atender às estratégias dos países Aliados (EUA, União Soviética, Reino Unido, Brasil e 48 outros países) contra os países do Eixo (Alemanha, Itália, Japão e outros menores) para conter o avanço das tropas de Hitler.

Impossível desvencilhar a história da Mina do Cauê da história da fundação da empresa Vale S. A., a qual explora minério de ferro na região de Itabira desde 1942, mesma data em que a Mina do Cauê começou a ser explotada. A Mina do Cauê operou de 1942 até sua exaustão em 2003 (Vale, 2016). As Figura 3.4 e Figura 3.5 retratam a cava da Mina do Cauê nos anos de 1992 e 2017, respectivamente. 


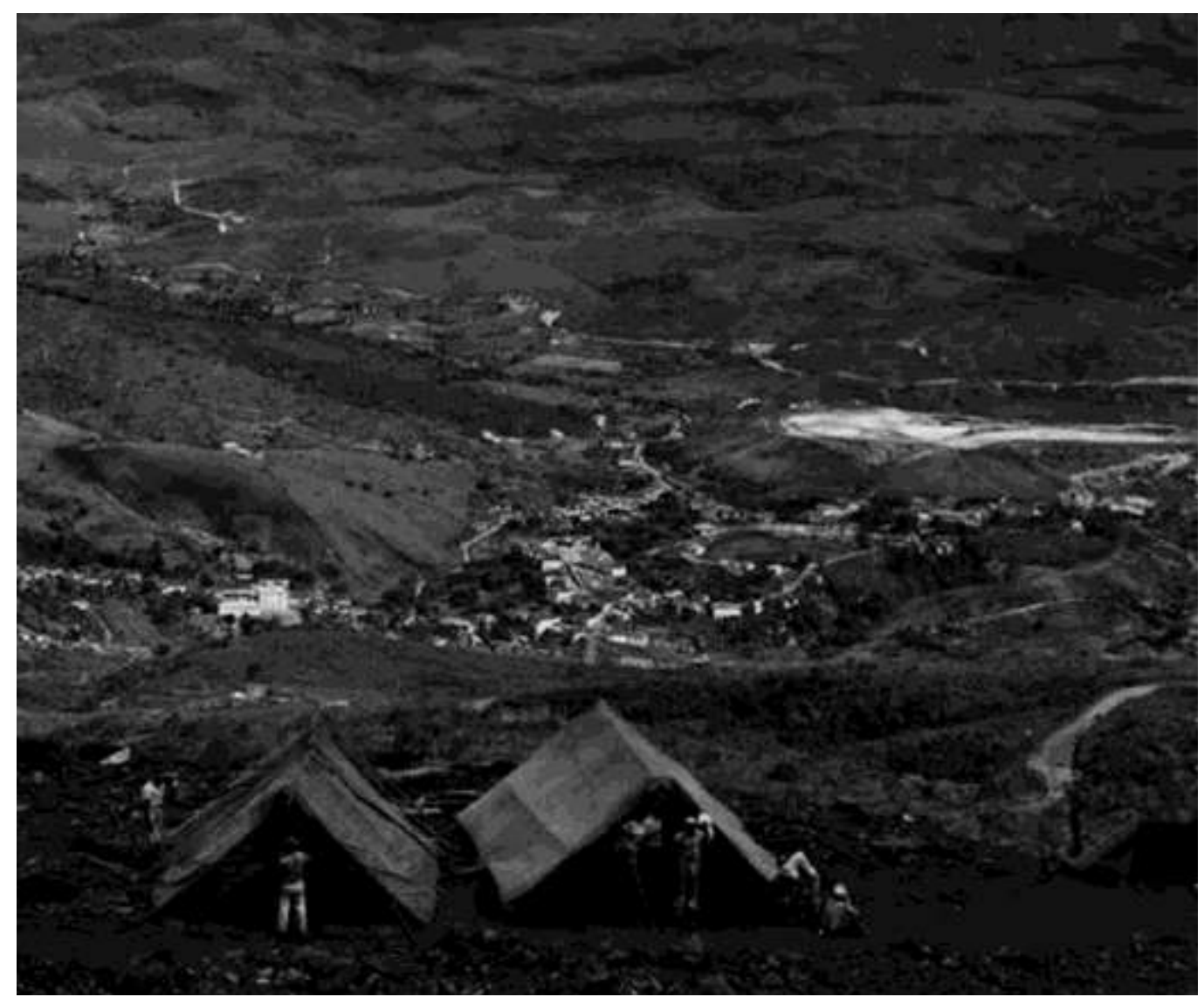

Figura 3.2 - Vista geral da cidade de Itabira a partir de um acampamento na Mina do Cauê na década de 1940 (fonte: Vale S.A., 2016).

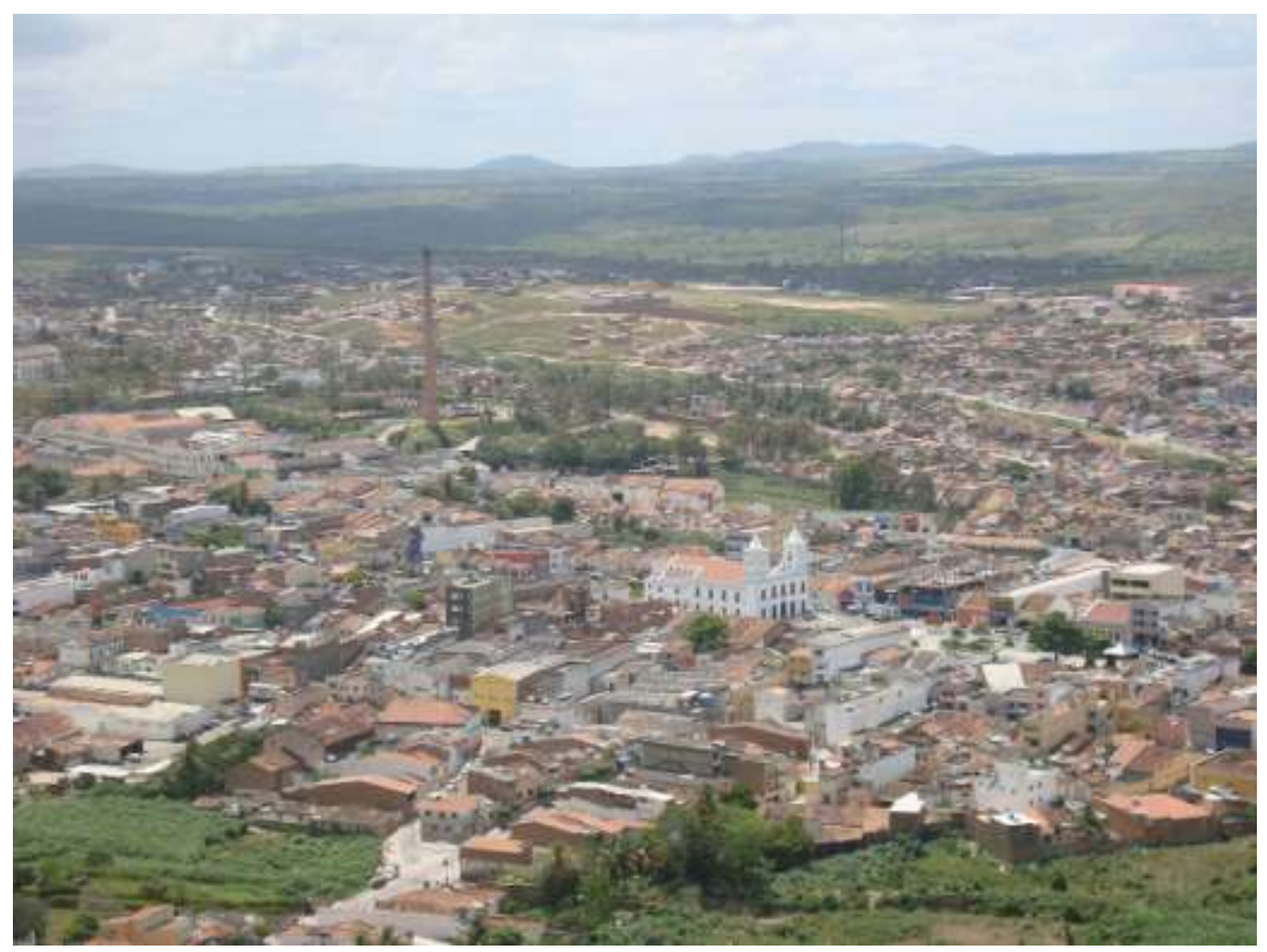

Figura 3.3 - Vista geral da cidade de Itabira no século XXI (fonte: Google, 2018). 


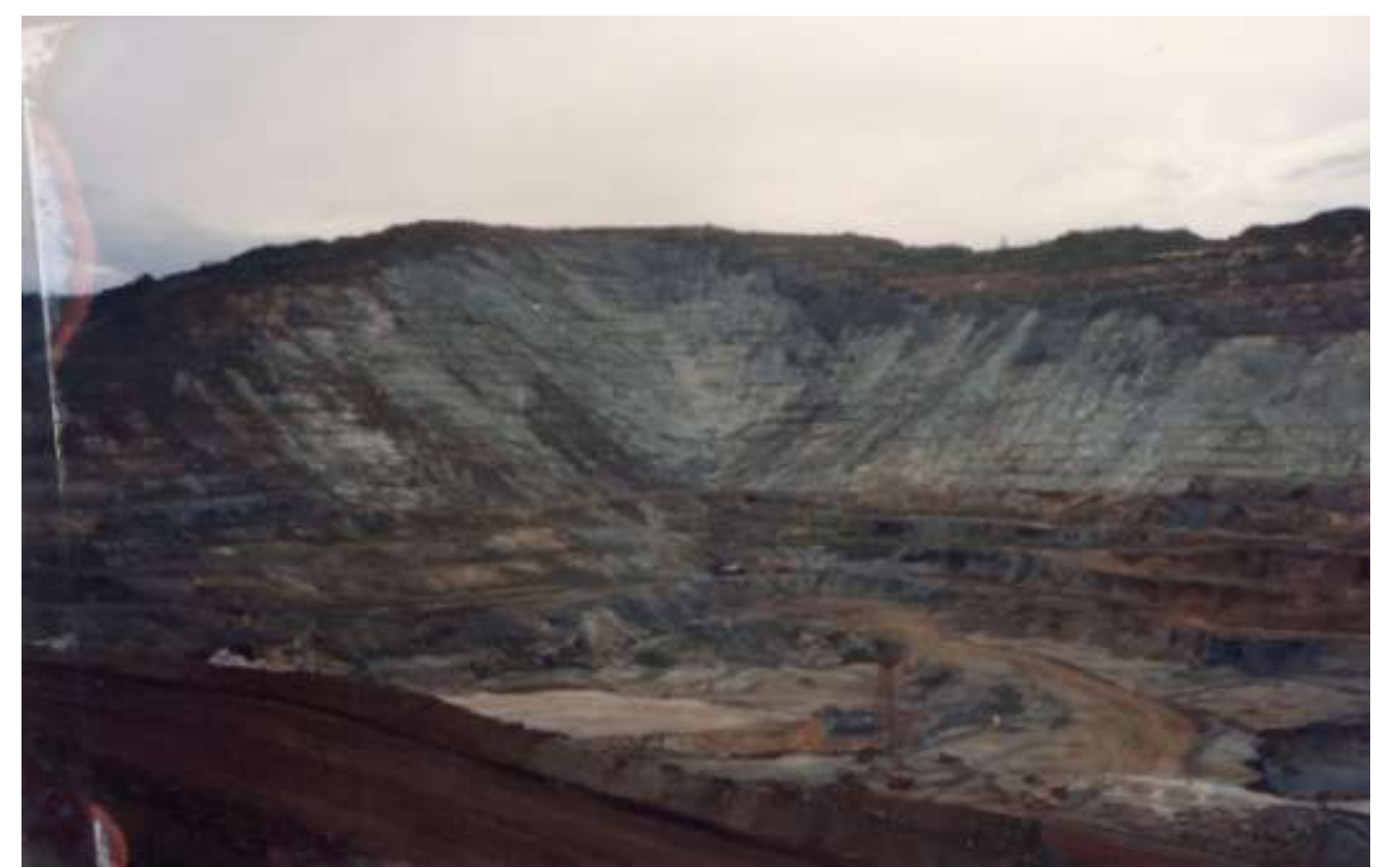

Figura 3.4 - Vista da cava de mineração da Mina do Cauê em 1992 (foto cedida por Sandro Sandroni).

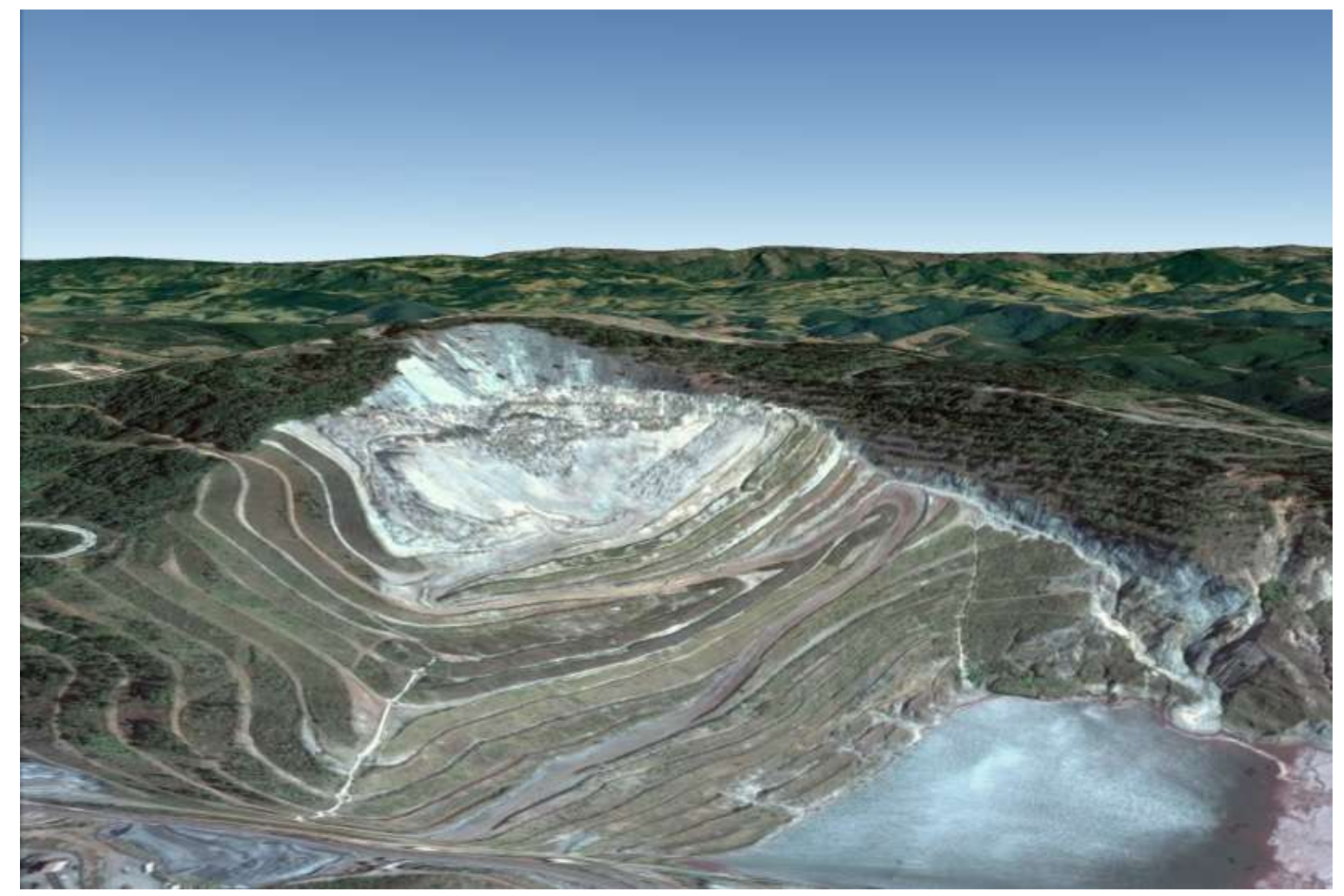

Figura 3.5 - Vista da cava de mineração da Mina do Cauê em 2017 (fonte: Google Earth Pro, 2017).

\section{3}

\section{Características Geológico-Geotécnicas}

Uma mina a céu aberto é composta por inúmeros taludes de dimensões variadas e distribuição irregular. Para fins de realização de análises probabilísticas de estabilidade, um talude já descrito em trabalhos anteriores (Sandroni e Sayão, 
1992, Farias e Assis 1998, Sayão et al., 2012 e Guedes 1997) será objeto de estudo devido à existência de dados suficientes para obtenção das grandezas estatísticas necessárias nos cálculos.

Apesar da heterogeneidade da mina, um talude ideal, composto por solo saprolítico de quartzito ferrífero oriundo da alteração de rocha xistosa rica em quartzo, mica e ferro, foi escolhido como talude representativo da Mina do Cauê, suas propriedades foram definidas e são apresentadas a seguir:

- Geometria:

Inicialmente descrita por Sandroni e Sayão (1992), a geometria do talude da Mina do Cauê é resumida nas seguintes características:

- Altura: 200m

- Inclinação: $34^{\circ}$

- Lençol Freático: um trecho inclinado que vai do pé do talude (cota $0 \mathrm{~m}$ ) até um ponto a exatamente $80 \mathrm{~m}$ abaixo da crista do talude, e um trecho horizontal de cota $120 \mathrm{~m}$ medido com piezômetros. A Figura 3.6 ilustra uma seção típica do talude de mineração.

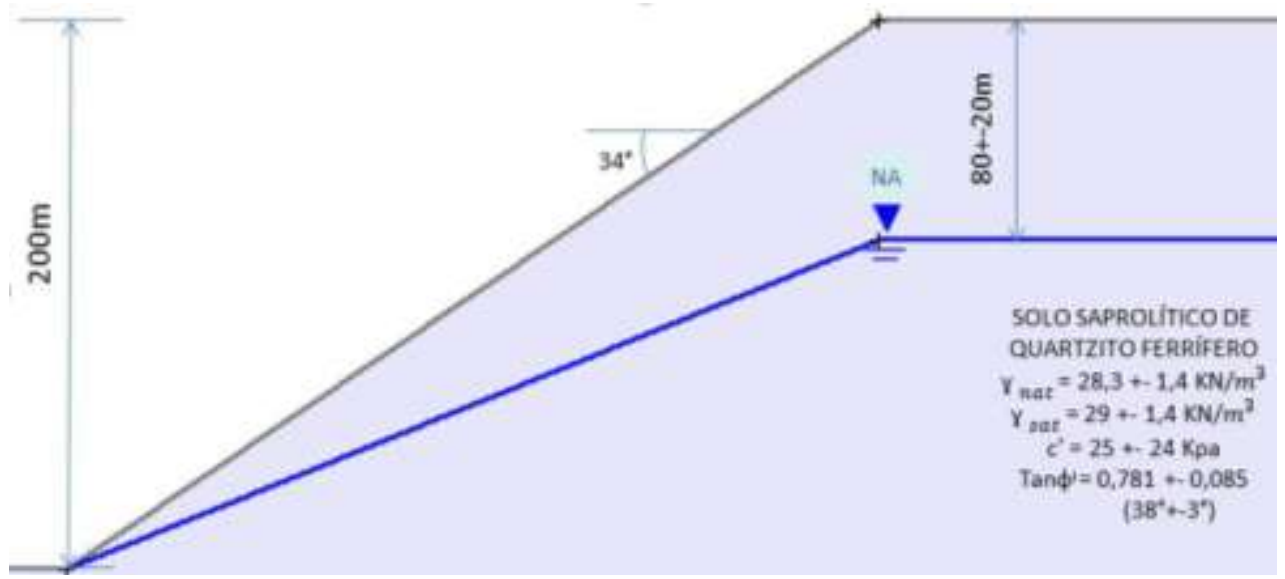

Figura 3.6 - Seção típica do talude da Mina do Cauê simplificada.

- Parâmetros:

Parâmetros geotécnicos do talude foram obtidos de 50 ensaios de cisalhamento direto de amostras não perturbadas (Sayão et. al, 2012). Este número de ensaios viabilizou a obtenção dos dados estatísticos utilizados como dados de 
entrada nas análises probabilísticas. Os resultados obtidos são apresentados na Tabela 3.1.

Tabela 3.1 - Parâmetros geotécnicos e estatísticos de talude da Mina do Cauê.

\begin{tabular}{|c|c|c|c|}
\hline Parâmetro & $\begin{array}{c}\text { Média } \\
\left(\bar{x}_{l}\right)\end{array}$ & $\begin{array}{c}\text { Variância } \\
(V[F S])\end{array}$ & $\begin{array}{l}\text { Desvio } \\
\text { Padrão } \\
(\sigma[F S])\end{array}$ \\
\hline Peso específico acima do NA - $\gamma_{n a t}\left(\mathrm{KN} / \mathrm{m}^{3}\right)$ & 28,3 & 1,96 & 1,4 \\
\hline Peso específico abaixo do NA- $\gamma_{s a t}\left(\mathrm{KN} / \mathrm{m}^{3}\right)$ & 29,0 & 1,96 & 1,4 \\
\hline Coesão - c' (KPa) & 25,0 & 590,0 & 24,0 \\
\hline Tangente do ângulo de atrito - Ф’ & 0,781 & 0,0072 & 0,09 \\
\hline Nível d'água - u & 120,0 & 400,0 & 20,0 \\
\hline
\end{tabular}




\section{4 \\ Reavaliação do Caso e Análises Complementares}

O objetivo geral deste estudo, como proposto no item 1.1, é apresentar formas possíveis de abordagem probabilística em análises de estabilidade de taludes de mineração. Neste estudo, são realizadas análises probabilísticas de estabilidade de um talude idealizado, escolhido como representativo da Mina do Cauê. A geometria do talude da mina, já exaurida, foi descrita por Sandroni e Sayão (1992) e está reproduzida no item 3.3, e ilustrada pela Figura 3.6.

A abordagem probabilística, entre outras atribuições, possibilita o cálculo da probabilidade de ruptura $(\operatorname{Pr})$, do índice de confiabilidade $(\beta)$, da participação relativa dos parâmetros considerados variáveis, e consequente avaliação do risco de um talude para que o engenheiro tenha o poder de gerenciá-lo e/ou controlá-lo da forma mais consciente possível.

Para realização das análises realizadas, optou-se pelo programa Slide 5.014, que realiza análises de equilíbrio limite pelos métodos empregados no estudo, e também realiza, automaticamente, as simulações de Monte Carlo.

No talude da Mina do Cauê já foram realizadas análises probabilísticas por Sandroni e Sayão (1992), Guedes (1997) e Farias e Assis (1998). Neste contexto, o presente estudo visa complementar estudos pré-existentes com reanálises e novas análises feitas com métodos e abordagens não apresentados até então. De forma geral, as análises aqui realizadas acrescentam conhecimento sobre a influência dos métodos de equilíbrio limite nos resultados das análises probabilísticas, assim como o estudo dos efeitos da fixação ou não da superfície crítica determinística nos resultados das análises probabilísticas.

Além da geometria, é necessário o conhecimento dos dados estatísticos e parâmetros tratados como variáveis do solo do talude para que as análises probabilísticas possam ser realizadas. Estes dados são resultantes de campanhas de campo que não fizeram parte deste estudo e estão sintetizados na Tabela 3.1. 


\section{1}

\section{Análises Determinísticas de Estabilidade}

A análise determinística é o primeiro passo para que se possa aplicar análises probabilísticas de estabilidade. Como mencionado anteriormente, um dos dados de entrada necessários para realização das análises é a geometria do talude. A Figura 3.6 apresenta a seção geométrica do talude da Mina do Cauê escolhida para a realização das análises aqui apresentadas. Como ilustrado, ele apresenta 200 metros de altura, $34^{\circ}$ de inclinação, e lençol freático composto por dois trechos retilíneos: um que se extende do pé do talude até um ponto verticalmente abaixo da crista, e outro horizontal a partir deste ponto. Ainda pela Figura 3.6, percebe-se que o trecho horizontal possui cota de 120 metros em relação ao pé do talude, medidos por observações piezométricas.

Nas análises de estabilidade também são necessárias as entradas de dados referentes aos parâmetros do solo, os quais são apresentados no Tabela 3.1. Por se tratar de um talude de solo, optou-se pela execução das análises de estabilidade em modo de ruptura circular. Conhecendo-se os dados necessários, foi realizado um total de 5 análises determinísticas no programa Slide 5.014, considerando os seguintes critérios:

- Métodos de análises empregados: Fellenius, Janbu Simplificado, Bishop Simplificado, Spencer e Morgenstern-Price (Morg-Price);

- Critério de ruptura: Mohr-Coulomb;

- Modo de ruptura: Superfície circular.

Utilizando-se os critérios mencionados, as análises com Slide forneceram fatores de segurança determinísticos apresentados na Tabela 4.1 para cada um dos métodos de equilíbrio limite empregados.

Tabela 4.1 - Fatores de segurança determinísticos

\begin{tabular}{|c|c|c|c|c|c|}
\hline Método & Fellenius & Janbu & Bishop & Spencer & Morg-Price \\
\hline FS & 1,170 & 1,179 & 1,264 & 1,259 & 1,259 \\
\hline
\end{tabular}




\section{2}

\section{Análises Probabilísticas de Estabilidade}

Neste capítulo são apresentados os resultados das análises de probabilidade de ruptura realizadas por 3 métodos probabilísticos: FOSM, Estimativas Pontuais e Monte Carlo. Para aplicação dos métodos probabilísticos adotados, foi necessária, também, a definição do método de equilíbrio limite utilizado nas análises probabilísticas. Portanto, no estudo probabilístico, optou-se pelo emprego dos mesmos métodos de equilíbrio limite empregados nas análises determinísticas, mesmo porque, para emprego do método FOSM, é necessário que o Fator de Segurança médio determinístico seja conhecido.

A probabilidade de ruptura corresponde à probabilidade do fator de segurança (FS) ser igual ou menor a 1. Os métodos FOSM e Estimativas Pontuais permitem a inferência do comportamento da função FS a partir do conhecimento das médias e desvios padrão dos parâmetros geotécnicos considerados variáveis. Neste caso, por existirem dados suficientes para obtenção dos parâmetros estatísticos, não se fez necessário o emprego do conceito de coeficiente de variação apresentado no item 2.2.

Nem todos os parâmetros definidos como variáveis no método FOSM foram considerados variáveis nos outros 2 métodos. Isto se justifica pelo fato de que o método FOSM, o primeiro a ser aplicado, permite o conhecimento da porcentagem de influência de cada parâmetro na Pr. Portanto, ao realizar-se as análises EP e MC, é possível tratar parâmetros que tenham pouca influência relativa na $\operatorname{Pr}$ como não variáveis.

O nível d’água foi considerado variável aleatória em todos os 3 métodos pois as superfícies de ruptura críticas cortam a linha freática, e a participação da piezometria (u) foi identificada como relevante nas análises de influência de parâmetros fornecidas pelo método FOSM. A análise por abordagem probabilística é válida para a condição de nível d'água descrita. Caso haja alteração nas condições piezométricas, é necessário reavaliar a seção.

Os próximos itens apresentam os resultados obtidos em cada um dos 3 métodos probabilísticos combinados a cada um dos 5 métodos de equilíbrio limite aplicados. 


\subsection{1}

\section{Análises FOSM}

O FOSM - First Order Second Moment - é um dos 3 métodos probabilísticos introduzidos no Capítulo 2 que, objetivamente, permite encontrar o desvio padrão $(\sigma)$ da função $\mathrm{FS}$, grandeza necessária no cálculo de $\beta$ que leva ao conhecimento de Pr. Sua metodologia consiste no cálculo da variância de FS (variável dependente) a partir da variação de cada parâmetro médio definido como variável, um a um, mantendo-se os demais fixos. Uma vez obtida a variância de cada parâmetro médio, o método permite a obtenção da variância do fator de segurança (FS). A raíz quadrada da variância de FS é seu desvio padrão, grandeza de investigação inicial, permitindo que a probabilidade de ruptura seja encontrada. Este procedimento foi descrito em etapas por Baecher e Christian (2003) e consiste em:

- Identificar os parâmetros variáveis que contribuem com as incertezas;

- Encontrar valores médios, desvios padrão e coeficientes de correlação entre as variáveis;

- Calcular o valor determinístico de FS com os valores médios das variáveis;

- Calcular as derivadas parciais de FS em relação às variáveis;

- Calcular a variância total de FS (Equações 2.27 e 2.28);

- Calcular Índice de confiabilidade $\beta$ e probabilidade de ruptura Pr.

As análises aqui apresentadas foram feitas com variações de $\pm 10 \%$ para cada parâmetro médio, seguindo a sugestão de Dell’Avanzi (1995). Na aplicação do FOSM, cinco parâmetros $(n=5)$ foram tratados como variáveis: c', $\Phi$ ', $\gamma_{n a t}, \gamma_{s a t}$ e u. Aqui são chamados ciclos cada análise probabilística que gera uma variância de FS, sendo eles distinguidos pelo método de equilíbrio limite empregado e pela consideração da superfície de ruptura crítica. Portanto, o número de análises de FS necessárias em cada ciclo de aplicação do FOSM foi de seis. Das seis, uma foi a determinística e as outras 5 foram as simulações probabilísticas referentes à cada variação de parâmetro, totalizando $n+1$ análises 
de estabilidade. Um exemplo de aplicação das seis análises envolvidas em um ciclo é encontrado na Tabela 4.2.

Tabela 4.2 - Exemplificação de n+1 análises no método FOSM por Bishop Simplificado e superfície crítica determinística fixa para a Mina do Cauê.

\begin{tabular}{|c|c|c|c|c|c|c|}
\hline \multirow[b]{2}{*}{ Parâmetros } & \multirow{2}{*}{$\begin{array}{c}\begin{array}{c}\text { Análise } \\
\text { Determinística }\end{array} \\
\text { Parâmetro } \\
\text { Médio }\end{array}$} & \multicolumn{5}{|c|}{ Análises Probabilísticas } \\
\hline & & $\begin{array}{c}c^{\prime}+ \\
10 \%\end{array}$ & $\begin{array}{c}\tan \Phi^{\prime}+ \\
10 \%\end{array}$ & $\begin{array}{l}\mathrm{y} \text { nat - } \\
10 \%\end{array}$ & $\begin{array}{c}\text { y sat + } \\
10 \%\end{array}$ & $\begin{array}{c}u+ \\
10 \%\end{array}$ \\
\hline$c^{\prime}$ & 25 & 27.5 & 25 & 25 & 25 & 25 \\
\hline $\tan \Phi^{\prime}$ & 0,781 & 0,781 & 0,894 & 0,781 & 0,781 & 0,781 \\
\hline y nat & 28,3 & 28,3 & 28,3 & 25,47 & 28,3 & 28,3 \\
\hline $\mathrm{y}$ sat & 29 & 29 & 29 & 29 & 31,9 & 29 \\
\hline $\mathrm{u}$ & 120 & 120 & 120 & 120 & 120 & 132 \\
\hline FS & 1,264 & 1,269 & 1,437 & 1,269 & 1,274 & 1,213 \\
\hline
\end{tabular}

Uma vez obtidos os seis fatores de segurança de um ciclo pelo método FOSM, a variância de FS pôde ser calculada pela Equação 2.27, o que permitiu o cálculo de $\beta$ e Pr para as condições especificadas. Os resultados finais desta análise serão apresentados juntos aos demais, a seguir.

O mesmo procedimento foi repetido por 10 ciclos (apêndice 2), resultando em 60 análises de equilíbrio limite onde foram variados o método de equilíbrio limite e a superfície crítica estudada. As 60 combinações são encontradas no apêndice 1. Os resultados das análises FOSM são resumidos na Tabela 4.3.

Tabela 4.3 - Resumo de resultados das análises FOSM.

\begin{tabular}{|c|c|c|c|c|c|}
\hline \multirow{2}{*}{$\begin{array}{c}\text { Método de } \\
\text { Equilíbrio } \\
\text { Limite }\end{array}$} & FS & \multicolumn{2}{|c|}{$\beta$} & \multicolumn{2}{|c|}{ Pr } \\
\cline { 3 - 6 } & Determinístico & $\begin{array}{c}\text { sup } \\
\text { fixa }\end{array}$ & $\begin{array}{c}\text { sup } \\
\text { livre }\end{array}$ & $\begin{array}{c}\text { sup } \\
\text { fixa }\end{array}$ & $\begin{array}{c}\text { sup } \\
\text { livre }\end{array}$ \\
\hline Fellenius & 1,17 & 1,07 & 1,07 & $1: 7$ & $1: 7$ \\
\hline Janbu & 1,18 & 1,17 & 1,18 & $1: 8$ & $1: 8$ \\
\hline Bishop & 1,26 & 1,62 & 1,62 & $1: 20$ & $1: 20$ \\
\hline Spencer & 1,26 & 1,59 & 1,61 & $1: 17$ & $1: 20$ \\
\hline Morg-Price & 1,26 & 1,54 & 1,56 & $1: 16$ & $1: 17$ \\
\hline
\end{tabular}

Uma particularidade proporcionada pelo FOSM, e aqui utilizada, é a quantificação da contribuição relativa de cada parâmetro considerado variável nas 
análises de estabilidade do talude. Na Tabela 4.4 são apresentadas as contribuições relativas de cada parâmetro nas diferentes combinações de análises.

Tabela 4.4 - Influência das variáveis aleatórias pelo método FOSM na Pr (\%)

\begin{tabular}{|c|c|c|c|c|c|c|c|c|c|c|}
\hline \multicolumn{11}{|c|}{ Influência das variáveis aleatórias pelo método FOSM na $\operatorname{Pr}(\%)$} \\
\hline \multirow{2}{*}{$\begin{array}{l}\text { método/ } \\
\text { variável }\end{array}$} & \multicolumn{2}{|c|}{ Fellenius } & \multicolumn{2}{|c|}{ Bishop } & \multicolumn{2}{|c|}{ Janbu } & \multicolumn{2}{|c|}{ Spencer } & \multicolumn{2}{|c|}{ Morg-Price } \\
\hline & $\begin{array}{l}\text { sup } \\
\text { fixa }\end{array}$ & $\begin{array}{l}\text { sup } \\
\text { livre }\end{array}$ & $\begin{array}{l}\text { sup } \\
\text { fixa }\end{array}$ & $\begin{array}{l}\text { sup } \\
\text { livre }\end{array}$ & $\begin{array}{l}\text { sup } \\
\text { fixa }\end{array}$ & $\begin{array}{l}\text { sup } \\
\text { livre }\end{array}$ & $\begin{array}{l}\text { sup } \\
\text { fixa }\end{array}$ & $\begin{array}{l}\text { sup } \\
\text { livre }\end{array}$ & $\begin{array}{l}\text { sup } \\
\text { fixa }\end{array}$ & $\begin{array}{l}\text { sup } \\
\text { livre }\end{array}$ \\
\hline $\tan \Phi^{\prime}$ & 60,07 & 60,09 & 63,78 & 63,79 & 65,55 & 65,58 & 68,60 & 67,93 & 63,78 & 65,15 \\
\hline u & 30,02 & 30,03 & 27,22 & 27,22 & 27,57 & 27,58 & 22,25 & 22,79 & 27,22 & 22,31 \\
\hline$c^{\prime}$ & 9,43 & 9,44 & 8,89 & 8,89 & 6,51 & 6,51 & 8,93 & 9,15 & 8,89 & 12,35 \\
\hline$\gamma$ sat & 0,45 & 0,41 & 0,09 & 0,07 & 0,33 & 0,29 & 0,20 & 0,11 & 0,09 & 0,17 \\
\hline$\gamma$ nat & 0,04 & 0,04 & 0,02 & 0,02 & 0,04 & 0,04 & 0,02 & 0,02 & 0,02 & 0,02 \\
\hline Total & 100,0 & 100,0 & 100,0 & 100,0 & 100,0 & 100,0 & 100,0 & 100,0 & 100,0 & 100,0 \\
\hline
\end{tabular}

Independente do método de equilíbrio limite e da fixação ou não da superfície crítica de ruptura, as contribuições relativas de cada parâmetro seguiram um padrão onde $\Phi^{\prime}$ foi o parâmetro de maior influência na $\operatorname{Pr}$, seguido de $\mathrm{u}$, e depois c'. Os pesos específicos, seco e saturado, se demonstraram muito pouco influentes na Pr, e por isso não foram considerados parâmetros variáveis nas análises por EP e MC.

\subsection{2 Análises por Estimativas Pontuais}

O método das Estimativas Pontuais (EP), descrito no Capítulo 2, é também um método probabilístico que permitiu o cálculo de $\beta$ e Pr para o talude de mineração. Assim como no FOSM, o método forneceu o desvio padrão $(\sigma)$ da variável dependente FS, o que levou ao conhecimento de $\beta$ e Pr do talude. Sua metodologia também consiste no cálculo da variância do fator de segurança (variável dependente) em função da variação de cada parâmetro médio definido como variável independente. Neste caso, os valores de entrada nas análises por estimativas pontuais foram variações de um desvio padrão $( \pm \sigma)$ para cada parâmetro médio considerado. Como no EP as análises são feitas para todas as combinações possíveis dos valores dos parâmetros acrescidos ou decrescidos de $\sigma$, o valor total de cálculos neste método é sempre igual a $2^{n}$, onde $n$ é o número de parâmetros considerados variáveis. 
Os parâmetros identificados como pouco influentes nos valores de Pr pelo método FOSM podem ser considerados determinísticos nas análises EP, de forma a diminuir efetivamente o número de análises envolvidas na aplicação deste método. Portanto, nestes cálculos foram considerados variáveis apenas os parâmetros que apresentaram maior influência no cálculo da Pr pelo método FOSM (Tabela 4.4). Estes parâmetros foram coesão (c'), ângulo de atrito ( $\left.\Phi^{\prime}\right)$ e piezometria (u). Assim, $n=3$, sendo necessárias 8 análises para se determinar a probabilidade de ruptura do talude em cada análise EP. Os valores de média e desvio padrão utilizados foram os mesmos apresentados no Tabela 3.1. Uma vez obtidos os fatores de segurança (FS) para cada combinação de parâmetros variados de $\pm \sigma$, foi possível calcular as variâncias de FS por meio da Equação 2.31: $V[F S]=E\left[F S^{2}\right]-(E[F S])^{2}$. Com as raízes quadradas das variâncias de FS foram obtidos seus desvios padrão, que permitiram cálculo de $\beta$ e $\operatorname{Pr}$ por Estimativas Pontuais para cada situação estudada.

O mesmo conceito de ciclos aplicado no método FOSM foi também utilizado para as análises EP. Cada análise probabilística que gera uma variância de FS é um ciclo. Aqui, também foram feitas análises com e sem fixação da superfície crítica pelos mesmos 5 métodos de equilíbrio limite aplicados no método FOSM. Portanto, foram realizados 10 ciclos referentes a 5 métodos de equilíbrio combinados com 2 opções de superfície de ruptura (superfície fixa e livre). Como explicado acima, cada ciclo envolve 8 análises, portanto os 10 ciclos realizados nesta sessão do estudo totalizam 80 análises apresentadas no apêndice 2. A Tabela 4.5 exemplifica um destes ciclos.

Os resultados das análises EP são resumidos na Tabela 4.6 em função dos 5 métodos de equilíbrio limite e fixação ou não da superfície, obtendo-se o índice de confiabilidade e probabilidade de ruptura. 
Tabela 4.5 - Exemplificação de $2^{n}$ análises no método EP por Bishop Simplificado e superfície crítica determinística fixa para a Mina do Cauê.

\begin{tabular}{|c|c|c|c|c|}
\hline \multirow{2}{*}{ Combinação } & \multicolumn{3}{|c|}{ Variáveis } & \multirow{2}{*}{$\begin{array}{l}\text { Fator de } \\
\text { Segurança }\end{array}$} \\
\hline & $\Phi^{\prime}$ & $\mathrm{u}$ & $c^{\prime}$ & \\
\hline+++ & 41 & 140 & 49 & 1,36 \\
\hline-++ & 35 & 140 & 49 & 1,11 \\
\hline+-+ & 41 & 100 & 49 & 1,52 \\
\hline--+ & 35 & 100 & 49 & 1,24 \\
\hline++- & 41 & 140 & 1 & 1,25 \\
\hline-+- & 35 & 140 & 1 & 1,01 \\
\hline+-- & 41 & 100 & 1 & 1,41 \\
\hline --- & 35 & 100 & 1 & 1,14 \\
\hline & & & $\mathrm{E}[\mathrm{FS}]$ & 1,25 \\
\hline & & & $\mathrm{V}[\mathrm{FS}]$ & 0,025 \\
\hline & & & $\sigma[\mathrm{FS}]$ & 0,158 \\
\hline & & & $\beta$ & $1: 20$ \\
\hline & & & $\mathrm{Pr}$ & 1,61 \\
\hline
\end{tabular}

Tabela 4.6 - Resumo de resultados das análises por Estimativas Pontuais.

\begin{tabular}{|c|c|c|c|c|c|}
\hline \multicolumn{4}{|c|}{ Método Probabilístico: Estimativas Pontuais } \\
\hline $\begin{array}{c}\text { Método de } \\
\text { Equilíbrio } \\
\text { Limite }\end{array}$ & \multirow{2}{*}{$\begin{array}{c}\text { FS } \\
\text { Determinístico }\end{array}$} & \multicolumn{2}{|c|}{$\beta$} & \multicolumn{2}{c|}{ Pr } \\
\cline { 3 - 6 } & $\begin{array}{c}\text { sup } \\
\text { fixa }\end{array}$ & $\begin{array}{c}\text { sup } \\
\text { livre }\end{array}$ & $\begin{array}{c}\text { sup } \\
\text { fixa }\end{array}$ & $\begin{array}{c}\text { sup } \\
\text { livre }\end{array}$ \\
\hline Fellenius & 1,17 & 1,09 & 1,05 & $1: 7$ & $1: 7$ \\
\hline Janbu & 1,18 & 1,17 & 1,13 & $1: 8$ & $1: 8$ \\
\hline Bishop & 1,26 & 1,61 & 1,44 & $1: 20$ & $1: 14$ \\
\hline Spencer & 1,26 & 1,48 & 1,21 & $1: 14$ & $1: 9$ \\
\hline Morg-Price & 1,26 & 1,61 & 1,43 & $1: 19$ & $1: 13$ \\
\hline
\end{tabular}

\subsection{3}

\section{Análises por Simulação de Monte Carlo}

Como nas análises EP, apenas os parâmetros que se mostraram mais influentes pelo método FOSM foram considerados variáveis nestas análises. São eles, c', $\Phi^{\prime}$ e u. O número de iterações envolvidos na Simulação de Monte Carlo é extremamente grande para que o método seja aplicado manualmente. Atualmente já existem programas de computadores capazes de gerarem valores e realizarem as simulações automaticamente. Um deles é o Slide, software da RocScience utilizado nas análises de equilíbrio limite apresentadas ao longo deste trabalho, e nas simulações de Monte Carlo resumidas na Tabela 4.7. Para realização das 
análises com superfície de ruptura fixa, utilizou-se a ferramenta Global Minimum oferecida pelo software, enquanto análises de superfície de ruptura livre foram realizadas pela análise Overall. Relevante considerar o tempo envolvido na análise Overall, a qual durou em torno de 72 horas para se completar uma análise onde apenas 3 parâmetros eram variáveis.

Tabela 4.7 - Resumo de resultados das análises por Simulação de Monte Carlo.

\begin{tabular}{|c|c|c|c|c|c|}
\hline \multicolumn{6}{|c|}{ Método Probabilístico: Monte Carlo } \\
\hline \multirow{2}{*}{$\begin{array}{l}\text { Método de } \\
\text { Equilíbrio Limite }\end{array}$} & \multirow{2}{*}{ FS Det } & \multicolumn{2}{|c|}{$\beta$} & \multicolumn{2}{|c|}{$\operatorname{Pr}$} \\
\hline & & $\begin{array}{l}\text { sup } \\
\text { fixa }\end{array}$ & $\begin{array}{l}\text { sup } \\
\text { livre }\end{array}$ & $\begin{array}{l}\text { sup } \\
\text { fixa }\end{array}$ & $\begin{array}{l}\text { sup } \\
\text { livre }\end{array}$ \\
\hline Fellenius & 1,17 & 1,27 & 1,27 & $1: 10$ & $1: 10$ \\
\hline Janbu & 1,18 & 1,34 & 1,34 & $1: 13$ & $1: 12$ \\
\hline Bishop & 1,26 & 1,87 & 1,87 & $1: 44$ & $1: 44$ \\
\hline Spencer & 1,26 & 1,88 & 1,85 & $1: 44$ & $1: 40$ \\
\hline Morg-Price & 1,26 & 1,87 & 1,84 & $1: 44$ & $1: 40$ \\
\hline
\end{tabular}




\section{5}

\section{Discussão dos Resultados}

As análises realizadas com os métodos FOSM, EP e MC foram comparadas considerando a fixação ou não da superfície de ruptura crítica e os 5 métodos de equilíbrio limite. Os resultados são resumidos na Tabela 5.1.

Tabela 5.1 - Resumo de resultados das análises probabilísticas e determinísticas.

\begin{tabular}{|c|c|c|c|c|c|c|c|c|c|c|c|c|c|}
\hline \multirow{2}{*}{ Método } & \multirow{2}{*}{ FS det } & \multicolumn{9}{|c|}{$\beta$} & \multicolumn{6}{|c|}{ Pr } \\
\cline { 3 - 14 } & & \multicolumn{2}{|c|}{ FOSM } & \multicolumn{2}{|c|}{ EP } & \multicolumn{2}{|c|}{ MC } & \multicolumn{2}{|c|}{ FOSM } & \multicolumn{2}{|c|}{ EP } & \multicolumn{2}{c|}{ MC } \\
\cline { 3 - 14 } & $\begin{array}{c}\text { sup } \\
\text { fixa }\end{array}$ & $\begin{array}{c}\text { sup } \\
\text { live }\end{array}$ & $\begin{array}{c}\text { sup } \\
\text { fixa }\end{array}$ & $\begin{array}{c}\text { sup } \\
\text { livre }\end{array}$ & $\begin{array}{c}\text { sup } \\
\text { fixa }\end{array}$ & $\begin{array}{c}\text { sup } \\
\text { livre }\end{array}$ & $\begin{array}{c}\text { sup } \\
\text { fixa }\end{array}$ & $\begin{array}{c}\text { sup } \\
\text { livre }\end{array}$ & $\begin{array}{c}\text { sup } \\
\text { fixa }\end{array}$ & $\begin{array}{c}\text { sup } \\
\text { live }\end{array}$ & $\begin{array}{c}\text { sup } \\
\text { fixa }\end{array}$ & $\begin{array}{c}\text { sup } \\
\text { livre }\end{array}$ \\
\hline Fellenius & 1,17 & 1,07 & 1,07 & 1,09 & 1,05 & 1,27 & 1,27 & $1: 7$ & $1: 7$ & $1: 7$ & $1: 7$ & $1: 10$ & $1: 10$ \\
\hline Janbu & 1,18 & 1,17 & 1,18 & 1,17 & 1,13 & 1,34 & 1,34 & $1: 8$ & $1: 8$ & $1: 8$ & $1: 8$ & $1: 13$ & $1: 12$ \\
\hline Bishop & 1,26 & 1,62 & 1,62 & 1,61 & 1,44 & 1,87 & 1,87 & $1: 20$ & $1: 20$ & $1: 20$ & $1: 14$ & $1: 43$ & $1: 43$ \\
\hline Spencer & 1,26 & 1,59 & 1,61 & 1,48 & 1,21 & 1,88 & 1,85 & $1: 17$ & $1: 20$ & $1: 14$ & $1: 9$ & $1: 44$ & $1: 40$ \\
\hline $\begin{array}{c}\text { Morg- } \\
\text { Price }\end{array}$ & 1,26 & 1,54 & 1,56 & 1,61 & 1,43 & 1,87 & 1,84 & $1: 16$ & $1: 17$ & $1: 19$ & $1: 13$ & $1: 44$ & $1: 40$ \\
\hline
\end{tabular}

A escolha do método de equilíbrio limite utilizado exerceu influência nos valores de $\beta$ e $\operatorname{Pr}$ obtidos pelos 3 métodos probabilísticos empregados, concordando com os comportamentos encontrados por Farias e Assis (1998) e Dell'Avanzi (1995). O método de Bishop e os métodos rigorosos (Spencer e Morg-Price) apresentaram maiores valores de $\beta$ quando comparados aos valores encontrados pelos métodos não rigorosos (Fellenius e Janbu). Este padrão foi observado nos 3 métodos probabilísticos (FOSM, EP e MC).

Por FOSM, constatou-se que, mantendo-se fixo o método de equilíbrio limite, a fixação ou não da superfície crítica levou a resultados de $\beta$ iguais. Isto comprova que, neste caso, o método FOSM não é sensível à fixação da superfície de ruptura.

A análise dos resultados do Tabela 4.4 permitiu constatar que, também por FOSM, fixando-se o método de equilíbrio limite, a fixação ou não da superfície de ruptura não afetou a influência relativa que cada parâmetro exerceu no índice $\beta$ do 
talude. A Figura 5.1 permite a visualização gráfica do padrão observado no Tabela 4.4 para análises feitas fixando-se o método de Bishop.

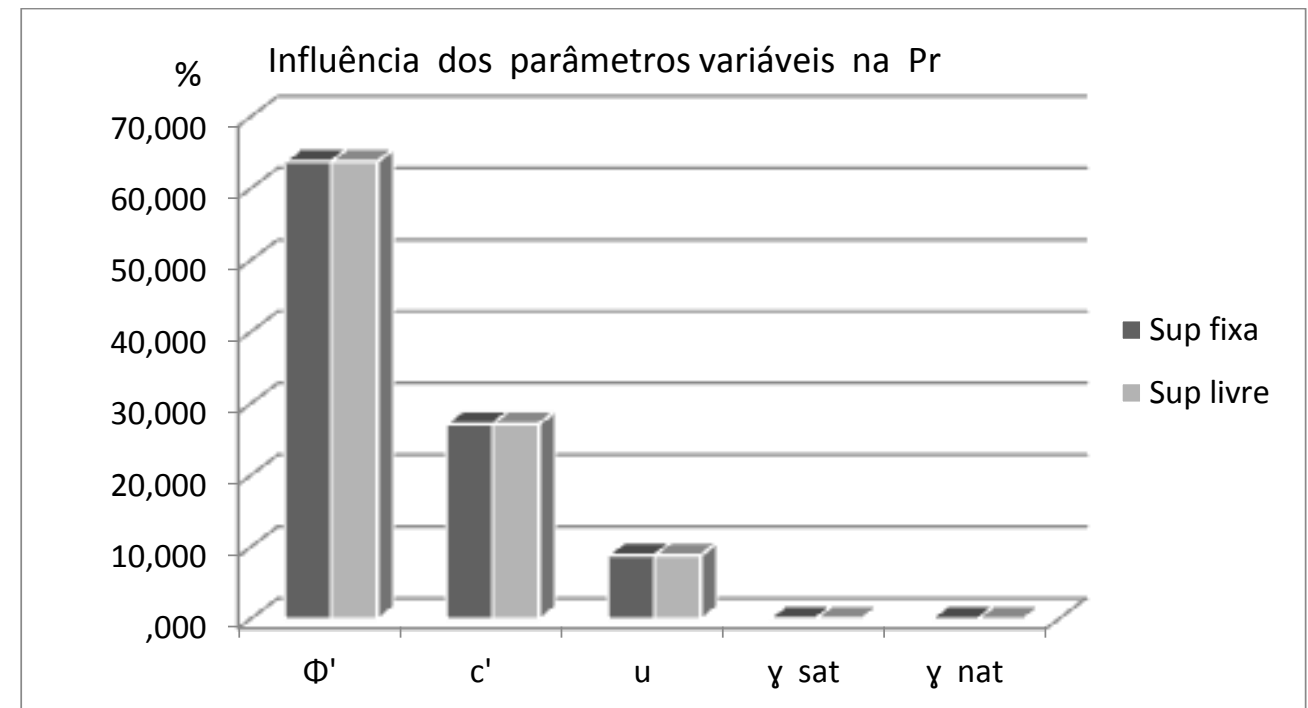

Figura 5.1- Gráfico de influência dos parâmetros variáveis na Pr para superfície crítica fixa ou livre por Bishop.

Por outro lado, mantendo-se a superfície crítica de ruptura fixa, foi observado que as participações relativas dos parâmetros nos valores de $\beta$ sofreram variações a depender do método de equilíbrio limite empregado, como mostra o gráfico da Figura 5.2. Nota-se, porém, que estas variações não implicaram em mudanças na hierarquia de importância dos parâmetros nos índices $\beta$ do talude estudado. 


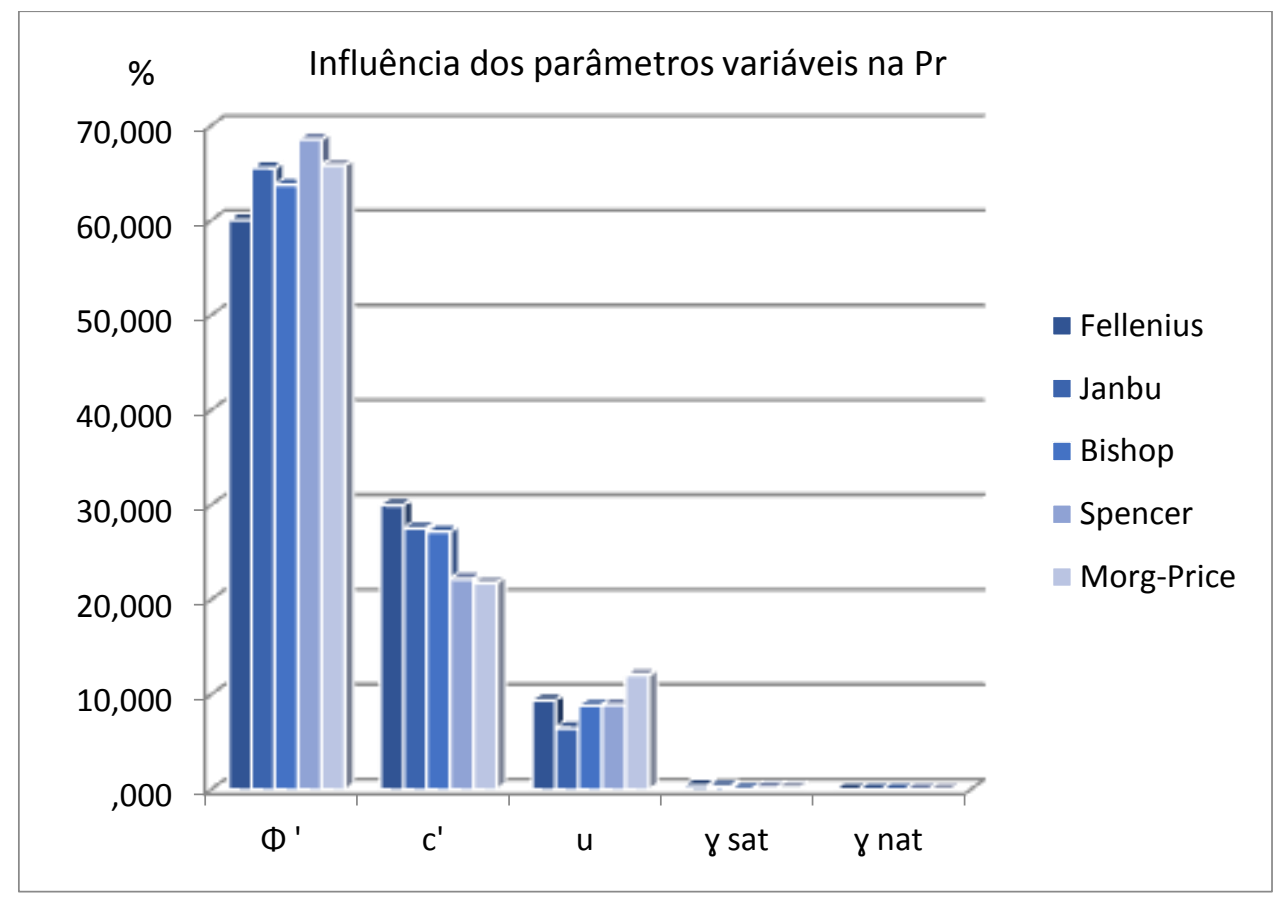

Figura 5.2- Influência dos parâmetros variáveis na Pr para métodos distintos de Equilíbrio Limite para superfície de ruptura fixa.

Apesar de não muito impactante (diferença máxima de $2,1 \%$ nas $\operatorname{Pr}$ encontradas pelo método Morg-Price), a fixação ou não da superfície de ruptura crítica determinística nas análises EP demonstrou afetar apenas os resultados das análises realizadas pelos métodos de Bishop, Spencer e Morg-Price, provavelmente por serem mais rigorosos e sofrerem impacto advindo da escolha da superfície de ruptura. Neste contexto, os valores de $\beta$ dentre os métodos rigorosos foram menores para superfícies de ruptura livres. Para os métodos não rigorosos (Fellenius e Janbu), a fixação ou não da superfície não influenciou os resultados de $\beta$.

Assim como nos outros dois métodos de análises probabilísticas, para o MC o método de equilíbrio limite exerceu grande influência nos valores de $\beta$ do talude de mineração estudado quando comparados métodos rigorosos e não rigorosos. Similarmente ao ocorrido nas análises FOSM e EP, os menores valores de $\beta$ são referentes às análises realizadas pelos métodos menos rigorosos, Fellenius e Janbu. Já a fixação ou não da superfície de ruptura crítica determinística exerceu pouca influência nos resultados de $\beta$ para as simulações de Monte Carlo. Em geral, os valores de $\beta$ por MC foram relativamente maiores do que os encontrados por FOSM e EP para todos os métodos de equilíbrio limite.

Além do método de equilíbrio limite, a probabilidade de ruptura também depende do método de análise probabilística empregado. Foram observadas 
discrepâncias relevantes entre valores de Pr obtidos por MC e os demais métodos probabilísticos (FOSM e EP). Quando analisado, o resultado de Pr por MC (pelo método de Spencer com superfície livre) chega a ser 8,6\% menor do que o valor de Pr encontrado por EP nas mesmas condições de equilíbrio limite e superfície de ruptura. Já as análises FOSM e EP apresentaram valores de Pr relativamente similares entre si (diferença máxima de 2,1\% entre FOSM e EP por Bishop com superfície de ruptura livre).

Após comparação de todos os resultados expostos na Tabela 5.1, recomenda-se não utilizar métodos de equilíbrio limite não rigorosos nas análises probabilísticas de estabilidade. Em relação ao método probabilístico, recomendase utilização do método FOSM por ser de aplicação mais rápida, simples e ter apresentado resultados mais conservadores do que as análises MC. Sugere-se, assim, em caso de ruptura circular similares a este, a utilização de análises FOSM pelo método de equilíbrio Morgenstern-Price com superfície crítica de ruptura fixa para as análises probabilísticas, por apresentar o $\beta$ mais conservador dentre os métodos rigorosos. Não descarta-se a utilização do método de Spencer uma vez que, além de ser o mais empregado atualmente em análises de estabilidade, não apresentou resultados de Pr tão destoantes dos encontrados por Morg-Price nas análises FOSM.

Apesar das diferenças de valores obtidos entre um método e outro, os valores de $\beta$ e Pr em todas as análises probabilísticas realizadas neste estudo (Tabela 5.1), se encontram dentro dos valores típicos apresentados por Avanzi e Sayão (1998) na Tabela 2.3 para taludes de mineração. Porém, análises realizadas com métodos de equilíbrio limite não rigorosos (Janbu e Fellenius) apresentaram valores de $\beta$ muito próximos ao limite inferior sugerido na Tabela $2.3 \mathrm{com}$ resultados conservadores por serem métodos simplificados. 


\section{6 Considerações Finais}

Fundamentos teóricos e procedimentos de aplicação dos métodos de análises probabilísticas mais comuns na geotecnia - FOSM, Estimativas Pontuais e Simulação de Monte Carlo - foram descritos neste trabalho, de forma a tornar a prática de análises probabilísticas mais usual em obras geotécnicas. Ressalta-se a importância da prática de análises probabilísticas em estudos geotécnicos de forma a complementar as tradicionais análises determinísticas, e não substituí-las.

\subsection{1}

\section{Conclusões e Recomendações}

Em concordância com trabalhos anteriores (Farias e Assis, 1998 e Dell'Avanzi, 1995), este estudo confirma a variação dos índices de confiabilidade ( $\beta$ ) em função do método de equilíbrio limite adotado nos três métodos probabilísticos estudados.

Nas trinta análises probabilísticas realizadas neste estudo, com uma única exceção não representativa, os métodos de equilíbrio limite não rigorosos resultaram em $\beta$ menores do que os demais métodos.

Os métodos FOSM e MC não foram sensíveis à variação da superfície crítica de ruptura, pois ao manter-se fixo o método de equilíbrio limite, os resultados de $\beta$ se mantiveram praticamente iguais para superfícies fixas e livres.

Nas análises EP, a fixação ou não da superfície crítica de ruptura determinística demonstrou afetar apenas resultados de análises realizadas pelos métodos de Bishop, Spencer e Morgenstern-Price, onde os valores de $\beta$ foram menores para superfície de ruptura livre.

É uma singularidade do método FOSM, fornecer a participação relativa de cada parâmetro variável na estabilidade da estrutura geotécnica estudada. Em se tratando do FOSM, a escolha do método de equilíbrio limite não implicou em 
mudanças na hierarquia de importância da participação relativa dos parâmetros nos índices de confiabilidade.

Em geral, o valor do índice $\beta$ dependeu do método de análise probabilística empregado. Neste estudo, para os diferentes métodos de equilíbrio limite, os valores de $\beta$ encontrados por MC foram relativamente maiores do que os encontrados por FOSM e EP.

Ao se comparar os métodos probabilísticos, observa-se que o método de Monte Carlo apresentou os maiores índices de confiabilidade $(\beta)$, o método EP apresentou valores menores, e o FOSM apresentou valores intermediários. Notase, porém, que Araujo (2018) obteve conclusões distintas ao analisar a segurança de uma barragem de terra. Provavelmente esta divergência sugere que é ainda prematuro tentar obter conclusões gerais, válidas para as diferentes estruturas geotécnicas.

Observada a insensibilidade dos métodos probabilísticos FOSM e MC à fixação da superfície crítica de ruptura, estes métodos de análise se apresentam mais consistentes do que o método EP. De acordo com os resultados encontrados, recomenda-se, na prática geotécnica, não utilizar métodos de equilíbrio limite não rigorosos nas análises probabilísticas de estabilidade.

Em situações similares a este estudo de caso sugere-se a utilização de análises FOSM pelo método de equilíbrio limite Morgenstern-Price, por ter apresentado $\beta$ menor dentre os métodos rigorosos. Não descarta-se a utilização do método de Spencer pois, além de ser o mais usual em análises de estabilidade atuais, não apresentou resultados de Pr tão destoantes dos encontrados por MorgPrice nas análises FOSM.

No caso do talude da Mina do Cauê, o Fator de Segurança obtido pelo método de equilíbrio limite Morgenstern-Price foi 1,26. Considerando-se distribuição normal, fixando-se a superfície de ruptura e aplicando-se o método Morgenstern-Price, o índice de confiabilidade $(\beta)$ encontrado pelo método FOSM foi de 1,54.

\section{1 .2}

\section{Sugestões Para Estudos Futuros}

A seguir são propostos assuntos para pesquisas futuras, em continuidade ao tema abordado neste trabalho: 
- Revisão de estudos anteriores e comparação dos resultados em busca de valores de referência de $\beta$ e Pr a serem considerados nos diferentes tipos de obras geotécnicas;

- Aplicação de análises probabilísticas em estudos de estabilidade de talude considerando o elemento altura uma variável aleatória e observando sua influência no valor de $\beta$;

- Aplicação de métodos probabilísticos em novos estudos de caso geotécnicos, em busca do entendimento das diferenças entre valores de $\beta$ da simulação de Monte Carlo e dos demais métodos;

- Mais investigações sobre o padrão de resultados dos métodos probabilísticos para entendimento das diferenças entre valores de Pr do método de Monte Carlo e outros. 


\section{Referências bibliográficas}

ARAUJO, M.B. (2018). Considerações Sobre Análise Probabilística em Estabilidade de Taludes de Barragem. Dissertação de Mestrado, Departamento de Engenharia Civil, Pontifícia Universidade Católica do Rio de Janeiro.

BAECHER G.B. (1982). Statistical Methods in Site Characterization. Updating Subsurface Samplings of Soils and Rocks and their In-situ Testing, Santa Barbara, Engineering Foundation, pp. 463-492.

BAECHER G.B., \& CHRISTIAN, J.T. (2003). Reliability and Statistics in Geotechnical Engineering. John Wiley \& Sons.

BISHOP, A.W. (1955). The Use of the Slip Circle in the Stability Analysis of Slopes. Géotechnique, vol. 5 (1).

CHRISTIAN, J.T., LADD, C. C. e BAECHER, G.B. (1992). Reliability Applied to Slope Stability Analysis. Journal of Geotechnical Engineering, ASCE, vol. 120 (12), pp. 2180-2207.

CRUDEN, D.M., MORGENSTERN, N.R., e EL-RAMLY, H. (2005). Probabilistic Assessment of Stability of a Cut Slope in Residual Soil. Géotechnique, vol. 55 (1), pp.77-84.

DELl'AVANZI, E. (1995). Confiabilidade e Probabilidade em Análises de Estabilidade de Taludes. Dissertação de Mestrado, Departamento de Engenharia Civil, Pontifícia Universidade Católica do Rio de Janeiro.

DELl'AVAnZI, E. e SAYÃO, A.S.F.J. (1998). Avaliação da Probabilidade de Ruptura de Taludes. $11^{\circ}$ COBRAMSEG, ABMS, Brasília, vol. 2, pp. 12891295.

DUNCAN, J. M. (2000). Factors of Safety and Reliability. Journal of Geotechnical and Geoenvironmental Engineering. vol. 126 (4), pp. 307-316.

EINSTEN, H.H. e BAECHER G.B. (1983). Probabilistic and Statistical Methods in Engineering Geology. Rock Mechanics and Rock Engineering, vol. 16, pp. 39-72.

EL-RAMLY, H. (2001). Probabilistic Analyses of Landslide Hazards and Risks: Bridging Theory and Practice. PhD. Thesis, University of Alberta, Edmonton, Canada.

EL-RAMLY, H., MORGENSTERN, N.R. e CRUDEN, D.M. (2003b). Reply to the Discussion by J. M. Duncan, M. Navin, and T. F. Wolff on "Probabilistic Slope Stability Analysis for Practice". Canadian Geotechnical Journal, vol. 40 (4), pp. 851-855. 
FARIAS, M.M. e ASSIS, A.P. (1998). Uma Comparação entre Métodos Probabilísticos Aplicados a Estabilidade de Taludes. $11^{\circ}$ COBRAMSEG, ABMS, Brasília, vol. 2, pp. 1305-1313.

FELLENIUS, W. (1936). Calculation of the Stability of Earth Dams. Transactions 2nd Congress on Large Dams, Washington, D. C., USA, vol. 4, pp. 445-459.

FLORES, E.A.F. (2008). Análises Probabilísticas da Estabilidade de Taludes Considerando a Variabilidade Espacial do Solo. Dissertação de Mestrado, Departamento de Engenharia Civil, Pontifícia Universidade Católica do Rio de Janeiro.

GOOGLE. (2017). Google Earth Pro. Versão 7.3.1.4507. Mina do Cauê, Itabira. Acesso em: outubro de 2017.

GUEDES, M. C. S. (1997). Considerações sobre Análises Probabilísticas de Estabilidade de Taludes. Dissertação de mestrado, Departamento de Engenharia Civil, Pontifícia Universidade Católica do Rio de Janeiro.

GRIFITHS, D. V. e FENTON, G.A. (2004). Probabilistic Slope Stability Analysis by Finite Elements. Journal of Geotechnical and Geoenvironmental Engineering, vol. 130 (5).

HARR, M. E. (1987). Reliability- Based Design in Civil Engineering. McGrawHill, Inc., U.S.A.

IBGE. Informações de domínio público. https://cidades.ibge.gov.br/, acessado em 20/11/2017.

JANBU, N., BJERRUM, L., KJAERNSLI, B. (1956). Soil mechanics applied to some engineering problems. Publication 16. Norwegian Geotechnical Institute, Oslo.

LAMBE, T. W., \& WHITMAN, R. V. (1969). Soil Mechanics. John Wiley \& Sons.

LEE, I. K., WEEKS, W. e INGLES, O. G. (1983). Geotechnical Engineering. Ed. Pitman. Marshfield, E.U.A.

LI, K. S. e LUMB, P. (1987). Probabilistic design of slopes. Canadian Geotechnical Journal, vol. 74, pp. 520-535.

LIMA, L.S.A. (1991). Uma Metodologia para Análise Probabilística de Estabilidade de Taludes. Dissertação de mestrado, COPPE, Universidade Federal do Rio de Janeiro.

MAIA, J. A. C. (2003). Métodos Probabilísticos Aplicados à Estabilidade de Taludes e Cavidades em Rocha. Dissertação de mestrado, Faculdade de Tecnologia, Universidade de Brasília. 
METROPOLIS, N. e ULAM, S. (1949). The Monte Carlo Method. Journal of the American Statistical Association, vol. 44, pp. 335-341.

MORGENSTERN, N. R. and PRICE, V.E. (1965). The Analysis of the Stability of General Slip Surfaces. Geotechnique, vol. 15 (1), pp. 79-93.

PACHECO, M. P. (1990). Conceitos de Probabilidade e Análise de Risco em Estudos e Projetos de Geotecnia. Proc. IX COBRAMSEF, ABMS, vol. 3, pp. 37-56, Salvador, Brasil.

PINTO, C. D. S. (2006). Curso básico de mecânica dos solos em 16 aulas (3 Ed.). São Paulo: Oficina de Textos.

RIBEIRO, R. C. (2008). Aplicações de Probabilidade e Estatística em Análises Geotécnicas. Tese de Doutorado, Departamento de Engenharia Civil, Pontifícia Universidade Católica do Rio de Janeiro.

ROCSCIENCE. Slide versão 5.014. 11. Rocscience, Toronto, Ontario, Canada.

ROSENBlueth, R.Y. (1975). Point Estimates for Probability Moments. Proc. of the National Academy of Sciences, Mathematics Section, vol. 72 (10), pp. 3812-3814.

SANDRONI, S. S. e SAYÃO, A. S. F. J. (1992). Avaliação Estatística do Coeficiente de Segurança de Taludes. $1^{\text {a }}$ COBRAE, Conferência Brasileira sobre Estabilidade de Taludes, Rio de Janeiro, ABMS, vol. 2, pp. 523-535.

SANDRONI, S. S., SANTANA, F. C., RAMOS, J. M. S. e SAYÃO, A. S. F. J. (1992). Talude Rompido em Solo Saprolítico de Micaxisto na Mina do Cauê.

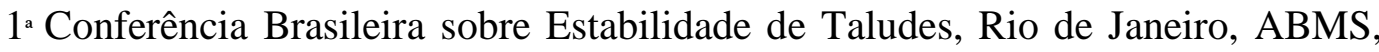
vol. 1, pp. 285-292.

SAYÃO, A. S.F.J., SANDRONI, S. S., FONTOURA, S.A.B., RIBEIRO, R.C.H. (2012). Considerations on the Probability of Failure of Mine Slopes. Soils and Rocks, vol. 35 (1), ABMS, pp. 31-37.

SILVA, C. C. (2015). Análise de Estabilidade de um talude da Cava de Alegria Utilizando Abordagem Probabilística. Dissertação de Mestrado, NUGEO, Universidade Federal de Ouro Preto.

SPENCER E. (1967). A Method of Analysis of the Stability of Embankment Assuming Inter-Slice Forces. Geotechnique, vol. 17, pp.11-26.

TERZAGHI, K. (1936). The Shearing Resistance of Saturated Soils and the Angle Between the Planes of Shear. Cambridge, Massachusetts. pp. 54-56.

U.S. ARMY CORPS OF ENGINEERS. (1995). Introduction to Probability and Reliability Methods for Use In Geotechnical Engineering, U. S. Army Corps of Engineers, Washington, DC.

VALE S.A. (2016). Memória da Tecnologia da Mineração em Itabira. Publicação Especial Comemorativa de 74 anos da Vale S.A. 
WHITMAN, R. V. (1984). Evaluating Calculated Risk in Geotechnical Engineering. Journal of the Geotechnical Engineering Division, ASCE, vol. 110 (2), pp. 145-188.

XU, B. e LOW, B. (2006). Probabilistic Stability Analyses of Embankments Based on Finite-Element Method. Journal of Geotechnical and Geoenvironmental Engineering, vol. 132 (11), pp. 1444-1454. 


\section{Apêndices}

\section{Apêndice I - Análises FOSM}

Quadro AI.1. Cálculos da probabilidade de ruptura pelo método FOSM por Fellenius com superfície de ruptura fixa.

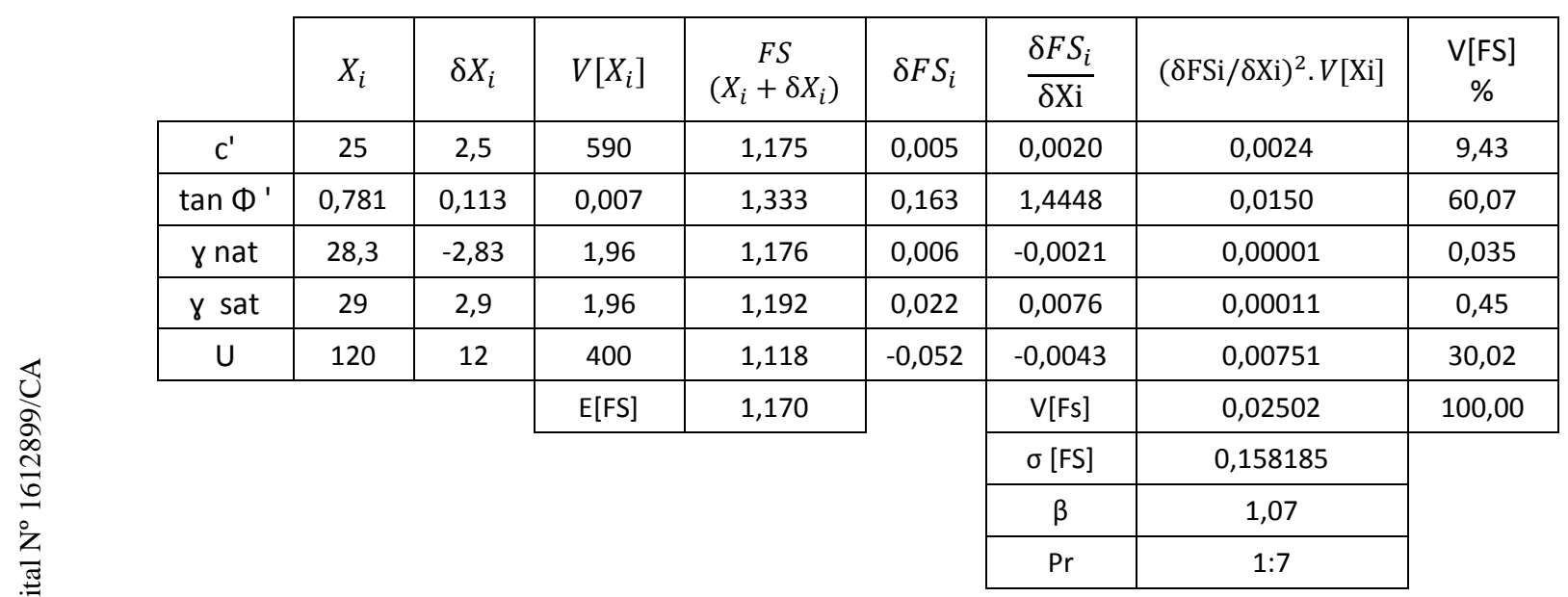

Quadro AI.2. Cálculos da probabilidade de ruptura pelo método FOSM por Fellenius com superfície de ruptura livre.

\begin{tabular}{|c|c|c|c|c|c|c|c|c|}
\hline & $X_{i}$ & $\delta X_{i}$ & $V\left[X_{i}\right]$ & $\begin{array}{c}F S \\
\left(X_{i}+\delta X_{i}\right)\end{array}$ & $\delta F S_{i}$ & $\frac{\delta F S_{i}}{\delta \mathrm{Xi}}$ & $(\delta \mathrm{FSi} / \delta \mathrm{Xi})^{2} \cdot V[\mathrm{Xi}]$ & $\begin{array}{c}\mathrm{V}[\mathrm{FS}] \\
\%\end{array}$ \\
\hline$c^{\prime}$ & 25 & 2,5 & 590 & 1,175 & 0,005 & 0,0020 & 0,0024 & 9,44 \\
\hline $\tan \Phi^{\prime}$ & 0,781 & 0,113 & 0,007 & 1,333 & 0,163 & 1,4448 & 0,0150 & 60,09 \\
\hline$\gamma$ nat & 28,3 & $-2,83$ & 1,96 & 1,176 & 0,006 & $-0,0021$ & 0,00001 & 0,035 \\
\hline$\gamma$ sat & 29 & 2,9 & 1,96 & 1,191 & 0,021 & 0,0072 & 0,0001 & 0,41 \\
\hline$U$ & 120 & 12 & 400 & 1,118 & $-0,052$ & $-0,0043$ & 0,00751 & 30.03 \\
\hline & & & $E[F S]$ & 1,170 & & $\mathrm{~V}[\mathrm{Fs}]$ & 0,02501 & 100,00 \\
\hline & & & & & & $\sigma[\mathrm{FS}]$ & 0,15815352 & \\
\hline & & & & & & $\beta$ & 1,07 & \\
\hline & & & & & & $\mathrm{Pr}$ & $1: 7$ & \\
\hline
\end{tabular}


Quadro AI.3. Cálculos da probabilidade de ruptura pelo método FOSM por Bishop com superfície de ruptura fixa:

\begin{tabular}{|c|c|c|c|c|c|c|c|c|}
\hline & $X_{i}$ & $\delta X_{i}$ & $V\left[X_{i}\right]$ & $\begin{array}{c}F S \\
\left(X_{i}+\delta X_{i}\right)\end{array}$ & $\delta F S_{i}$ & $\frac{\delta F S_{i}}{\delta \mathrm{Xi}}$ & $(\delta \mathrm{FSi} / \delta \mathrm{Xi})^{2} . V[\mathrm{Xi}]$ & $\begin{array}{c}\mathrm{V}[\mathrm{FS}] \\
\%\end{array}$ \\
\hline$c^{\prime}$ & 25 & 2,5 & 590 & 1,269 & 0,005 & 0,0020 & 0,00236 & 8,89 \\
\hline $\tan \Phi^{\prime}$ & 0,781 & 0,113 & 0,007 & 1,437 & 0,173 & 1,5334 & 0,01693 & 63,79 \\
\hline$\gamma$ nat & 28,3 & $-2,83$ & 1,96 & 1,269 & 0,005 & $-0,0018$ & 0,00001 & 0,023 \\
\hline$\gamma$ sat & 29 & 2,9 & 1,96 & 1,274 & 0,01 & 0,0034 & 0,00002 & 0,09 \\
\hline$U$ & 120 & 12 & 400 & 1,213 & $-0,051$ & $-0,0042$ & 0,00722 & 27,22 \\
\hline & & & $\mathrm{E}[\mathrm{FS}]$ & 1,264 & & $\mathrm{~V}[\mathrm{Fs}]$ & 0,02654 & 100,00 \\
\hline & & & & & & $\sigma[\mathrm{FS}]$ & 0,16293 & \\
\hline & & & & & & $\beta$ & 1,62 & \\
\hline & & & & & & $\operatorname{Pr}$ & $1: 20$ & \\
\hline
\end{tabular}

Quadro AI.4. Cálculos da probabilidade de ruptura pelo método FOSM por Bishop com superfície de ruptura livre:

\begin{tabular}{|c|c|c|c|c|c|c|c|c|}
\hline & $X_{i}$ & $\delta X_{i}$ & $V\left[X_{i}\right]$ & $\begin{array}{c}F S \\
\left(X_{i}+\delta X_{i}\right)\end{array}$ & $\delta F S_{i}$ & $\frac{\delta F S_{i}}{\delta \mathrm{Xi}}$ & $(\delta \mathrm{FSi} / \delta \mathrm{Xi})^{2} \cdot V[\mathrm{Xi}]$ & $\begin{array}{c}\mathrm{V}[\mathrm{FS}] \\
\%\end{array}$ \\
\hline$c^{\prime}$ & 25 & 2,5 & 590 & 1,269 & 0,005 & 0,0020 & 0,00236 & 8,89 \\
\hline $\tan \Phi^{\prime}$ & 0,781 & 0,113 & 0,007 & 1,437 & 0,173 & 1,5334 & 0,01693 & 63,78 \\
\hline$\gamma$ nat & 28,3 & $-2,83$ & 1,96 & 1,269 & 0,005 & $-0,0018$ & 0,00001 & 0,023 \\
\hline$\gamma$ sat & 29 & 2,9 & 1,96 & 1,273 & 0,009 & 0,0031 & 0,00002 & 0,09 \\
\hline U & 120 & 12 & 400 & 1,213 & $-0,051$ & $-0,0042$ & 0,007225 & 27,22 \\
\hline & & & $E[F S]$ & 1,264 & & $\mathrm{~V}[\mathrm{Fs}]$ & 0,02654 & 100,00 \\
\hline & & & & & & $\sigma[\mathrm{FS}]$ & 0,16293 & \\
\hline & & & & & & $\beta$ & 1,62 & \\
\hline & & & & & & $\mathrm{Pr}$ & $1: 20$ & \\
\hline
\end{tabular}


Quadro AI.5. Cálculos da probabilidade de ruptura pelo método FOSM por Janbu com superfície de ruptura fixa.

\begin{tabular}{|c|c|c|c|c|c|c|c|c|}
\hline & $X_{i}$ & $\delta X_{i}$ & $V\left[X_{i}\right]$ & $\begin{array}{c}F S \\
\left(X_{i}+\delta X_{i}\right)\end{array}$ & $\delta F S_{i}$ & $\frac{\delta F S_{i}}{\delta \mathrm{Xi}}$ & $(\delta \mathrm{FSi} / \delta \mathrm{Xi})^{2} . V[\mathrm{Xi}]$ & $\begin{array}{c}\mathrm{V}[\mathrm{FS}] \\
\%\end{array}$ \\
\hline$c^{\prime}$ & 25 & 2,5 & 590 & 1,183 & 0,004 & 0,0016 & 0,0015 & 6,51 \\
\hline $\tan \Phi^{\prime}$ & 0,781 & 0,113 & 0,007 & 1,343 & 0,164 & 1,4537 & 0,0152 & 65,55 \\
\hline$\gamma$ nat & 28,3 & $-2,83$ & 1,96 & 1,185 & 0,006 & $-0,0021$ & 0,00001 & 0,038 \\
\hline$\gamma$ sat & 29 & 2,9 & 1,96 & 1,197 & 0,018 & 0,0062 & 0,00008 & 0,33 \\
\hline$U$ & 120 & 12 & 400 & 1,131 & $-0,048$ & $-0,0040$ & 0,00640 & 27,57 \\
\hline & & & $\mathrm{E}[\mathrm{FS}]$ & 1,179 & & $\mathrm{~V}[\mathrm{Fs}]$ & 0,02321 & 100,00 \\
\hline & & & & & & $\sigma[\mathrm{FS}]$ & 0,152347 & \\
\hline & & & & & & $\beta$ & 1,17 & \\
\hline & & & & & & $\operatorname{Pr}$ & $1: 8$ & \\
\hline
\end{tabular}

Quadro AI.6. Cálculos da probabilidade de ruptura pelo método FOSM por Janbu com superfície de ruptura livre.

\begin{tabular}{|c|c|c|c|c|c|c|c|c|}
\hline & $X_{i}$ & $\delta X_{i}$ & $V\left[X_{i}\right]$ & $\begin{array}{c}F S \\
\left(X_{i}+\delta X_{i}\right)\end{array}$ & $\delta F S_{i}$ & $\frac{\delta F S_{i}}{\delta \mathrm{Xi}}$ & $(\delta \mathrm{FSi} / \delta \mathrm{Xi})^{2} \cdot V[\mathrm{Xi}]$ & $\begin{array}{c}\mathrm{V}[\mathrm{FS}] \\
\%\end{array}$ \\
\hline$c^{\prime}$ & 25 & 2,5 & 590 & 1,183 & 0,004 & 0,0016 & 0,0015 & 6,51 \\
\hline $\tan \Phi^{\prime}$ & 0,781 & 0,113 & 0,007 & 1,343 & 0,164 & 1,4537 & 0,0152 & 65,58 \\
\hline$\gamma$ nat & 28,3 & $-2,83$ & 1,96 & 1,185 & 0,006 & $-0,0021$ & 0,00001 & 0,038 \\
\hline$\gamma$ sat & 29 & 2,9 & 1,96 & 1,196 & 0,017 & 0,0059 & 0,00007 & 0,29 \\
\hline U & 120 & 12 & 400 & 1,131 & $-0,048$ & $-0,0040$ & 0,00640 & 27,58 \\
\hline & & & $E[F S]$ & 1,179 & & $\mathrm{~V}[\mathrm{Fs}]$ & 0,0232 & 100,00 \\
\hline & & & & & & $\sigma[\mathrm{FS}]$ & 0,15232 & \\
\hline & & & & & & $\beta$ & 1,07 & \\
\hline & & & & & & $\mathrm{Pr}$ & $1: 8$ & \\
\hline
\end{tabular}


Quadro AI.7. Cálculos da probabilidade de ruptura pelo método FOSM por Spencer com superfície de ruptura fixa.

\begin{tabular}{|c|c|c|c|c|c|c|c|c|}
\hline & $X_{i}$ & $\delta X_{i}$ & $V\left[X_{i}\right]$ & $\begin{array}{c}F S \\
\left(X_{i}+\delta X_{i}\right)\end{array}$ & $\delta F S_{i}$ & $\frac{\delta F S_{i}}{\delta \mathrm{Xi}}$ & $(\delta \mathrm{FSi} / \delta \mathrm{Xi})^{2} . V[\mathrm{Xi}]$ & $\begin{array}{c}\mathrm{V}[\mathrm{FS}] \\
\%\end{array}$ \\
\hline$c^{\prime}$ & 25 & 2,5 & 590 & 1,264 & 0,005 & 0,0020 & 0,0024 & 8,93 \\
\hline $\tan \Phi^{\prime}$ & 0,781 & 0,113 & 0,007 & 1,438 & 0,179 & 1,5866 & 0,0181 & 68,60 \\
\hline$\gamma$ nat & 28,3 & $-2,83$ & 1,96 & 1,264 & 0,005 & $-0,0018$ & 0,00001 & 0,023 \\
\hline$\gamma$ sat & 29 & 2,9 & 1,96 & 1,274 & 0,015 & 0,0052 & 0,00005 & 0,20 \\
\hline$U$ & 120 & 12 & 400 & 1,213 & $-0,046$ & $-0,0038$ & 0,00588 & 22,25 \\
\hline & & & $\mathrm{E}[\mathrm{FS}]$ & 1,259 & & $\mathrm{~V}[\mathrm{Fs}]$ & 0,0264 & 100,00 \\
\hline & & & & & & $\sigma[\mathrm{FS}]$ & 0,16255 & \\
\hline & & & & & & $\beta$ & 1,59 & \\
\hline & & & & & & $\operatorname{Pr}$ & $1: 20$ & \\
\hline
\end{tabular}

Quadro AI.8. Cálculos da probabilidade de ruptura pelo método FOSM por Spencer com superfície de ruptura livre.

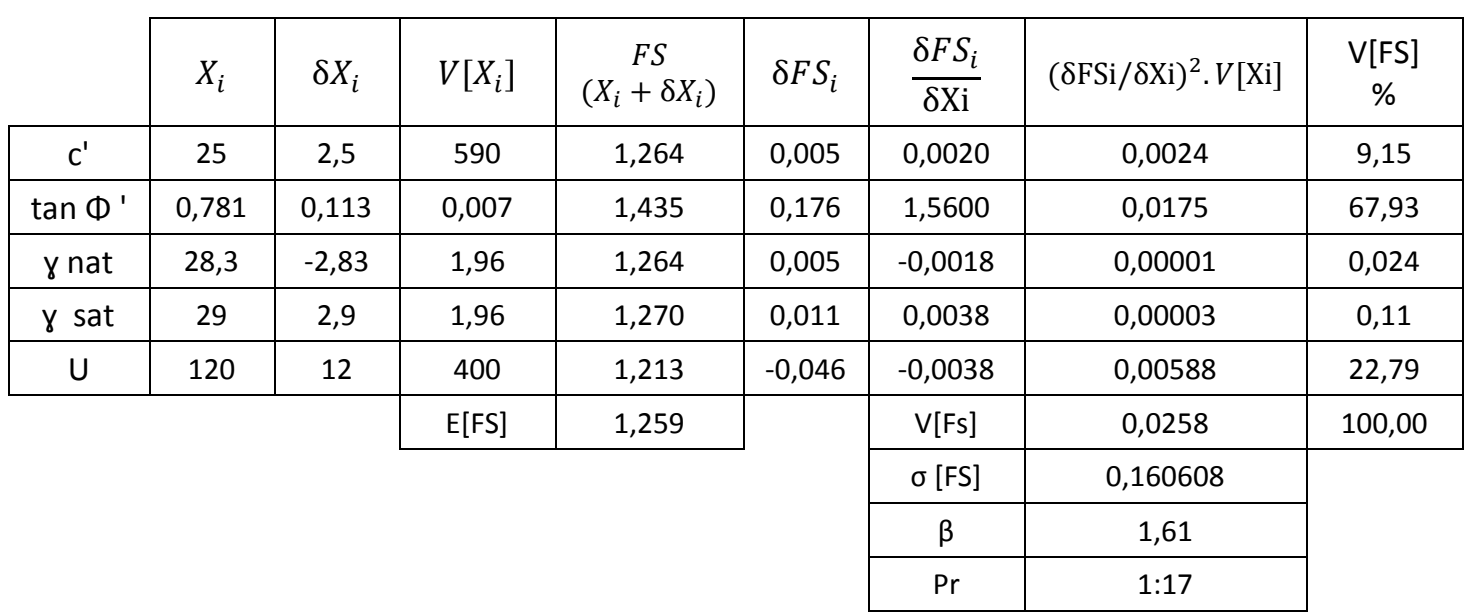


Quadro AI.9. Cálculos da probabilidade de ruptura pelo método FOSM por Morgenstern-Price com superfície de ruptura fixa.

\begin{tabular}{|c|c|c|c|c|c|c|c|c|}
\hline & $X_{i}$ & $\delta X_{i}$ & $V\left[X_{i}\right]$ & $\begin{array}{c}F S \\
\left(X_{i}+\delta X_{i}\right)\end{array}$ & $\delta F S_{i}$ & $\frac{\delta F S_{i}}{\delta \mathrm{Xi}}$ & $(\delta \mathrm{FSi} / \delta \mathrm{Xi})^{2} . V[\mathrm{Xi}]$ & $\begin{array}{c}\mathrm{V}[\mathrm{FS}] \\
\%\end{array}$ \\
\hline$c^{\prime}$ & 25 & 2,5 & 590 & 1,265 & 0,006 & 0,0024 & 0,0034 & 12,08 \\
\hline $\tan \Phi^{\prime}$ & 0,781 & 0,113 & 0,007 & 1,440 & 0,181 & 1,6044 & 0,0185 & 65,88 \\
\hline$\gamma$ nat & 28,3 & $-2,83$ & 1,96 & 1,264 & 0,005 & $-0,0018$ & 0,00001 & 0,022 \\
\hline$\gamma$ sat & 29 & 2,9 & 1,96 & 1,275 & 0,016 & 0,0055 & 0,0001 & 0,21 \\
\hline$U$ & 120 & 12 & 400 & 1,212 & $-0,047$ & $-0,0039$ & 0,0061 & 21,81 \\
\hline & & & $\mathrm{E}[\mathrm{FS}]$ & 1,259 & & $\mathrm{~V}[\mathrm{Fs}]$ & 0,0281 & 100,00 \\
\hline & & & & & & $\sigma[\mathrm{FS}]$ & 0,167729 & \\
\hline & & & & & & $\beta$ & 1,54 & \\
\hline & & & & & & $\operatorname{Pr}$ & $1: 17$ & \\
\hline
\end{tabular}

Quadro AI.10. Cálculos da probabilidade de ruptura pelo método FOSM por Morgenstern-Price com superfície de ruptura livre.

\begin{tabular}{|c|c|c|c|c|c|c|c|c|}
\hline & $X_{i}$ & $\delta X_{i}$ & $V\left[X_{i}\right]$ & $\begin{array}{c}F S \\
\left(X_{i}+\delta X_{i}\right)\end{array}$ & $\delta F S_{i}$ & $\frac{\delta F S_{i}}{\delta \mathrm{Xi}}$ & $(\delta \mathrm{FSi} / \delta \mathrm{Xi})^{2} \cdot V[\mathrm{Xi}]$ & $\begin{array}{c}\mathrm{V}[\mathrm{FS}] \\
\%\end{array}$ \\
\hline$c^{\prime}$ & 25 & 2,5 & 590 & 1,265 & 0,006 & 0,0024 & 0,0034 & 12,36 \\
\hline $\tan \Phi^{\prime}$ & 0,781 & 0,113 & 0,007 & 1.437 & 0,178 & 1,5778 & 0,0179 & 65,18 \\
\hline$\gamma$ nat & 28,3 & $-2,83$ & 1,96 & 1.264 & 0,005 & $-0,0018$ & 0,00001 & 0,022 \\
\hline$\gamma$ sat & 29 & 2,9 & 1,96 & 1.271 & 0,012 & 0,0041 & 0,00003 & 0,12 \\
\hline U & 120 & 12 & 400 & 1.212 & $-0,047$ & $-0,0039$ & 0,00614 & 22,32 \\
\hline & & & $E[F S]$ & 1,259 & & $\mathrm{~V}[\mathrm{Fs}]$ & 0,02750 & 100,00 \\
\hline & & & & & & $\sigma[\mathrm{FS}]$ & 0,1658238 & \\
\hline & & & & & & $\beta$ & 1,56 & \\
\hline & & & & & & $\mathrm{Pr}$ & $1: 16$ & \\
\hline
\end{tabular}


Apêndice II - Análises por Estimativas Pontuais

Quadro AII.1. Cálculos da probabilidade de ruptura pelo método das Estimativas Pontuais por Fellenius com superfície de ruptura fixa.

\begin{tabular}{|c|c|c|c|c|c|}
\hline Análise & $\Phi^{\prime}$ & $\mathrm{u}$ & $c^{\prime}$ & FS & $\mathrm{FS}^{2}$ \\
\hline+++ & 41 & 140 & 49 & 1,238 & 1,533 \\
\hline-++ & 35 & 140 & 49 & 1,014 & 1,028 \\
\hline+-+ & 41 & 100 & 49 & 1,420 & 2,017 \\
\hline--+ & 35 & 100 & 49 & 1,161 & 1,348 \\
\hline++- & 41 & 140 & 1 & 1,153 & 1,329 \\
\hline-+- & 35 & 140 & 1 & 1,00 & 0,863 \\
\hline+-- & 41 & 100 & 1 & 1,335 & 1,782 \\
\hline--- & 35 & 100 & 1 & 1,076 & 1,158 \\
\hline & & & & $\mathrm{E}[\mathrm{FS}]$ & 1,166 \\
\hline & & & & $\mathrm{E}\left[\mathrm{FS}^{2}\right]$ & 1,382 \\
\hline & & & & $\mathrm{V}[\mathrm{FS}]$ & 0,023 \\
\hline & & & & $\sigma[\mathrm{FS}]$ & 0,152 \\
\hline & & & & $\beta$ & 1,09 \\
\hline & & & & $\mathrm{Pr}$ & $1: 7$ \\
\hline
\end{tabular}

Quadro AII.2. Cálculos da probabilidade de ruptura pelo método das Estimativas Pontuais por Fellenius com superfície de ruptura livre.

\begin{tabular}{|c|c|c|c|c|c|}
\hline Análise & $\Phi^{\prime}$ & $\mathrm{u}$ & $c^{\prime}$ & FS & $\mathrm{FS}^{2}$ \\
\hline+++ & 41 & 140 & 49 & 1,236 & 1,528 \\
\hline-++ & 35 & 140 & 49 & 1,012 & 1,024 \\
\hline+-+ & 41 & 100 & 49 & 1,420 & 2,017 \\
\hline--+ & 35 & 100 & 49 & 1,161 & 1,348 \\
\hline++- & 41 & 140 & 1 & 1,303 & 1,698 \\
\hline -+- & 35 & 140 & 1 & 1,051 & 1,106 \\
\hline+-- & 41 & 100 & 1 & 1,152 & 1,327 \\
\hline-- & 35 & 100 & 1 & 1,00 & 0,862 \\
\hline & & & & $\mathrm{E}[\mathrm{FS}]$ & 1,158 \\
\hline & & & & $\mathrm{E}\left[\mathrm{FS}^{2}\right]$ & 1,364 \\
\hline & & & & $\mathrm{V}[\mathrm{FS}]$ & 0,023 \\
\hline & & & & $\sigma[\mathrm{FS}]$ & 0,151 \\
\hline & & & & $\beta$ & 1,05 \\
\hline & & & & $\operatorname{Pr}$ & $1: 7$ \\
\hline
\end{tabular}


Quadro AII.3. Cálculos da probabilidade de ruptura pelo método das Estimativas Pontuais por Bishop com superfície de ruptura fixa.

\begin{tabular}{|c|c|c|c|c|c|}
\hline Análise & $\Phi^{\prime}$ & $\mathrm{u}$ & $c^{\prime}$ & FS & $\mathrm{FS}^{2}$ \\
\hline+++ & 41 & 140 & 49 & 1,356 & 1,839 \\
\hline-++ & 35 & 140 & 49 & 1,114 & 1,241 \\
\hline+-+ & 41 & 100 & 49 & 1,518 & 2,304 \\
\hline--+ & 35 & 100 & 49 & 1,243 & 1,545 \\
\hline++- & 41 & 140 & 1 & 1,249 & 1,560 \\
\hline -+- & 35 & 140 & 1 & 1,007 & 1,014 \\
\hline+- & 41 & 100 & 1 & 1,411 & 1,991 \\
\hline --- & 35 & 100 & 1 & 1,137 & 1,293 \\
\hline & & & & $\mathrm{E}[\mathrm{FS}]$ & 1,254 \\
\hline & & & & $\mathrm{E}\left[\mathrm{FS}^{2}\right]$ & 1,598 \\
\hline & & & & $\mathrm{V}[\mathrm{FS}]$ & 0,025 \\
\hline & & & & $\sigma[\mathrm{FS}]$ & 0,158 \\
\hline & & & & $\beta$ & 1,61 \\
\hline & & & & $\mathrm{Pr}$ & $1: 20$ \\
\hline
\end{tabular}

Quadro AII.4. Cálculos da probabilidade de ruptura pelo método das Estimativas Pontuais por Bishop com superfície de ruptura livre.

\begin{tabular}{|c|c|c|c|c|c|}
\hline Análise & $\Phi^{\prime}$ & $\mathrm{u}$ & $c^{\prime}$ & FS & $\mathrm{FS}^{2}$ \\
\hline +++ & 41 & 140 & 49 & 1,352 & 1,828 \\
\hline-++ & 35 & 140 & 49 & 1,108 & 1,229 \\
\hline+-+ & 41 & 100 & 49 & 1,517 & 2,302 \\
\hline--+ & 35 & 100 & 49 & 1,243 & 1,546 \\
\hline++- & 41 & 140 & 1 & 1,246 & 1,553 \\
\hline-+- & 35 & 140 & 1 & 1,004 & 1,007 \\
\hline+-- & 41 & 100 & 1 & 1,306 & 1,705 \\
\hline --- & 35 & 100 & 1 & 1,053 & 1,109 \\
\hline & & & & $\mathrm{E}[\mathrm{FS}]$ & 1,229 \\
\hline & & & & $\mathrm{E}\left[\mathrm{FS}^{2}\right]$ & 1,535 \\
\hline & & & & $\mathrm{V}[\mathrm{FS}]$ & 0,025 \\
\hline & & & & $\sigma[\mathrm{FS}]$ & 0,158 \\
\hline & & & & $\beta$ & 1,44 \\
\hline & & & & $\mathrm{Pr}$ & 1:14 \\
\hline
\end{tabular}


Quadro AII.5. Cálculos da probabilidade de ruptura pelo método das Estimativas Pontuais por Janbu com superfície de ruptura fixa.

\begin{tabular}{|c|c|c|c|c|c|}
\hline Análise & $\Phi^{\prime}$ & u & $c^{\prime}$ & FS & $\mathrm{FS}^{2}$ \\
\hline+++ & 41 & 140 & 49 & 1,257 & 1,580 \\
\hline-++ & 35 & 140 & 49 & 1,029 & 1,059 \\
\hline+-+ & 41 & 100 & 49 & 1,421 & 2,019 \\
\hline--+ & 35 & 100 & 49 & 1,162 & 1,350 \\
\hline++- & 41 & 140 & 1 & 1,172 & 1,374 \\
\hline-+- & 35 & 140 & 1 & 1,00 & 1,00 \\
\hline+-- & 41 & 100 & 1 & 1,336 & 1,785 \\
\hline --- & 35 & 100 & 1 & 1,076 & 1,158 \\
\hline & & & & $\mathrm{E}[\mathrm{FS}]$ & 1,175 \\
\hline & & & & $\mathrm{E}\left[\mathrm{FS}^{2}\right]$ & 1,402 \\
\hline & & & & $\mathrm{V}[\mathrm{FS}]$ & 0,022 \\
\hline & & & & $\sigma[\mathrm{FS}]$ & 0,149 \\
\hline & & & & $\beta$ & 1,17 \\
\hline & & & & $\mathrm{Pr}$ & $1: 8$ \\
\hline
\end{tabular}

Quadro AII.6. Cálculos da probabilidade de ruptura pelo método das Estimativas Pontuais por Janbu com superfície de ruptura livre.

\begin{tabular}{|c|c|c|c|c|c|}
\hline Análise & $\Phi^{\prime}$ & $\mathrm{u}$ & $c^{\prime}$ & FS & $\mathrm{FS}^{2}$ \\
\hline+++ & 41 & 140 & 49 & 1,255 & 1,575 \\
\hline-++ & 35 & 140 & 49 & 1,027 & 1,055 \\
\hline+-+ & 41 & 100 & 49 & 1,421 & 2,019 \\
\hline--+ & 35 & 100 & 49 & 1,161 & 1,349 \\
\hline++- & 41 & 140 & 1 & 1,169 & 1,367 \\
\hline-+- & 35 & 140 & 1 & 1,00 & 1,00 \\
\hline+-- & 41 & 100 & 1 & 1,303 & 1,698 \\
\hline--- & 35 & 100 & 1 & 1,051 & 1,105 \\
\hline & & & & $\mathrm{E}[\mathrm{FS}]$ & 1,166 \\
\hline & & & & $\mathrm{E}\left[\mathrm{FS}^{2}\right]$ & 1,382 \\
\hline & & & & $\mathrm{V}[\mathrm{FS}]$ & 0,022 \\
\hline & & & & $\sigma[\mathrm{FS}]$ & 0,148 \\
\hline & & & & $\beta$ & 1,13 \\
\hline & & & & $\mathrm{Pr}$ & 1:8 \\
\hline
\end{tabular}


Quadro AII.7. Cálculos da probabilidade de ruptura pelo método das Estimativas Pontuais por Spencer com superfície de ruptura fixa.

\begin{tabular}{|c|c|c|c|c|c|}
\hline Análise & $\Phi^{\prime}$ & $\mathrm{u}$ & $c^{\prime}$ & FS & $\mathrm{FS}^{2}$ \\
\hline+++ & 41 & 140 & 49 & 1,356 & 1.839 \\
\hline -++ & 35 & 140 & 49 & 1,113 & 1,239 \\
\hline+-+ & 41 & 100 & 49 & 1,518 & 2,304 \\
\hline--+ & 35 & 100 & 49 & 1,136 & 1,290 \\
\hline++- & 41 & 140 & 1 & 1,249 & 1,560 \\
\hline -+- & 35 & 140 & 1 & 1,006 & 1,012 \\
\hline+-- & 41 & 100 & 1 & 1,411 & 1,991 \\
\hline --- & 35 & 100 & 1 & 1,136 & 1,290 \\
\hline & & & & $\mathrm{E}[\mathrm{FS}]$ & 1,241 \\
\hline & & & & $\mathrm{E}\left[\mathrm{FS}^{2}\right]$ & 1,566 \\
\hline & & & & $\mathrm{V}[\mathrm{FS}]$ & 0,027 \\
\hline & & & & $\sigma[\mathrm{FS}]$ & 0,163 \\
\hline & & & & $\beta$ & 1,48 \\
\hline & & & & $\mathrm{Pr}$ & 1:14 \\
\hline
\end{tabular}

Quadro AII.8. Cálculos da probabilidade de ruptura pelo método das Estimativas Pontuais por Spencer com superfície de ruptura livre.

\begin{tabular}{|c|c|c|c|c|c|}
\hline Análise & $\Phi^{\prime}$ & $\mathrm{u}$ & $c^{\prime}$ & FS & $\mathrm{FS}^{2}$ \\
\hline+++ & 41 & 140 & 49 & 1,355 & 1,836 \\
\hline-++ & 35 & 140 & 49 & 1,106 & 1,224 \\
\hline+-+ & 41 & 100 & 49 & 1,514 & 2,291 \\
\hline--+ & 35 & 100 & 49 & 1,053 & 1,109 \\
\hline ++- & 41 & 140 & 1 & 1,245 & 1,550 \\
\hline -+- & 35 & 140 & 1 & 1,000 & 1,000 \\
\hline+-- & 41 & 100 & 1 & 1,305 & 1,703 \\
\hline --- & 35 & 100 & 1 & 1,053 & 1,109 \\
\hline & & & & $\mathrm{E}[\mathrm{FS}]$ & 1,204 \\
\hline & & & & $\mathrm{E}\left[\mathrm{FS}^{2}\right]$ & 1,478 \\
\hline & & & & $\mathrm{V}[\mathrm{FS}]$ & 0,028 \\
\hline & & & & $\sigma[\mathrm{FS}]$ & 0,169 \\
\hline & & & & $\beta$ & 1,21 \\
\hline & & & & $\mathrm{Pr}$ & $1: 9$ \\
\hline
\end{tabular}


Quadro AII.9. Cálculos da probabilidade de ruptura pelo método das Estimativas Pontuais por Morgenstern-Price com superfície de ruptura fixa.

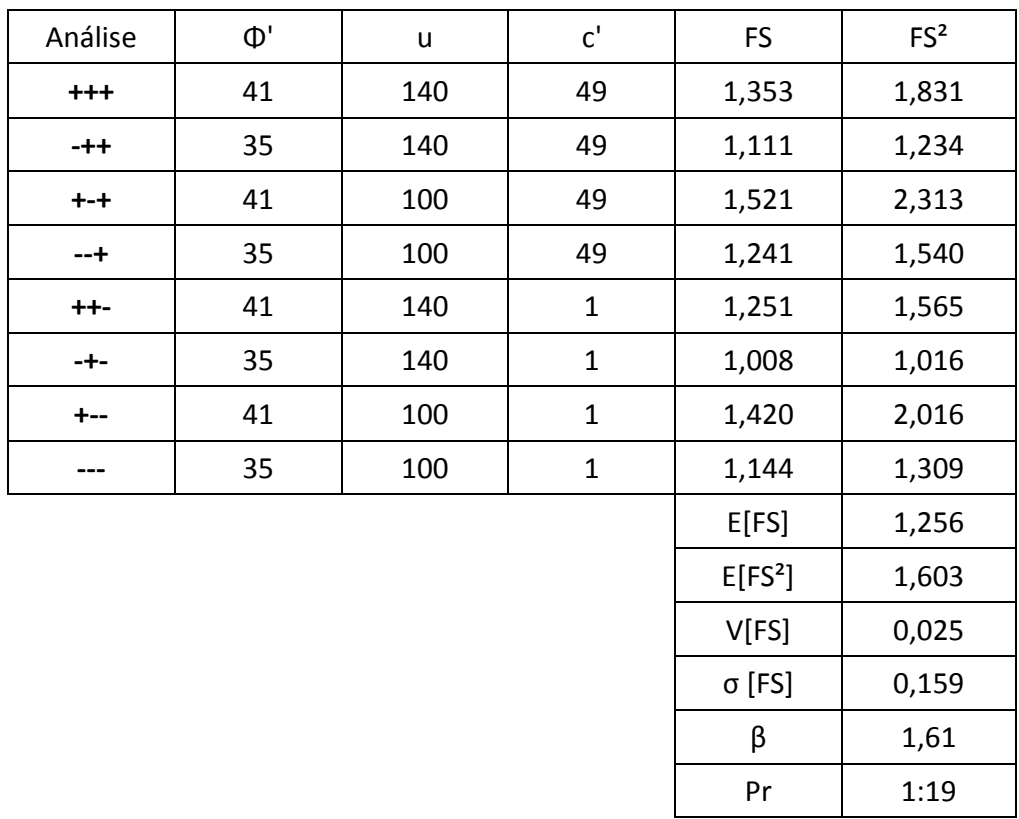

Quadro AII.10. Cálculos da probabilidade de ruptura pelo método das Estimativas Pontuais por Morgenstern-Price com superfície de ruptura livre.

\begin{tabular}{|c|c|c|c|c|c|}
\hline Análise & $\Phi^{\prime}$ & $\mathrm{u}$ & $c^{\prime}$ & FS & $\mathrm{FS}^{2}$ \\
\hline+++ & 41 & 140 & 49 & 1,353 & 1,829 \\
\hline-++ & 35 & 140 & 49 & 1,107 & 1,224 \\
\hline+-+ & 41 & 100 & 49 & 1,516 & 2,297 \\
\hline--+ & 35 & 100 & 49 & 1,240 & 1,538 \\
\hline++- & 41 & 140 & 1 & 1,244 & 1,547 \\
\hline -+- & 35 & 140 & 1 & 1,000 & 1,000 \\
\hline+-- & 41 & 100 & 1 & 1,305 & 1,704 \\
\hline --- & 35 & 100 & 1 & 1,053 & 1,110 \\
\hline & & & & $\mathrm{E}[\mathrm{FS}]$ & 1,227 \\
\hline & & & & $\mathrm{E}\left[\mathrm{FS}^{2}\right]$ & 1,531 \\
\hline & & & & $\mathrm{V}[\mathrm{FS}]$ & 0,025 \\
\hline & & & & $\sigma[\mathrm{FS}]$ & 0,159 \\
\hline & & & & $\beta$ & 1,43 \\
\hline & & & & $\mathrm{Pr}$ & $1: 13$ \\
\hline
\end{tabular}

